\title{
annual report 2005
}

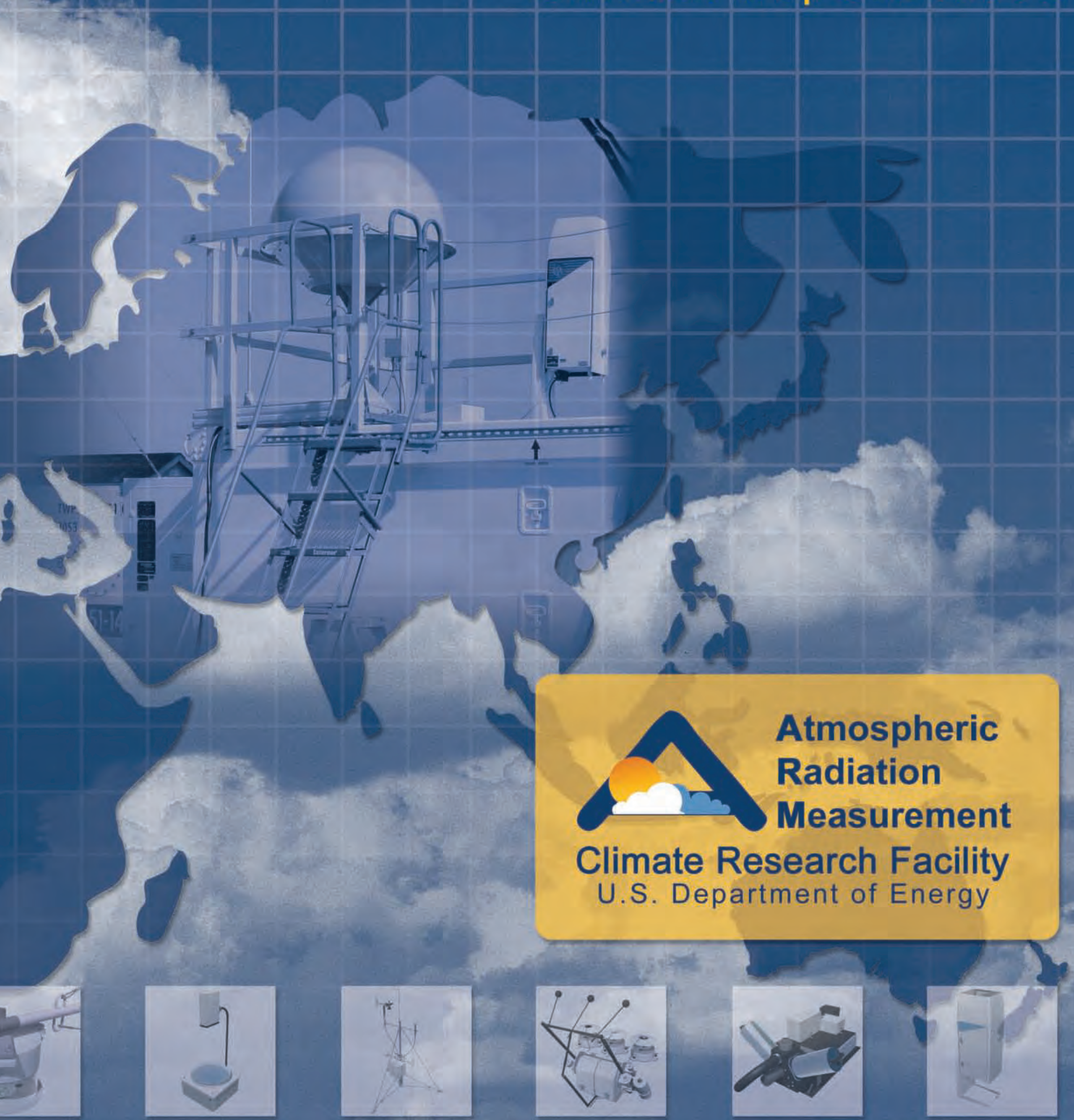




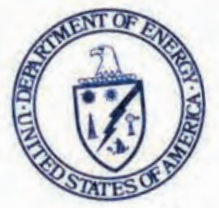

Department of Energy

Washington, DC 20585

December 1, 2005 Program and ARM Climate Research Faci

As a world-class user facility for the global change research cocientific infrastructure to not Climate Research Facility (ACRF) provides state properties and radiative feedback, but only ARM scientists engaged in sted in interdisciplinary sthe Tropical Western Pacific-as also researchers worldwide in ilaska, Oklahoma, and the ACRF continues to lead permanent instrumenile Facility for temporary deploy on enhancements to its user well as a new Mtific collaborations while focusing

successful sciabilities. Significant achievements in 2005 inclu

- Completing a successful first deployment of the ARM Mobile 2005

- Completing a shore in California between March and Seashored Aerospace Vehicle

- Establishing a closer relationship with the ARM Un campaigns

Program to better coordinate collabsite with the Data Archive, including the

- Integrating the ARM Program wer interface for ordering ARM data.

the user base in 2004 reaped

In addition to these achievements, efforts to broaden the noteworthy user statistics: significant benefits in 2005 , resulting in

- Site visits almost doubled from 2004 its scientific infrastructure

- The ACRF received 28 proposals to use its sciely 1 terabyte per month, with data

- Requests for ARM data averaged app inflow. outflow consistently surpassing data in ARM's international team of scientists continue to be major journal articles and 111 cloud and radiative research, publishing their resuls science team also served in key conference papers in 2005 . $3^{\text {rd }}$ Pan-GCSS (GEWEX Cloud Sy major contributors to a leadership rodels and Climate in Athens, Greece, and pheres.

Thank you for interest in and support

Wanda R. Ferrell, PhD

ARM Program Manager

Climate Change Research Division

Q9. Pinted with soy ink on tecycled paper 


\section{Table of Contents}

Program Overview.

The Role of Clouds in Climate.

ARM Science Goals

ARM Climate Research Facility: Successful Science Program Leads to User Facility Designation.....

Sites Around the World Enable Real Observations.

State-of-the-Art Instrumentation Yields Comprehensive Data Sets

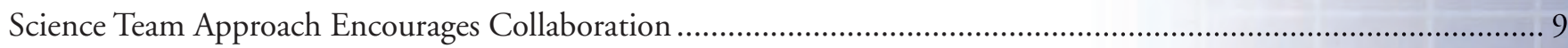

Working Groups Provide Leadership, Focus on Specific Problems ................................................................... 9

Oversight Ensures Relevant Science, Promotes Facility Use.......................................................................... 10

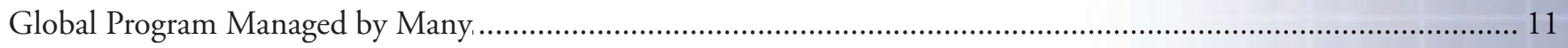

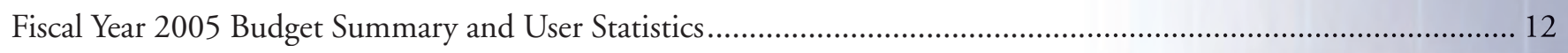

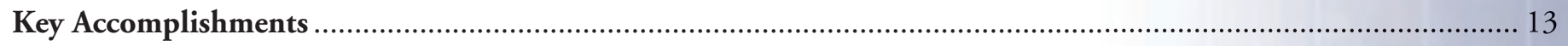

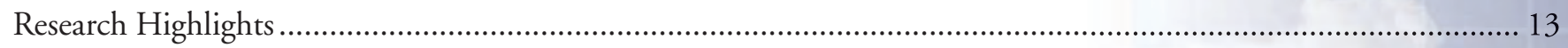

- Characterizing the Coexistence of Water and Ice in Arctic Clouds

- ARM Program Research Improves Longwave Radiative Transfer Models

- Droplet Nucleation Finally Included in Global Climate Model

- Small Processes Make a Big Difference in Model Outcomes

- ARM Research Spotlighted in Special Issue of Journal

- New Scheme More Accurate for Cloud Droplet Formation, Dispersion

Featured Field Campaigns.

- Mixed-Phase Arctic Cloud Experiment

- Marine Stratus Radiation, Aerosol, and Drizzle IOP

- Aerosol Lidar Validation Experiment

Infrastructure Achievements

- Site Operations

- Instrument Enhancements

- Data Delivery

- Communication, Education, and Outreach

FY 2005 Field Campaigns

On the cover: A telemetry antenna (left) and a ceilometer (right) collect data atop one of the ARM Mobile Facility (AMF) operations shelters at Point Reyes National Seashore in California. The telemetry antenna receives signals from small sensors attached to weather balloons released into the air, while the ceilometer uses pulses of light to measure cloud-base height and potential backscatter signals from aerosols and precipitation. These instruments, along with many others, took part in a 6-month field campaign at the seashore to collect data on marine stratus clouds and aerosol properties. 
Previous research has shown that cloud radiative forcing and feedbacks are one of the major sources of uncertainty in simulations of climate change over the next century. The ARM Program focuses on obtaining continuous field measurements of atmospheric properties and processes, and from these measurements, developing data products that promote the advancement of climate models.

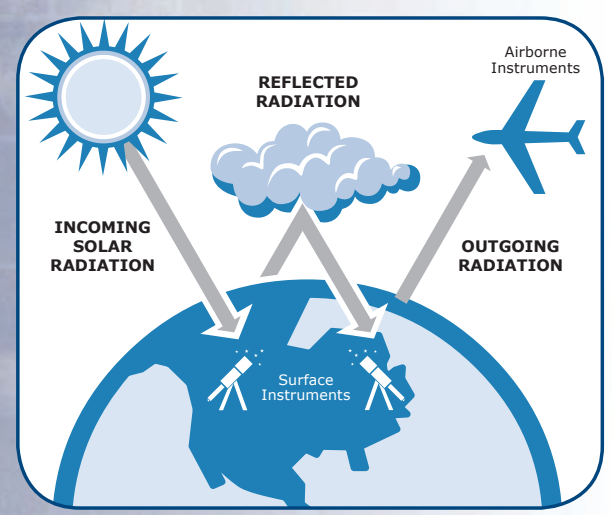

ARM researchers use data collected from ground-based and airborne instruments to study the natural phenomena that occur in clouds, and how those cloud conditions affect incoming and outgoing radiative energy.

\section{(3) Program Overview}

\section{The Role of Clouds in Climate}

Sophisticated computer models of the earth's climate system are the principal tools used by scientists for simulating climate and predicting its change. The credibility and validity of these models are dependent upon, among other things, their ability to correctly represent physical processes, such as the exchange of energy between earth and the atmosphere. The representation of cloud processes and their impact on this energy exchange-referred to as earth's radiation balancenized for decades as the source of much uncertainty surrounding the prediction of climate variability and change.

The U.S. Global Change Research Act of 1990 established an interagency program within the Executive Office of the President to coordinate U.S. agency-sponsored scientific research designed to monitor, understand, and predict changes in the global environment. To address the need for new research on clouds and radiation, the U.S. Department of Energy (DOE) established the Atmospheric Radiation Measurement (ARM) Program, managed through the Office of Science. As part of the DOE's overall Climate Change Science Program, a primary objective of the ARM Program is improved scientific understanding of the fundamental physics related to interactions between clouds and radiative feedback processes in the atmosphere.

\section{ARM Science Goals}

One of the DOE's major goals is to develop global climate models capable of simulating the timing and magnitude of greenhouse gas-induced global warming and the regional effects of such warming. Therefore, the goal of the ARM Program is to improve the treatment of clouds and radiation processes in global climate models.

ARM's goal is addressed through a combination of continuous ground-based observations, data analysis, modeling of local and regional physics, and development of parameterizations for global models. Through these activities, the ARM Program seeks the answers to two principal questions:

- How accurate are both longwave and shortwave radiative transfer calculations for any given column of the atmosphere?

- How well can cloud properties in a column of the atmosphere be predicted from knowledge of larger-scale atmospheric properties?

Because of the complexity and global scope of the research involved in answering these questions, the ARM Program collaborates extensively with other laboratories, agencies, universities, and private firms in gathering and sharing data. This collaborative approach allows ARM to leverage its investment in research sites, instruments, data, and science to gain the knowledge necessary to improve the accuracy of the computer models used to simulate global and regional climate changes. 
Kiosk Goes to Washington: In 2005, the ARM information kiosk joined other research program materials in an exhibit about the DOE Office of Science. On display for 7 months in the Forrestal Building lobby in Washington, D.C., the exhibit was organized to reintroduce the Office of Science to the DOE community. It included posters, scientific artifacts, and interactive kiosks from the seven program offices and DOE national laboratories. Secretary of Energy Samuel W. Bodman, Under Secretary David Garman, and the Secretary's Chief of Staff Eric Burgeson toured the exposition on opening day. In addition to the kiosk, an ARM radiometer (an instrument that measures radiant energy) joined other scientific artifacts in the display cases.

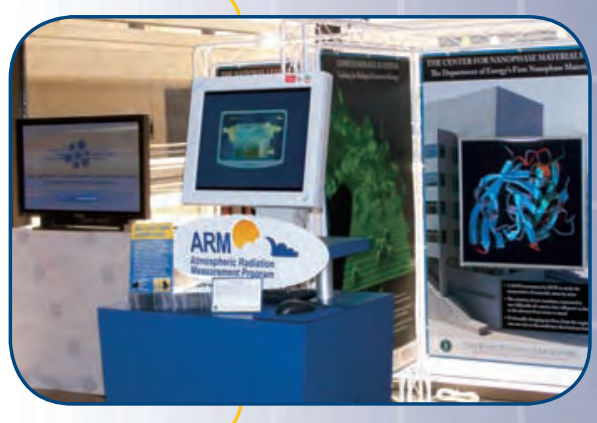

\section{ARM Climate Research Facility: Successful Science Program Leads to User Facility Designation}

Through the ARM Program, the DOE funded the development of several highly instrumented ground stations for studying cloud formation processes and their influence on radiative transfer, and for measuring other parameters that determine the radiative properties of the atmosphere. This scientific infrastructure, and resultant Data Archive, is a valuable national and international asset for advancing scientific knowledge of Earth systems. In fiscal year (FY) 2003, the DOE designated the ARM sites as a national scientific user facility: the ARM Climate Research Facility (ACRF). The ACRF has enormous potential to contribute to a wide range of interdisciplinary science in areas such as meteorology, atmospheric aerosols, hydrology, biogeochemical cycling, and satellite validation, to name only a few.

Three primary locations - the Southern Great Plains, Tropical Western Pacific, and North Slope of Alaska—and the portable ARM Mobile Facility are heavily instrumented to collect massive amounts of atmospheric measurements needed to create data files. Using these data, ARM scientists are studying the effects and interactions of sunlight, radiant energy, and clouds to understand their impact on temperatures, weather, and climate. As part of this effort, ARM scientists and ACRF infrastructure staff provide value-added processing to the data files to create new data streams called value-added products. Software tools are then provided to help open and analyze these products. Program documentation, from setting up the sites to developing the value-added products, is available for each step in this process.

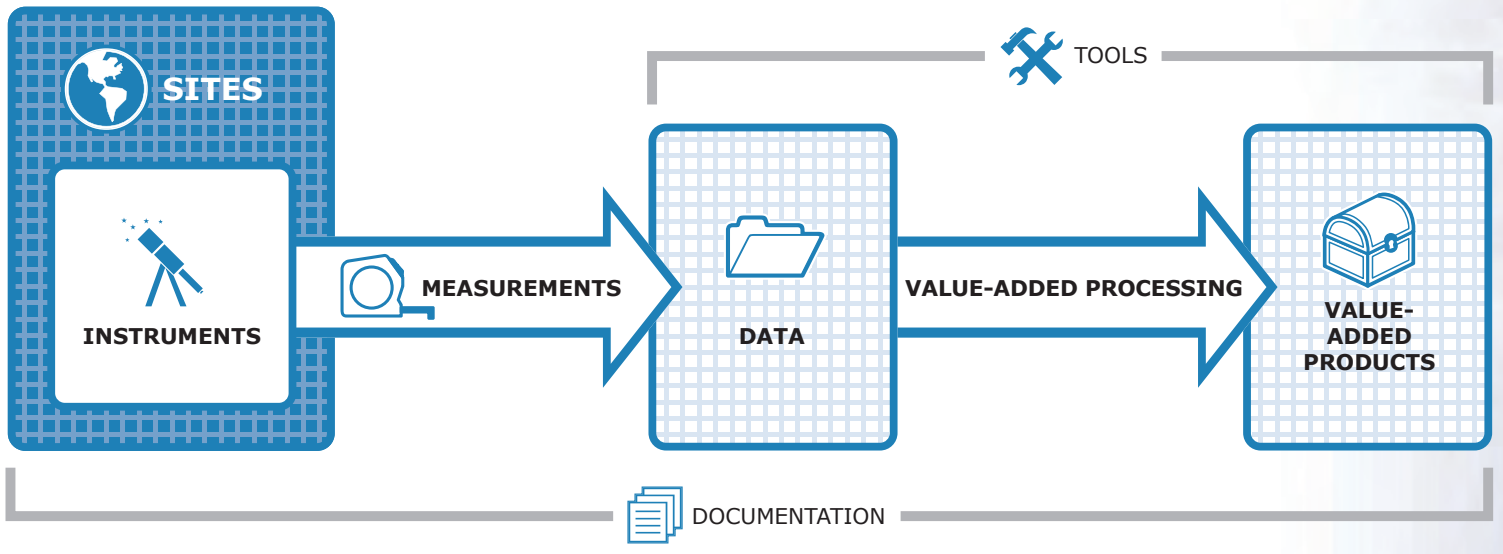




\title{
Sites Around the World Enable Real Observations
}

A central feature of the ACRF is a set of instrumented field research locales for measuring atmospheric radiation and the properties controlling this radiation, such as the distribution of clouds and water vapor. To obtain the most useful climate data, three locales were chosen that represent a broad range of weather conditions.

\section{Southern Great Plains}

The Southern Great Plains (SGP) site was the first field measurement site established by ARM. The SGP experiences a wide variety of cloud types and surface flux properties, as well as large seasonal variations in temperature and specific humidity. The site consists of a highly instrumented Central Facility near Lamont, Oklahoma, and smaller "satellite" facilities scattered over approximately 142,450 square kilometers in north-central Oklahoma and south-central Kansas. Cooperative partnerships have evolved with a variety of government laboratories and agencies, and also with universities, permitting collaborative use of several state-of-the-science radar and climate observing systems and networks. Collection of continuous measurements at this location began in 1994, with a complete suite of instruments operating since 1996. This site is now the largest and most extensive climate research field site in the world.

\begin{abstract}
Annual Inspections Improve Quality: Each year, a small team of scientists and engineers conduct inspections of all 27 satellite facilities at the SGP. They review each facility from the perspective of science, engineering, operations, and safety. This activity, known as the Continuous Quality Improvement Program, ensures that instruments and facilities are in compliance with established ACRF procedures and the ARM Program's scientific expectations. The inspections encompass each facility's grounds, instruments, and equipment, plus maintenance procedures, technician proficiency, and other work-quality measures. Analysis of each measure provides feedback for planning and implementing improvements in instrument performance and maintenance, site maintenance, and future site development.
\end{abstract}

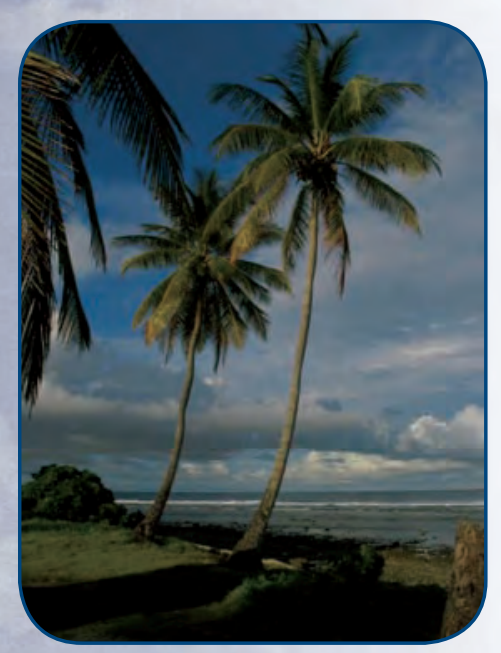

Due to the consistently warmest sea surface temperatures on the planet, the TWP locale plays an important role in the interannual variability observed in the global climate system.

\section{Tropical Western Pacific}

The Tropical Western Pacific (TWP) locale spans an area roughly between $10^{\circ} \mathrm{N}$ to $10^{\circ} \mathrm{S}$ of the equator from Indonesia to the dateline. This area-referred to as the Pacific "warm pool"-is characterized by warm sea temperatures, deep and frequent atmospheric convection, high rain rates, strong coupling between the atmosphere and ocean, and substantial variability associated with El Niño. Three instrumented sites operate in the TWP locale. The first of these sites was established in 1996 on Manus Island, Papua New Guinea. Site operations on Manus are conducted in collaboration with the Papua New Guinea National Weather Service. The second TWP site was established on Nauru Island in 1998. Nauru operations are performed with the cooperation of the Nauru Department of Island Development and Industry. A third TWP facility began operating in April 2002 at Darwin, Australia, in partnership with the Australian Bureau of Meteorology. This facility collects data typical of tropical land convection and monsoon circulations. 
Communication is Key at TWP: In the communities where ACRF sites are located, the scientific infrastructure often spurs curiosity and interest. Because the complexity of atmospheric research can be difficult to understand, ACRF establishes working relationships with schools, local administrators, and community leaders to promote science education and awareness of climate research. In 2005, ACRF Education and Outreach staff visited the TWP locale to begin developing an educational kiosk about ACRF and climate change in the Pacific, and its impacts on the people living there. Using interviews with scientists and community members, the kiosk project is an important element of ACRF's community relations in the Pacific.

\section{North Slope of Alaska}

The North Slope of Alaska (NSA) locale is situated on the edge of the Arctic Ocean. This area provides important information for ARM research because fundamentally different climate processes — such as planetary heat loss from the poles and extensive sheets of ice that affect solar absorption and sea level—occur at high latitudes. Due to generally cold temperatures, atmospheric water vapor concentrations in the Arctic are quite low, allowing heat energy from the surface to escape through the atmosphere more easily than in other regions. The NSA's principal instrumented facility was installed near Barrow in 1997, followed by a smaller remote site at Atqasuk in 1999. Routine operations at these sites are conducted in partnership with employees of Ukpeagvik Iñupiat Corporation/Science Division.

U.S. Senators View the Effects of Climate Change: As data about climate change continues to grow, nowhere is it as evident as in the Arctic. In August 2005, Senators John McCain (Arizona), Hillary Rodham Clinton (New York), Susan Collins (Maine), and Lindsey Graham (South Carolina), visited Barrow, Alaska, on a bi-partisan trip to examine the effects of global climate change in cold latitudes. In addition to talking with community members, the senators observed numerous research facilities including the ACRF site.

\section{ARM Mobile Facility}

The ARM Mobile Facility (AMF) was developed to address science questions beyond those addressed by the "fixed" measurement sites. The AMF is similar to the permanent ARM sites in that it contains many of the same instruments and data systems, but is designed to be deployed around the world for campaigns lasting 6-12 months. The AMF consists of a minimum of two lightweight shelters, a baseline suite of instruments, data communications, and data systems. Designed to collaborate with other agency experiments (particularly those with aircraft), it also has the ability to host instruments other than the baseline collection. Data streams produced by the AMF are available to the atmospheric community for use in testing and improving parameterizations in global climate models.

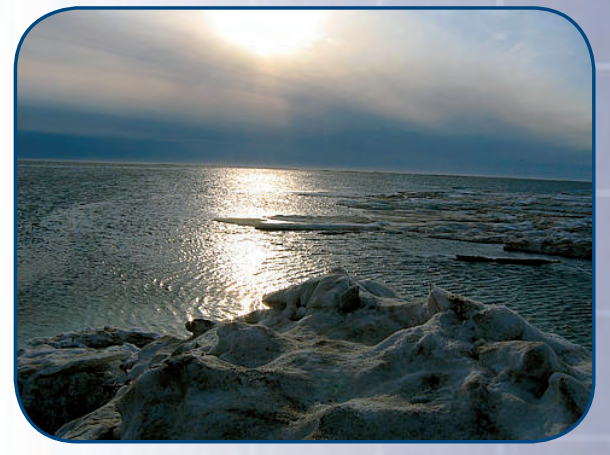

The NSA provides data about cloud and radiative processes in the Arctic, which has been identified as one of the most sensitive regions to climate change.

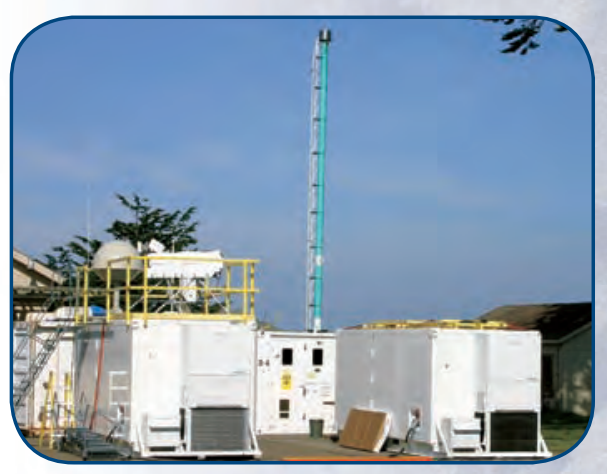

An aerosol observing system (green stack) was added to the baseline suite of AMF instruments after proving its value during a successful 6-month field campaign at Point Reyes National Seashore in California in 2005. In 2006, the AMF begins a yearlong deployment in West Africa.

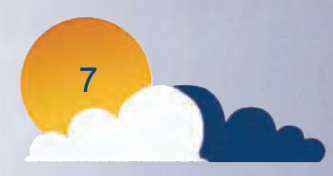


New Data Streams from ARM Mobility Facility Deployment Sites: To supplement measurements taken by the AMF, new climate data streams were made available in 2005 by the ACRF External Data Center (XDC) for Point Reyes National Seashore in California-the location of the first AMF deployment-and for its next deployment site at Niamey, Niger, West Africa. These data streams are provided by collaborators at the National Centers for Environmental Prediction and the European Center for Medium Range Weather Forecasting. They use different algorithms, cover a larger area, and assimilate data from a variety of aircraft, satellite, and ground-based sources. The slightly different measurements they provide are available at the Data Archive for ARM scientists and the broader scientific community as they conduct complementary research in these climate regions of interest.

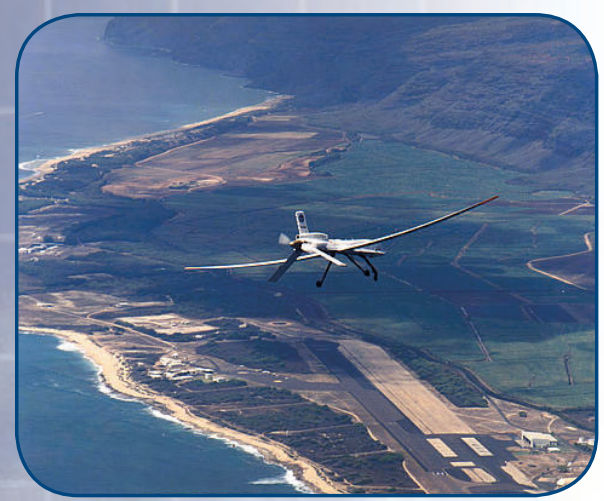

Research aircraft used in ARM field campaigns include UAVs such as the Altus (shown above) and GNAT from General Atomics - Aeronautical Systems, and instrumented piloted aircraft such as the Egrett from Grob Aerospace, DOE's Twin Otter, and the Proteus from Scaled Composites, LLC.

\section{Unmanned Aerospace Vehicle Program}

The ARM Unmanned Aerospace Vehicle (ARM-UAV) Program complements ARM's long-term ground-based measurements of cloud and atmospheric properties by emphasizing instrumented airborne measurement campaigns. Originally developed for defense surveillance, UAVs and piloted aircraft are now used to obtain key climate measurements that cannot be made by other means. In situ data obtained from instrumented aircraft at various altitudes provide critical data for studying how clouds interact with solar and thermal radiation.

Taking to the Skies: Various UAVs and piloted aircraft have contributed to ARM field campaigns during the past decade. A few of the many notable accomplishments by the UAV Program include: (1) the first science flights using a UAV in 1993, (2) the first use of an unescorted UAV in general-use airspace in 1996, and (3) the development of a global positioning systembased technique that allows a precise, vertically stacked flight of a UAV and a piloted aircraft for cloud absorption measurements.

\section{State-of-the-Art Instrumentation Yields Comprehensive Data Sets}

ARM's approach to instrument development and procurement began with a fundamentally new idea in mind: carry out continuous and simultaneous ground-based observations of the atmospheric column using a suite of passive and active sensors. Previously, most sensors used to investigate atmospheric properties and compositions were strictly research instruments and, in many cases, inadequately understood and calibrated. The goal of ARM's instrument development initiative was to bring existing research instrumentation to the advanced state of development required to allow routine, highly accurate operation in remote areas of the world, and to develop new instrumentation as required.

Bigger, Better Cessna Ready to Record Aerosol and Carbon Cycle Data: A new Cessna Turbo 206 was contracted to conduct combined in situ aerosol profiling and airborne carbon measurements for the next 2 years at the SGP site. These measurements will provide data to quantify profiles of carbon dioxide concentration from the surface to mid-troposphere, carbon dioxide budgets in air-mass, and contributions of fossil fuel combustion to atmospheric carbon dioxide. These data are considered essential for quantifying regional carbon exchange and tracing the balance between anthropogenic (human-produced) emissions and biogeochemical cycling, which are identified as priorities by the U.S. Climate Change Science Program and the North American Carbon Program. 
Because side-by-side comparisons and calibration techniques are critical to instrument understanding, the ACRF routinely sponsors and hosts field campaigns focused on this subject. As a result, the new generation of ground-based, remotesensing instruments include millimeter-wave cloud radar, Raman lidar, infrared interferometers using electronic coolers (instead of cryogens), and updated sky imagers, among others. These instruments arrays represent some of the most sophisticated tools available for conducting atmospheric research.

In addition to the instruments, data on surface and atmospheric properties are also gathered through aircraft, forecast models, satellites, field campaigns, and valueadded processing. Once collected, the information is sent to site data systems and reviewed for quality. Approved data are then stored in the Data Archive for use by the atmospheric science community.

\section{Science Team Approach Encourages Collaboration}

ARM's Science Team is a unique collaboration of laboratory, university, agency, and private partners from around the globe. From the United States and abroad, cloud and radiation scientists ranging from senior scientists to post-docs and students comprise the team. Though diverse in geographic location, these science representatives provide the most direct channel through which ARM research results can affect development and evaluation of global climate models. Key support is provided by software and hardware engineers who maintain the infrastructure necessary for advancing ARM Science Team research.

ARM Researchers Shine in New Book on 3D Radiative Transfer: In August 2005, a new book called "3D Radiative Transfer in Cloudy Atmospheres" hit the shelves. Authored by leading $3 D$ radiation scientists from around the worldmore than half of whom receive research funding from the ARM Program-this 700-page volume extensively discusses two main application areas: the impact of clouds on the Earth's radiation budget, which is an essential aspect of climate modeling; and remote observation of clouds, especially with advanced sensors on current and future satellite missions.

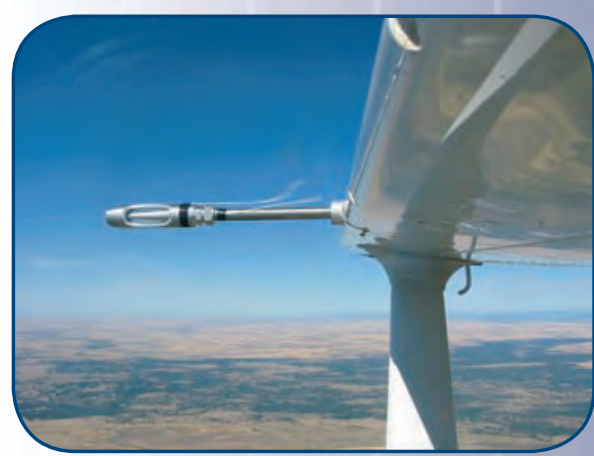

The Cessna aircraft's new, improved sampling probe design will provide much better measurements of larger particles.

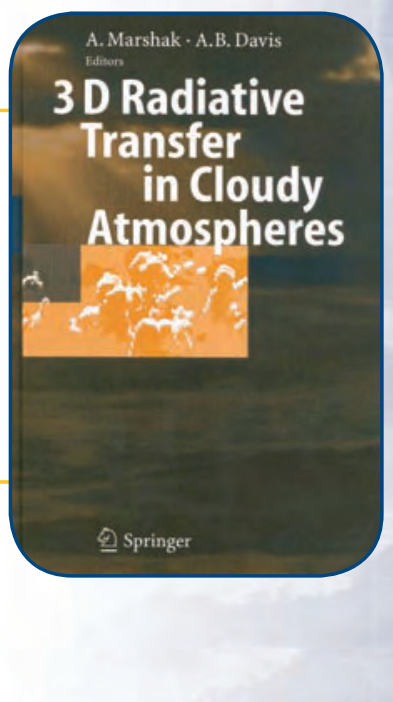

To enable focused research on the various pieces of the cloud physics puzzle, the ARM Program divides its research into key areas, or Working Groups. These groups are the principal organizational structure within the ARM Science Team. Each Working Group concentrates on a specific set of issues related to climate modeling. The Working Groups include:

- Aerosols - relate observations of radiative fluxes and radiances to atmospheric composition, and use these relationships to develop and test parameterizations to accurately predict atmospheric radiative properties 
Through the development of a broad range of retrieval techniques using single and multiple data streams, the ARM Program made key advances in the areas of radiation and aerosol parameterizations, cloud properties algorithms, and cloud modeling/parameterizations versus observations and data analysis.
- Cloud Parameterization and Modeling - relate observations and data analysis to climate model development and evaluation to improve cloud parameterizations in global climate models

- Cloud Properties - develop and implement algorithms that characterize the physical state of the cloudy atmosphere, including cloud occurrence, cloud condensed water amount, and cloud optical properties

- Instantaneous Radiative Flux - test radiation parameterizations, particularly for shortwave radiation and cloudy-sky conditions, at the accuracy required for climate studies.

\section{Oversight Ensures Relevant Science, Promotes Facility Use}

\begin{abstract}
Oversight of the ACRF is provided by the DOE ARM Program Manager, representing the advisory committee for the DOE's Office of Biological and Environmental Research. In addition, a DOE-appointed Science Board reviews research proposals and recommends priorities for increasing the utility of the ACRF. The Science Board coordinates with the ACRF Infrastructure Management Board (IMB) to assess the availability and resource requirements of the proposed facility usage.

The objective of the IMB is to provide fair and equitable distribution of available funds between the fixed-site facility infrastructure costs, field campaigns (also known as intensive operational periods, or IOPs), and special projects. An important part of their function is to increase external (non-ARM) use of the ACRF without inhibiting the achievement of ARM scientific progress.
\end{abstract}

Review Panel Gives ACRF High Marks, Recommendations for Improvement: In early 2005, the DOE ARM Program Manager convened an outside panel of experts to review the management and development of the ACRF, and its progress in meeting the overall needs of the science community. The panel concluded that the ACRF organization and management appeared very well structured and exceedingly receptive to the needs of the user community. One panel member stated, "There is absolutely no question that exceptional support and facilitation of advances in cloud and radiative transfer research has been a hallmark of the ACRF. Developing support capabilities for water cycle, hydrology, carbon, and broader aerosol research is proving to show great potential and should continue to be a focus area for new capabilities within the ACRF." They also judged the ACRF to be committed to a program of continuing improvements for research support and to safety at all sites. The panel commented that data access via the website was exceptionally complete and well structured.

Recommendations from the panel related to improving the user interface for online data access, standardizing and automating instrument calibration methods, and broadening outreach to the user community. They also noted the importance of prioritizing limited resources, stating, "...longterm viability of data storage should be a concern to DOE management, especially if the overarching goal relates to climate-by its nature, a long-term issue." The complete panel report is available at http://www.arm.gov/publications/programdocs/doe-er-arm-0502.pdf. 
Recommendations for future development of the facility are developed annually by the IMB and include input from the Science Board. These recommendations are presented to the DOE ARM Program Manager for consideration and potential inclusion in budget and spending plans.

\section{ACRF Science Board: The 11-member ACRF Science}

Board is chaired by a respected scientist in the field of climate science or a related science. The Chair is appointed by the DOE ARM Program Manager. In addition to the Chair, the Science Board includes five members from the ARM Science Team Executive Committee who represent the interests of the ARM Program, and five members who represent the interests of the broader scientific community, including the DOE Atmospheric Science Program. The DOE ARM Program Manager approves Board membership, and is assisted by the ACRF Science Liaison in coordinating meetings and reviews with the Science Board.

ACRF Infrastructure Management Board: The IMB consists of a Technical Director, Operations Manager, Data Archive Manager, Support Administrator, and the ACRF Science Liaison, who serves as a link between the IMB and the ACRF Science Board. The IMB coordinates the screening of science requests for use of the ACRF. Once a request has been sent to the Science Board for evaluation, the IMB provides to the Science Board detailed information regarding costs, resource use, and potential impacts to ARM Program needs at the ACRF.

\section{Global Program Managed by Many}

Eight national laboratories and numerous government agencies, universities, private companies, and foreign organizations are involved in the ARM Program and ACRF. Each entity serves a vital role in managing and conducting the research, operations, and administration of the science program and user facility. Representatives of the ARM Program make up the majority of ACRF users.

For ARM Program science activities, direction and oversight is the responsibility of DOE Headquarters. A Science Team Executive Committee reviews scientific progress and provides recommendations for future research. Working Group representatives coordinate and modify the ARM research agenda as appropriate. The site infrastructure that enables ARM science is managed through the ACRF.

The ACRF is also directed by DOE Headquarters. An Infrastructure Management Board coordinates the scientific, operational, data, financial, and administrative function of the ACRF. An 11-member Science Board, selected by the DOE ARM Program Manager, serves as an independent review body to ensure appropriate scientific use of the ACRF. 


\section{Fiscal Year 2005 Budget Summary and User Statistics}

\begin{tabular}{|c|c|}
\hline \multicolumn{2}{|c|}{$\begin{array}{c}\text { Atmospheric Radiation Measurement Program } \\
\text { FY } 2005 \text { Budget }(\$ K)\end{array}$} \\
\hline Total ARM Program & 44,611 \\
\hline Infrastructure & 31,441 \\
\hline Science & 13,170 \\
\hline
\end{tabular}

User Statistics for the Period of

October 1, 2004 - September 30, 2005

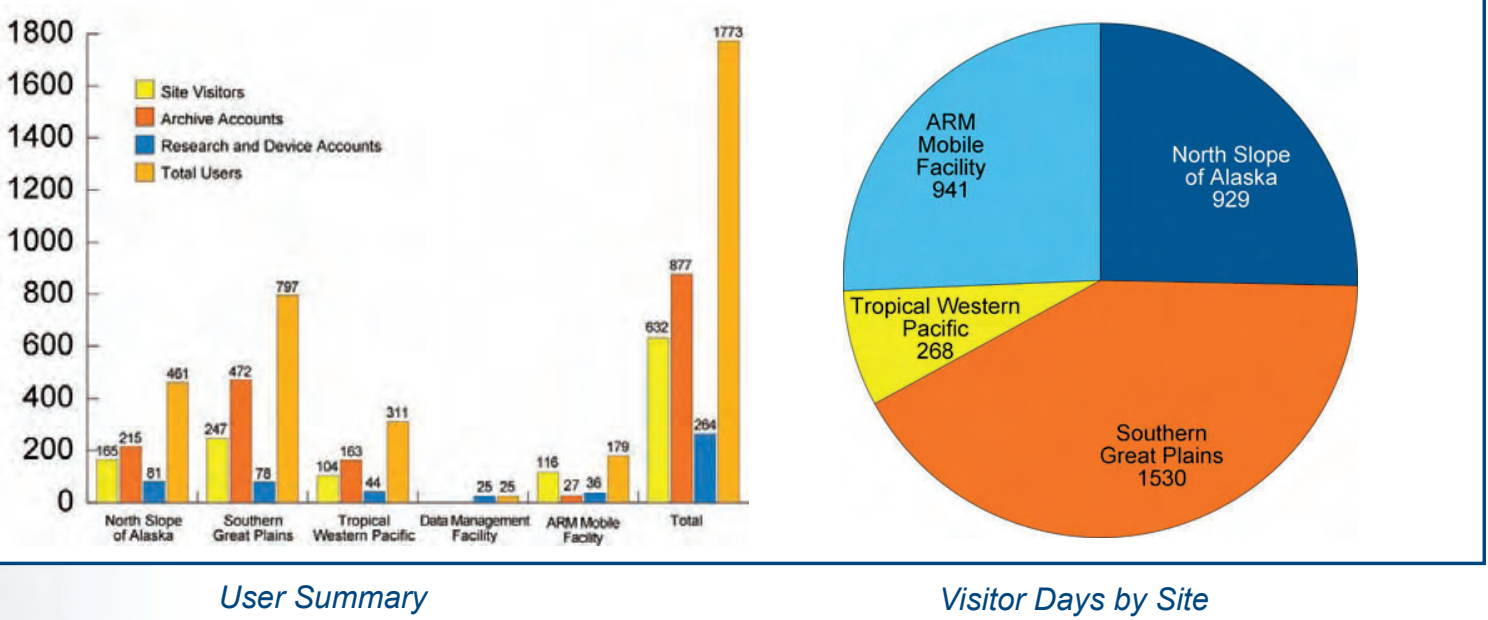

\begin{tabular}{|c|c|c|}
\hline \multicolumn{3}{|c|}{$\begin{array}{c}\text { Operational Statistics for the Period } \\
\text { October 1, 2004 - September 30, 2005 }\end{array}$} \\
\hline & \multicolumn{2}{|c|}{ Data Availability } \\
\hline SITE & GOAL & ACTUAL \\
\hline NSA & 0.90 & 0.90 \\
\hline SGP & 0.95 & 0.95 \\
\hline TWP & 0.85 & 0.89 \\
\hline AMF* $^{*}$ & 0.95 & 0.92 \\
\hline Site Average & 0.91 & 0.92 \\
\hline
\end{tabular}

*Because the AMF is a temporary site, its data availability is based on operational days during field deployment, not 24 hours a day/365 days a year like the fixed sites. 


\section{Key Accomplishments}

The following pages highlight a selection of research results, field campaigns, and infrastructure achievements from FY 2005 (October 2004 through September 2005). A complete list of FY 2005 field campaigns and publications is provided in the back of this report. More detailed information can be found on the following web pages:

- http://www.arm.gov/publications/pub_database.stm for Publications

- http://www.db.arm.gov/cgi-bin/IOP/iops.pl for Field Campaigns

- http://www.arm.gov/acrflupdates.stm for Operations Updates.

\section{Research Highlights}

Members of ARM's Science Team publish an average of 150 refereed journal articles per year, and ARM data are used in many studies published by other scientific organizations. In addition, ARM investigators present their research at key conferences each year. These documented research efforts represent tangible evidence of ARM's contribution to advances in almost all areas of atmospheric radiation and cloud research, and their relevance to climate change modeling efforts.

\section{Characterizing the Coexistence of Water and Ice in Arctic Clouds}

Mixed-phase clouds may contain regions of pure water and pure ice interspersed with regions in which both phases coexist. Details about the distribution of these phases within the cloud, and the total amount of the cloud characterized by each phase, affects the radiative impact of the cloud on the Earth's surface and atmosphere. Researchers sponsored by the ARM Program used in situ measurements obtained during the First International Satellite Cloud Climatology Project Regional Experiment Arctic Cloud Experiment (FIRE-ACE) and the Surface Heat Budget of the Arctic (SHEBA) project to examine the nature of mixed-phase clouds to determine the relative importance of each phase upon the radiative properties of an Arctic cloud field.

Results of their analyses corroborated a previous study showing that a large percentage of the clouds in a typical Arctic cloud field consisted exclusively of ice crystals or supercooled water droplets, even though they occurred in the temperature range (between $0^{\circ}$ and $-30^{\circ} \mathrm{C}$ ) where mixed-phase clouds are prescribed by some theories. This finding is inconsistent with the implementation of many parameterizations currently used in large-scale models. Using observational data collected from 18 flights during FIRE-ACE, the researchers analyzed measurements of drop and ice crystal particle-size distribution, water content, and icing rate. They also used the observations from FIRE-ACE to determine how the properties of the mixedphase clouds differed from the clouds consisting of just liquid or ice, and compared those findings against a parameterization scheme that predicts the radiative characteristics of mixed-phase cloud fields. The scheme predicted a substantially larger contribution from ice to the overall radiative impacts of the cloud than was found in the observations.

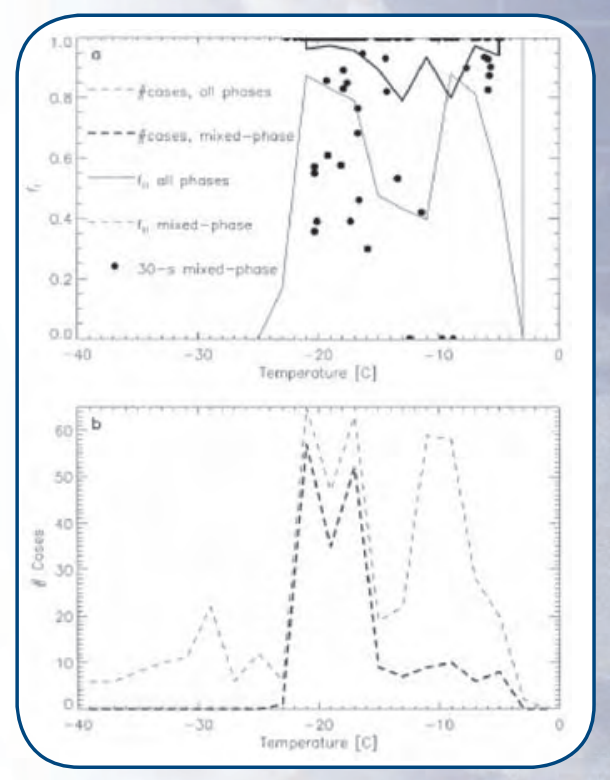

Analyses of in-cloud observations obtained during FIRE-ACE showed that over one-third (33\%) of the clouds were mixedphase, about half of the clouds were ice phase, and just $16 \%$ were liquid phase.

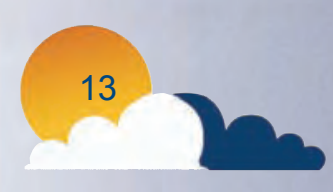


For temperature ranges where water and ice may coexist, an accurate representation of not only the average liquid water content of the cloud field, but also the details of the distribution of liquid water and the nature of its organization, is needed for accurate simulation of Arctic mixed-phase clouds in large-scale models.

(Reference: McFarquhar, GM, and SG Cober. 2004. "Characterizing the co-existence of water and ice in arctic clouds." Journal of Climate, 17: 3799-3813.)

\section{ARM Program Research Improves Longwave Radiative Transfer Models}

As one of four primary research groups within the ARM Program science team, the Instantaneous Radiative Flux (IRF) Working Group focuses on testing radiation parameterizations at the accuracy required for climate studies. They identified as a key priority the improvement of clear-sky downwelling longwave radiance calculations produced by a line-by-line radiative transfer model (LBLRTM). A well-validated LBLRTM could then be used to "build" rapid radiative transfer models or parameterizations for use in global climate models.

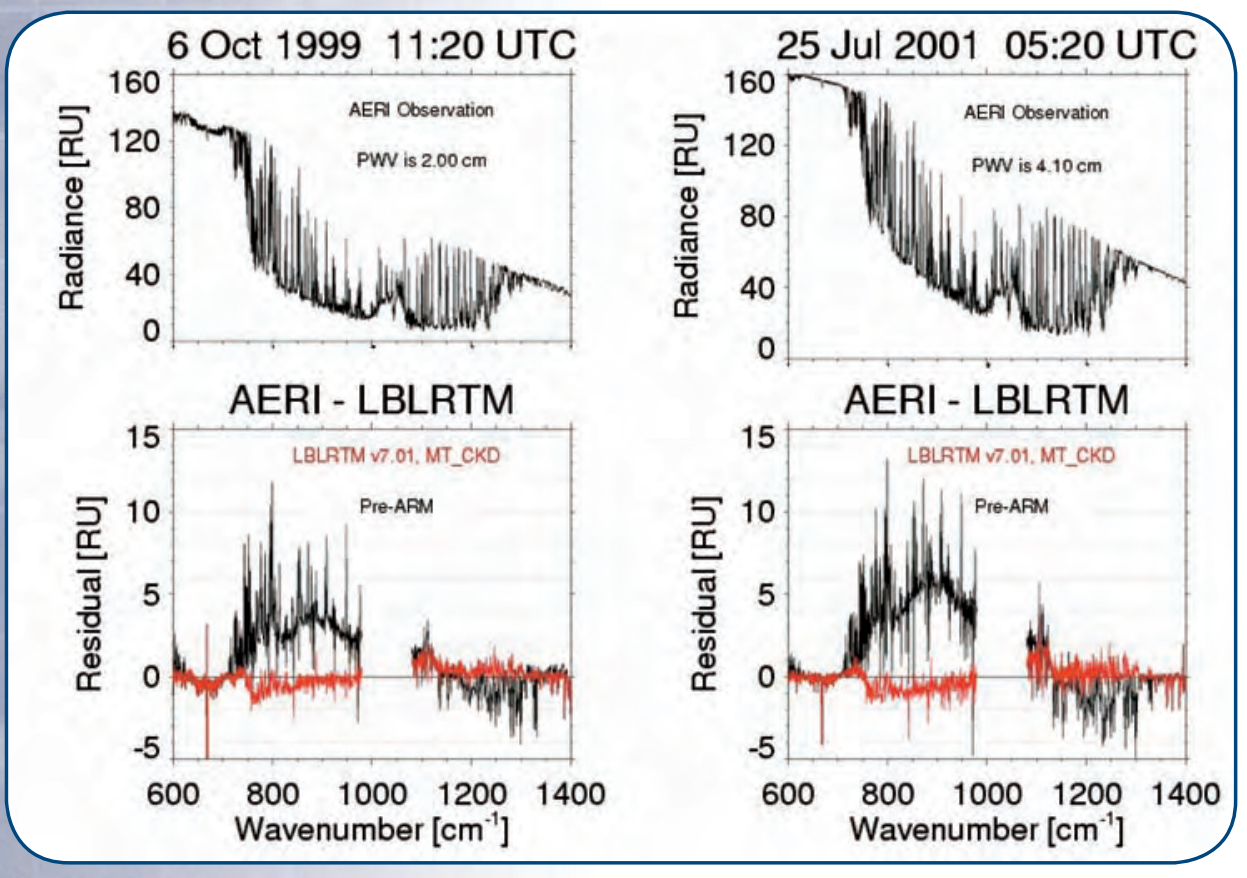

Top panels: Examples of downwelling infrared radiance observed by the AERI for two different clear-sky cases with different amounts of water vapor. Bottom panels: Differences between the AERI observations and calculations made using the LBLRTM at the start of the ARM Program (pre-ARM in black) and circa 2003 (red), showing the vast improvement in the ability to model downwelling infrared radiation. In terms of longwave radiative flux, the error in the downwelling flux was 6-8 W/m $\mathrm{m}^{2}$ using the pre-ARM model, while the error is less than $1.5 \mathrm{~W} / \mathrm{m}^{2}$ using the improved 2003 model.
The IRF Working Group identified the Atmospheric Emitted Radiance Interferometer (AERI) — an instrument developed for the ARM Program that collects continuous measurements of downwelling infrared radiance at high spectral resolution with better than $1 \%$ accuracy —as an ideal candidate for obtaining the measurements needed to conduct the validation effort. The validation effort required accurate observations of atmospheric state (i.e., profiles of water vapor and temperature) to use as input into the model. The research team conducted a Quality Measurement Experiment, or QME, to evaluate: (1) the accuracy of the AERI, (2) the accuracy of the input data used to drive the LBLRTM, and (3) the accuracy of the LBLRTM and its components. The QME effort led to improvements in all three areas.

Major progress was reported in 2003 as results became available from ARM field campaigns conducted to improve the water vapor observations used to drive the LBLRTM. Recently published research describes the capabilities of the AERI and the comparisons conducted between the AERI observations and LBLRTM calculations. The original accuracy of "state-of-the-art" models in 1990 had longwave flux residuals on the order of 6 to $8 \mathrm{~W} / \mathrm{m}^{2}$; through development and validation of the LBLRTM, errors in longwave flux calculations were reduced to less than $1.5 \mathrm{~W} / \mathrm{m}^{2}$. This research, involving scientists from a large number of organizations funded by ARM and spearheaded by the IRF Working Group, reduces the uncertainties in 
model simulations of heating and cooling of the Earth's atmosphere, and represents a major accomplishment for the ARM Program. (Reference: Turner, DD, DC Tobin, SA Clough, PD Brown, RG Ellingson, EJ Mlawer, RO Knuteson, HE Revercomb, TR Shippert, and WL Smith. 2004. "The QME AERI LBLRTM: A closure experiment for downwelling high spectral resolution infrared radiance.” Journal of Atmospheric Sciences, 61: 2657-2675.)

\section{Droplet Nucleation Finally Included in Global Climate Model}

Tiny aerosol particles affect Earth's climate in several ways: directly, through scattering and absorption of solar and infrared radiation, and indirectly, by influencing the creation (or nucleation) of cloud droplets, leading to increased surface area and reflectivity of clouds. To what extent these different aerosol effects impact the Earth's energy balance is a subject under much investigation by the climate research community.

Researchers funded by the ARM Program developed a treatment of droplet nucleation and applied it to the Community Atmosphere Model (CAM) from the National Center for Atmospheric Research. In coupling the droplet nucleation scheme with aerosols in CAM, the simulated energy balance of the climate-a critical measure of model performance-was very close to the energy balance simulated with droplet number prescribed at a distribution of highly tuned values. This agreement also held when the dependence of droplet "autoconversion" (merging of droplets - a key process for precipitation formation) on droplet number was treated.

Previously published research in this area identified the importance of improving a number of parameters when simulating droplet nucleation, particularly with respect to the relationship between aerosol, cloud updraft velocity, and droplet number concentration. These findings led to the current effort to fine tune the associated droplet nucleation parameters within CAM. In particular, the lower boundary of updraft vertical velocity was adjusted to improve the agreement of droplet prediction for current aerosol emissions. Thus, CAM can now use the predicted droplet number to treat indirect effects of aerosols, an important climateforcing mechanism that has been neglected in all previous climate simulations by CAM. (References: Ghan, SJ, LR Leung, RC Easter, and H Abdul-Razzak. 1997. "Prediction of droplet number in a general circulation model." Journal of Geophysical Research, 102: 21,777-21, 794, and Ghan, SJ, RC Easter, E Chapman, H Abdul-Razzak, Y Zhang, R Leung, N Laulainen, R Saylor, and R. Saveri. 2001. "A physically-based estimate of radiative forcing by anthropogenic sulfate aerosol." Journal of Geophysical Research, 106: 5279-5294.)

\section{Small Processes Make a Big Difference in Model Outcomes}

Typical climate models are based on a grid pattern that blankets the globe, with each square of the grid covering an area of about $300 \mathrm{~km}$ by $300 \mathrm{~km}$. Each square then extends vertically into the sky, resulting in approximately 8,192 "columns" of atmospheric properties. This large-scale grid is used because of the extensive computational time needed for smaller grids. However, because cloud and radiative effects occur on small scales, their processes are parameterized. This means

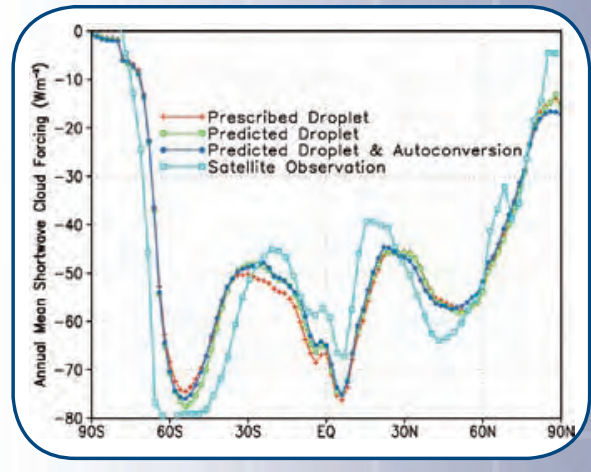

Reflection of sunlight by clouds simulated with predicted droplet number with (dark blue) and without (green) the autoconversion feedback agrees remarkably well with the reflection simulated with prescribed droplet number (red). Satellite observations (light blue) are shown for comparison. 


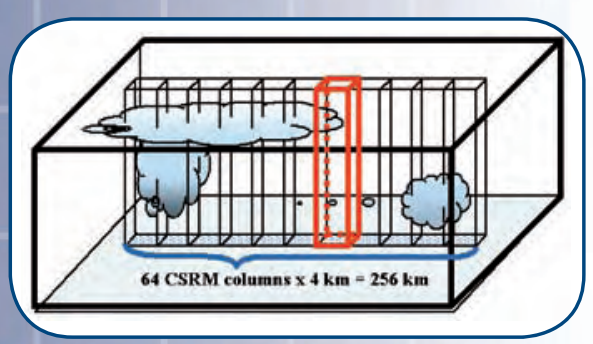

To address small scale atmospheric processes, cloud system resolving models divide a typical global climate model grid cell into 64 columns, each approximately $4 \mathrm{~km}$ wide.

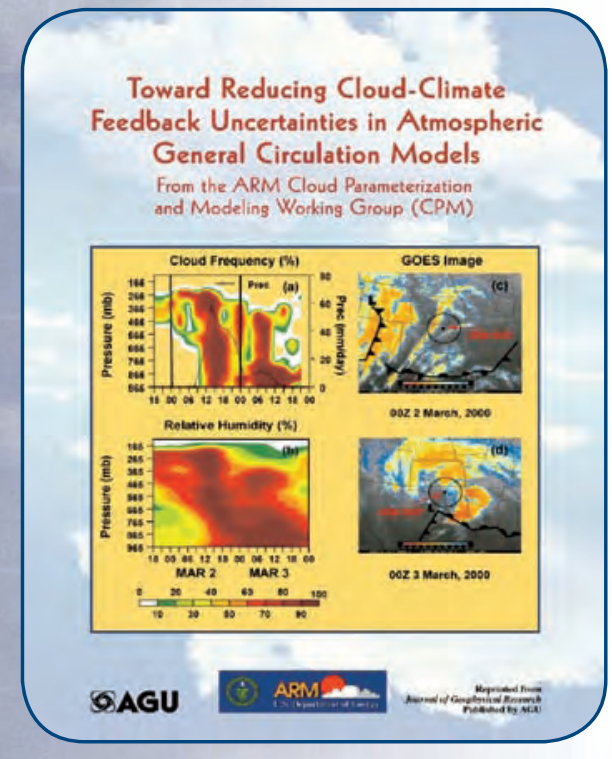

Scientists from the CPM Working Group are featured in a special section of the Journal of Geophysical Research Atmospheres. the effects are expressed as a set of simple approximate relationships, rather than through explicit equations that simulate the actual physical processes in the climate model. Scientists sponsored by the ARM Program found that these small-scale processes may have important impacts on the climate and climate change simulated by global climate models.

In their study, the researchers replaced the conventional global climate model cloud parameterization in each of the model's 8,192 columns with a two-dimensional cloud system-resolving model (CSRM) which used 64 columns. They then calculated the radiative heating rates independently for each of the 64 CSRM columns. The researchers performed three model experiments using the nested model system, also known as the Multi-scale Modeling Framework, to explore the sensitivity of the model to the coupling between radiative heating and model dynamics. Model experiment runs were conducted for only a single season due to computational constraints.

Results of the comparison study showed that experiments using the independently calculated heating rate profiles produced a similar large-scale model climate state. Experiment runs using a single averaged heating rate profile produced a different model climate state. This suggests that small-scale variability in cloud scale properties feeds up and modifies the large-scale average states. (Reference: Cole, JNS, HW Barker, DA Randall, MF Khairoutdinov, and EE Clothiaux. 2005. "Global consequences of interactions between clouds and radiation at scales unresolved by global climate models." Journal of Geophysical Research, 32, L06703, doi:10.1029/2004GL020945).

\section{ARM Research Spotlighted in Special Issue of Journal}

In the August issue of the Journal of Geophysical Research - Atmospheres (Vol. 110 No. D15), recent research from the members of the ARM Cloud Parameterization and Modeling (CPM) Working Group is presented in a special section entitled "Toward Reducing Cloud-Climate Feedback Uncertainties in Atmospheric General Circulation Models." This collection of research focuses on better understanding and improving the representation of clouds in general circulation models by using observations at process levels.

The first paper in the collection reports an assessment of the current status of cloud simulations in general circulation models from modelers in the United States and Europe. The remaining 17 papers can be categorized into four groups: (1) a case study of cloud simulations during the ARM/GCSS (Global Energy and Water Experiments-Cloud System Studies) case 4, (2) developments of cloud parameterization algorithms using ARM data, (3) model cloud processes evaluated against ARM measurements, and (4) research results concerning measurements of clouds.

The CPM Working Group addresses the importance of relating observations and data analysis to climate model development and evaluation. They expose key issues regarding the design of general circulation models that impact the representation of cloud-climate feedback processes. Results from these studies are then used to improve cloud parameterizations in global climate models. (Reference: Journal of Geophysical Research, Vol. 110, D15, 2005). 


\section{New Scheme More Accurate for Cloud Droplet Formation, Dispersion}

Global estimates of the indirect aerosol effect that are much larger than $1 \mathrm{~W} \mathrm{~m}^{-2}$ in magnitude are difficult to reconcile with observations, yet climate models give estimates between -1 and $-4.4 \mathrm{~W} \mathrm{~m}^{-2}$. A study in 2002 by Liu and Daum (Nature, 419) showed that increases in cloud droplet concentration $(\mathrm{N})$ are associated with increased dispersion (breadth) of the cloud droplet-size distribution, and that the increased dispersion counteracts the first indirect aerosol effect. Subsequent global climate model simulations confirmed that neglect of the dispersion effect (the width of the distribution of cloud droplet sizes) can lead to overestimation of the first indirect aerosol effect.

A recent study by ARM Program researchers in partnership with atmospheric scientists in Australia, presents new global climate model-based calculations of the second indirect effect using a new autoconversion scheme, called " $R_{6}$ scheme," which accounts for this dispersion effect. The $\mathrm{R}_{6}$ scheme also more accurately treats the efficiency with which cloud droplets coalesce to form drizzle drops, compared to the earlier " $\mathrm{R}_{3}$ scheme" most often used in climate models.

To quantify the impact of the new scheme on the second indirect effect, the researchers used the Commonwealth Scientific and Industrial Research Organization (CSIRO) Mark 3 global climate model at low resolution. The researchers obtained a global-mean value of $-0.28 \mathrm{~W} \mathrm{~m}^{-2}$, compared to $-0.71 \mathrm{~W} \mathrm{~m}^{-2}$ with the $\mathrm{R}_{3}$ scheme. Their estimate of the total indirect aerosol effect on liquid-water clouds changed from -1.63 to $-1.09 \mathrm{~W} \mathrm{~m}^{-2}$. The difference was due to (1) the new scheme's smaller autoconversion rate, and (2) an autoconversion threshold that increases more slowly with cloud droplet concentration. The strong impact of the smaller autoconversion rate shows the importance of accurately modeling this process, in that the magnitude of the second indirect effect depends on absolute changes of precipitation $(\mathrm{P})$ with $\mathrm{N}$. Either with or without the dispersion effect, the $\mathrm{R}_{6}$ scheme has a much smaller autoconversion rate than the $\mathrm{R}_{3}$ scheme, so the changes of $\mathrm{P}$ with variations of $\mathrm{N}$ are smaller. The dispersion effect was also found to have a significant impact on the second indirect effect, mainly by causing the autoconversion threshold to increase more slowly with cloud droplet concentration.

The results obtained with the $\mathrm{R}_{6}$ scheme are easier to reconcile with observations, because this scheme can be used in a global climate model without causing a global cooling to occur during the 20th Century. In addition, the impact of the smaller autoconversion rate on the second indirect effect shows the importance of careful evaluation of autoconversion schemes and avoidance of artificial "tuning" of rates or thresholds. (Reference: Rotstayn, L, and Y Liu, "A smaller global estimate of the second indirect aerosol effect," Geophysical Research Letters: Vol. 32, L05708, March 2005.)

\section{Featured Field Campaigns}

ACRF users-whether sponsored by ARM or other scientific organizations-regularly conduct field campaigns to augment routine data acquisitions and to test and validate new instruments. A field campaign that is proposed, planned, and implemented at one or more research sites is also referred to as an intensive opera-

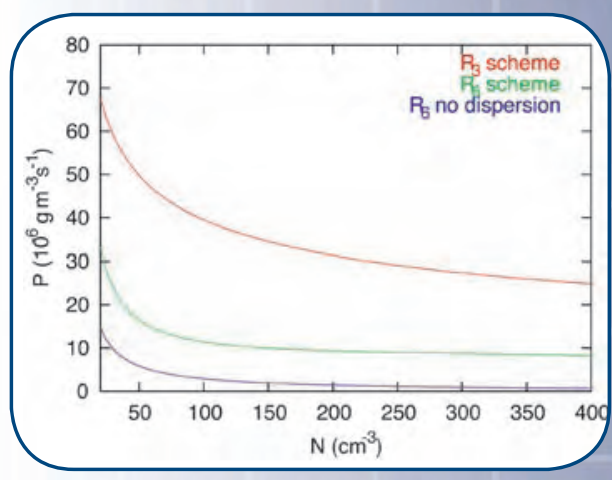

Shown are the autoconversion rates given by the $R_{3}$ scheme and the $R_{6}$ scheme, with and without the dispersion effect. The magnitude of the second indirect effect depends on absolute changes of precipitation with cloud droplet concentration, as shown by the slopes of the curves.

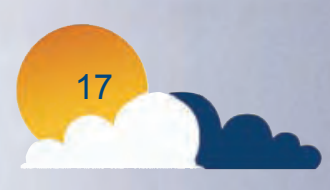




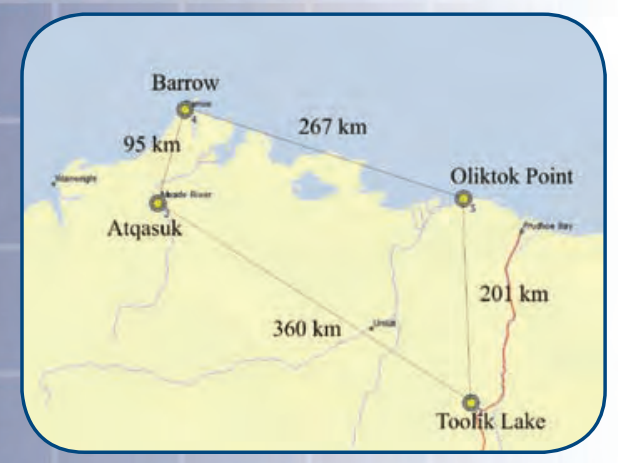

This map shows the experimental domain of M-PACE.

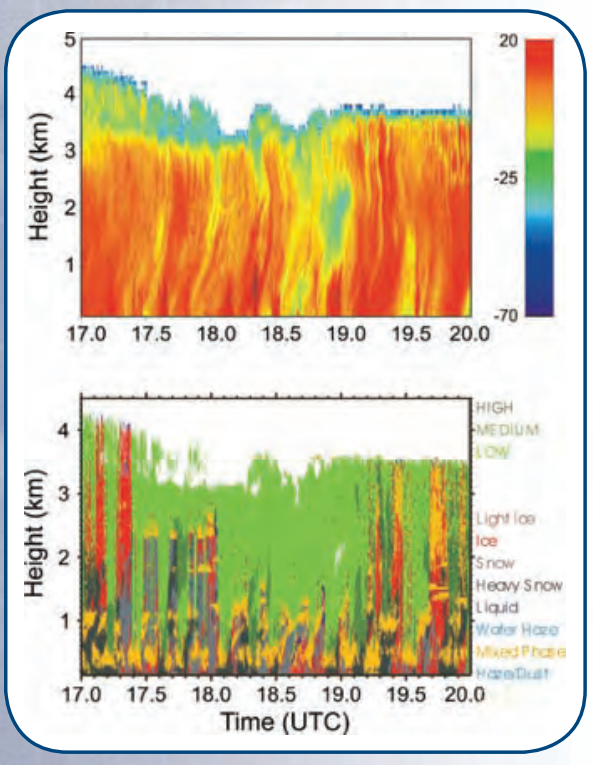

In an image taken from a millimeter cloud radar on October 6, 2004, at Barrow, Alaska, the top panel shows ice precipitation falling from the cloud layer as regions of higher reflectivity (red). The bottom panel includes a cloud mask produced by combining cloud radar and lidar data. Combining the data streams allows for a richer picture of the cloud layer, as evidenced by the many broken liquid layers within the ice precipitation falling from the upper-most cloud layer. tional period, also known as an IOP, as during this time, increased activities to support additional data acquisition occur. These concentrated efforts direct focused resources on a specific research area, resulting in valuable data to further scientific understanding of cloud and radiative processes.

\section{Mixed-Phase Arctic Cloud Experiment}

The largest and most ambitious field campaign conducted thus far at the NSA locale took place in October 2004. The Mixed-Phase Arctic Cloud Experiment (M-PACE) involved 4 weeks of intensive ground, remote sensing, aircraft, and radiosonde measurement activities focused on obtaining microphysical data on mixed-phase arctic clouds. Mixed-phase clouds are composed of both ice and water, as opposed to only ice or water. This cloud type dominates low-lying clouds in the Arctic, but a comprehensive data set for analyzing their contribution to the arctic climate is currently not available. The primary goal for this experiment was to collect a focused set of data needed to advance the understanding of dynamic processes in arctic mixed-phase clouds, including cloud microphysical processes and radiative transfer through clouds. These data sets can then be used in computer models that simulate the arctic climate.

The experimental area, which simulated a single-column modeling grid-box, consisted of four surface-based sites. The two NSA sites at Barrow and Atqasuk were supplemented with a radiosonde station at Toolik Lake, and the Pacific Northwest National Laboratory's Atmospheric Remote Sensing Laboratory-a mobile measurement facility with many of the same instrument capabilities as the ACRF fixed sites—at Oliktok Point. A tethered balloon measurement system was also deployed from this location. Throughout the experiment, radiosonde data were acquired at 6-hour intervals from the four ground-based sites.

To complement the ground-based measurements, two instrumented aircraft participated in the experiment: the University of North Dakota's Citation served as an in situ platform, while the piloted Proteus, sponsored by the ARM-UAV program, served as a remote sensing aircraft. The Citation flew 13 missions and the Proteus flew 5 missions in support of M-PACE. In addition, DOE's Multispectral Thermal Imager satellite system surveyed Barrow and Oliktok Point at high resolution in 15 spectral bands as often as possible throughout the experiment.

Results: The M-PACE documented the microphysical characteristics of several types of Arctic mixed-phase clouds. In general, the observed mixed-phase clouds contained a great deal of liquid to temperatures as low as $-25^{\circ} \mathrm{C}$, frequently with liquid tops that precipitated ice. Multiple liquid layer clouds were also observed. Data from the ARM millimeter cloud radar at Barrow showed pulses of ice precipitation falling in streaks from a liquid-topped mixed-phase cloud. However, when the cloud radar data were combined with the Wisconsin micropulse lidar data using retrieval techniques developed by ARM scientists, a richer picture of this mixed-phase cloud was revealed. Using these two data streams, multiple liquid layers appear, each with ice precipitation shafts. Data such as these will be used to both improve and validate Arctic cloud and climate models.

Data obtained by the Cloud Particle Imager instrument onboard the Citation aircraft also showed spherical liquid drops throughout much of the upper portion 
of the cloud layer, with ice crystals falling out as precipitation in the lower sections of the cloud. Aerosol data from the Citation suggests that the reason for the large abundance of liquid water within Arctic mixed-phase clouds is due to very low ice nucleation particle counts. With counts lower by almost a factor of 100 compared to those observed at other latitudes, this measurement has important implications

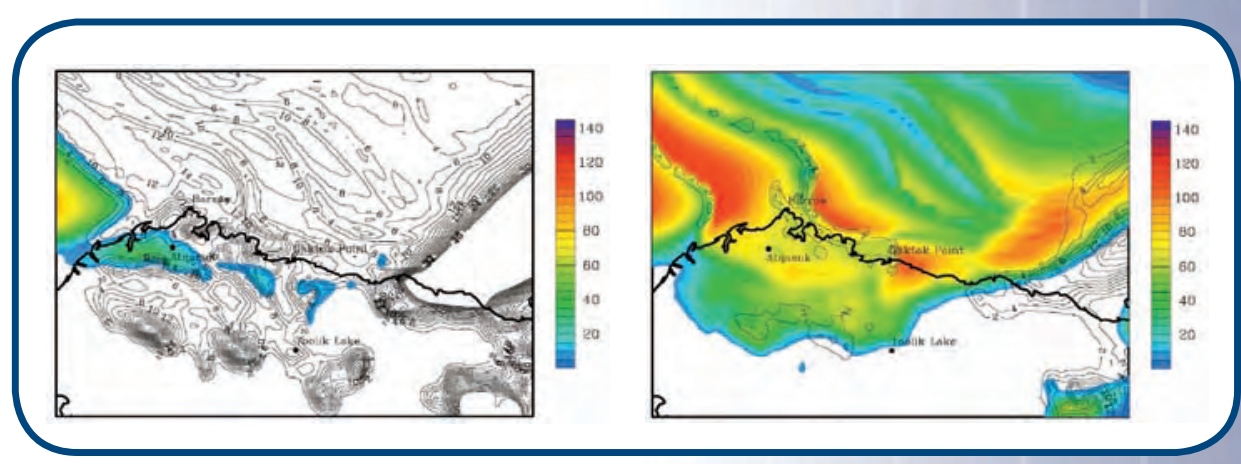
for Arctic cloud and climate models. Current models run during M-PACE tended to produce clouds composed completely of ice, even though the observed clouds were mostly liquid. When ice nucleation calculations in the model were updated using the observations from M-PACE, the clouds remained liquid, as observed. This result has important consequences for the Arctic energy budget, because ice clouds allow more cooling of the Arctic surface by emitted infrared radiation than do liquid clouds.

\section{Marine Stratus Radiation, Aerosol, and Drizzle IOP}

Point Reyes National Seashore, north of San Francisco, California, marked the site of the inaugural campaign for the AMF in spring 2005. The 6-month Marine Stratus Radiation, Aerosol, and Drizzle (MASRAD) field campaign focused on the microphysical and radiative characteristics of marine stratus, one of the most prevalent cloud types on the planet. Marine stratus clouds are thought to be susceptible to modification via the by-products of fossil fuel consumption. A better understanding of the processes that lead to potential cloud modifications is a multiagency climate change priority. Despite their importance to the earth-ocean-atmosphere system, relatively few detailed and comprehensive data sets of marine stratus clouds are available.

During the field campaign, ARM researchers collaborated with the U.S. Office of Naval Research, DOE's Atmospheric Science Program, and individual university investigators. Their goals were to collect data to better understand the rate at which different types of aerosol particles are converted to cloud droplets and how these cloud droplets eventually grow to produce drizzle. To collect the data, two research aircraft participated in the project along with the AMF. The AMF made continuous, detailed measurements of cloud microphysics, cloud updraft structure, thermodynamic structure, and surface radiation in the marine stratus clouds.

At the same time, investigators from DOE's Atmospheric Science Program and other groups and agencies made detailed measurements of the aerosol structure at the surface and from aircraft during the month of July. Included in the suite of surface and aerosol measurements was specific information about the chemistry and nucleating properties of aerosols observed at the surface, enabling researchers to diagnose the source region of the aerosols.

Results: Marine clouds and fog were observed almost continuously from mid-June through mid-September. Early analyses of the data collected during MASRAD showed a wide variety of aerosol types, including episodes containing significant

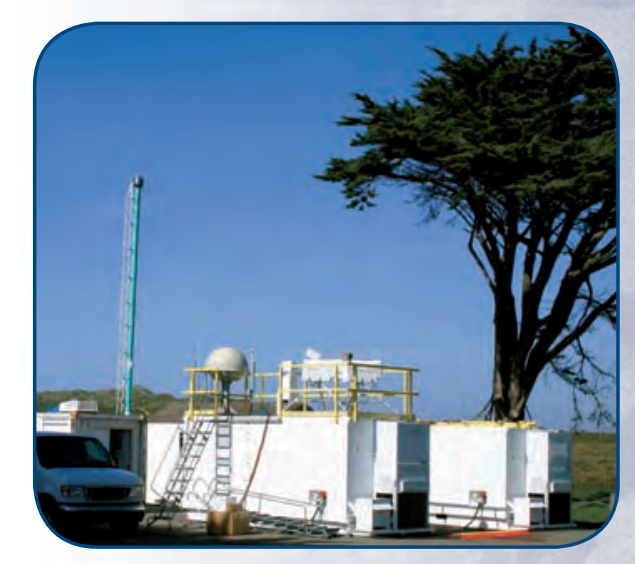

State-of-the-art active and passive remote sensors measured the detailed microphysical structure of marine stratus clouds at the AMF deployment site, about 1 mile from the ocean at Point Reyes National Seashore.
A simulation of the October 10, 2004, case day using typical cloud parameterizations in the Regional Atmospheric Modeling System is shown at left, with ice water path $\left(\mathrm{g} \mathrm{m}^{-2}\right)$ contoured and liquid water path $\left(\mathrm{g} \mathrm{m}^{-2}\right)$ shaded. At right, the same model simulation, using ice nucleation data from the Citation aircraft, shows an extensive liquid cloud deck with small amounts of ice, which is similar to observations from the same day.

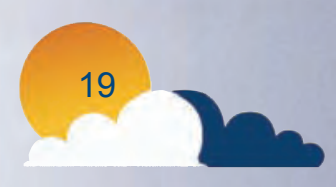




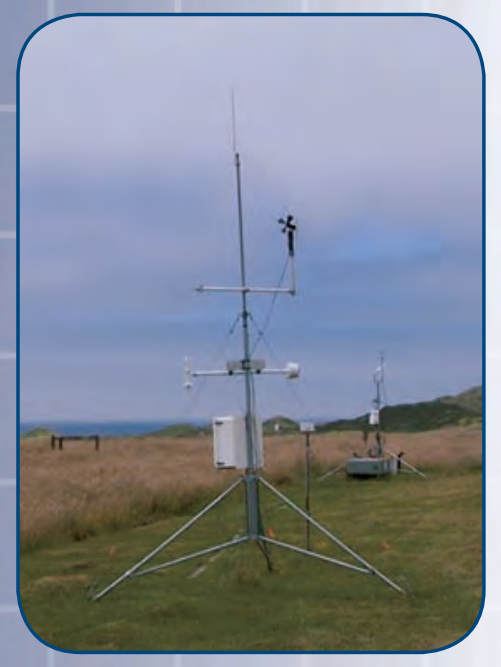

With the Pacific Ocean in the distance, a surface meteorology system collects wind, temperature, pressure, and humidity data as marine clouds drift over the field instruments at the AMF deployment site at Point Reyes National Seashore.

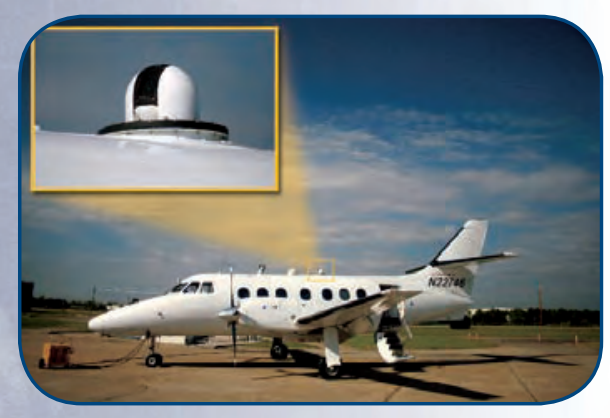

Outside the hangar in Ponca City, Oklahoma, the optical head of the AATS-14 (inset) can be seen as the white dome on the roof of the Jetstream-31 aircraft. The AATS-14 obtained extinction vertical profiles from spiral ascents and descents over the SGP site during ALIVE. amounts of anthropogenic (human-produced) aerosol. Because the cloud base was so low during MASRAD, the surface aerosols were concluded to be the same type as those nucleated in the clouds above, demonstrating that under certain conditions, there is a direct link between the aerosol and cloud properties at the surface site.

The data also showed the presence of remarkably thin clouds composed of extremely small cloud droplets during the daytime on many occasions. Lidar data indicated significant variability in the cloud droplet structure at cloud base on the scale of minutes, and trajectory analyses suggested the number of aerosols in a given sample that could serve as cloud condensation nuclei was strongly dependent upon the past trajectory of the sample. Aircraft measurements detected the presence of elevated layers of aerosol in the region; investigations are underway to determine the impact of these layers on the cloud structure. Preliminary analysis of cloud radar data show a rich mixture of updraft and downdraft structures observed during the experiment, and efforts are underway to link these structures with the observed aerosol nucleating characteristics.

\section{Aerosol Lidar Validation Experiment}

The Aerosol Lidar Validation Experiment (ALIVE), a collaborative effort with the ARM Program and National Aeronautics and Space Administration (NASA), took place in September 2005 at the SGP site. The major goal of the experiment was to collect airborne remote sensing data on atmospheric aerosols for validation studies of the SGP Raman lidar and micropulse lidars. The airborne data were collected by the NASA Ames Airborne Tracking 14-Channel Sunphotometer (AATS-14) flown aboard a Jetstream-31 research aircraft from Sky Research. Validation activities such as these are important for calibrating all measurements to consistent standards and reduce scientific uncertainties in the data used by computer models.

Prior to ALIVE, the 2003 Aerosol IOP at the SGP site provided one of the best measurement sets obtained to date for evaluating the scientific capability for measuring the vertical profile of ambient aerosol extinction in the lower troposphere. However, validation results showed that an undetected loss of sensitivity of the SGP Raman lidar had occurred leading up to the Aerosol IOP, resulting in a significant high bias in derived aerosol extinction. Major upgrades were made to the Raman lidar in 2004 to restore and improve its data-gathering capabilities and sensitivity. To prove the integrity of the entire Raman lidar aerosol extinction record, data obtained by the AATS-14 during ALIVE will be compared against the upgraded Raman lidar and the validated data from the Aerosol IOP.

Logging 20 flight hours between September 11 and 22, 2005, the Jetstream-31 conducted 12 flights over the SGP site. Five of these flights coincided with the flights by a new ARM in situ aerosol profile aircraft, the Cessna Turbo 206, to help evaluate the performance of instruments for collecting in situ aerosol profile measurements. Onboard the Jetstream-31 the AATS-14 obtained more than 40 vertical profiles at altitudes between $500 \mathrm{ft}$ and 23,000 ft from spiral ascents and descents. Cirrus clouds presented a major obstacle for the radiation instruments aboard the Jetstream-31, although considerable efforts were made to minimize their effect through timing of the vertical profiles using various forecasting and nowcast- 
ing tools. A Scanning Polarimeter instrument from NASA's Goddard Institute for Space Studies Research also operated aboard the Jetstream-31 as a piggyback instrument, contributing an additional 3 flight hours to the ALIVE field campaign, and will provide multi-spectral measurements of upwelling polarization and radiance.

Results: Final calibrations are now underway for many of the instruments involved in ALIVE. As an example, the AATS-14 was calibrated before ALIVE at the Mauna Loa Observatory in Hawaii (11,000 ft above sea level) using a technique known as Langley plots. At the conclusion of ALIVE, it was sent there again for final calibration, and is being refined by inspecting the measurements taken at the highest altitude flight legs during ALIVE.

Because the field campaign was conducted late in the year, initial comparisons between the lidars, AATS-14, and ground-based sunphotometers data are in the early stages. A status report on ALIVE will be presented at the ARM Working Group meetings in late 2005, with additional results presented at the 2006 ARM Science Team Meeting in Albuquerque, New Mexico.

\section{Infrastructure Achievements}

Infrastructure activities include management of site operations at the research facilities, instrumentation and engineering support, data quality and storage, and communication and education/outreach. All of these areas are key components of enabling ARM science and promoting the capabilities of the ACRF for new users.

\section{Site Operations}

\section{User Facilities Improved at the NSA Locale}

After experiencing crowded working conditions during complex field campaigns in 2004, followed by several power outages this past winter, NSA operations staff implemented numerous measures to improve the situation. A new emergency response plan addressing numerous emergency conditions was developed and put in place. The plan summarizes response actions in the event of power failures, fires, floods, and medical emergencies. As part of the plan, a snowblower, replacement snowmobile, and backup generator were procured to give operators the capability to access, clear, and deploy emergency heaters during extreme weather conditions. Other actions taken included an investigation into potential upgrades for the site's power line-which also feeds power to equipment used by National Oceanic and Atmospheric Administration (NOAA), U.S. Geological Survey, and nearby National Science Foundation (NSF) projects. This activity revealed the utility line was operating ever closer to maximum capacity, using obsolete, decades-old equipment. A cooperative effort to remedy the situation is under discussion among the affected parties.

To handle additional users and instruments, and alleviate overcrowding, modifications to an existing instrument platform in Barrow were completed in fall 2004 in preparation for adding a larger guest facility to it this summer. The new guest facility, constructed from the existing platform, now consists of two insulated shipping containers mounted on pilings, with a top-side mezzanine to accommodate

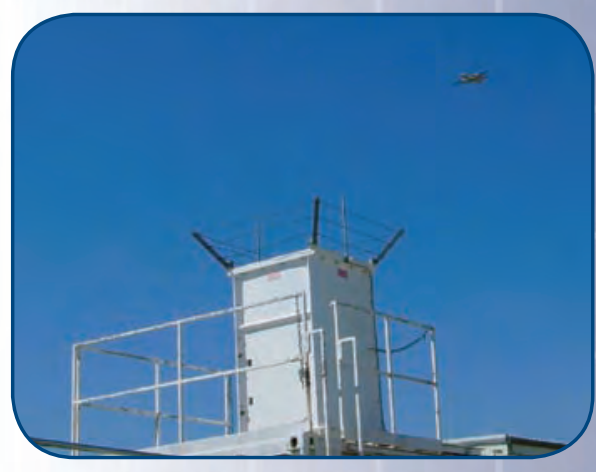

The Jetstream-31 made numerous passes over the Raman lidar at the SGP site during ALIVE. The Raman lidar is an active, ground-based laser remote sensing instrument that measures vertical profiles of water-vapor mixing ratio and several cloud-and aerosol-related quantities.

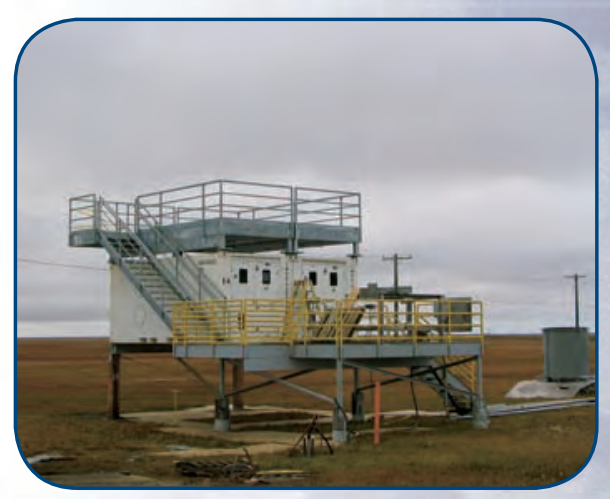

In September, installation was completed on the new Guest Instrument Facility in Barrow to provide additional instrument space and ease crowded working conditions. 
additional user instruments. In addition, a heated laboratory area within the site maintenance building was developed to provide even more room for researchers and their equipment. And for added operations capability, a new flatbed 4-wheel drive, crewcab pickup truck was procured for the Barrow site.

\section{Aging, Overworked Computer Network at SGP Gets Overhauled}

At the SGP site's Central Facility - the most heavily used computer network of all the ACRF sites—several upgrades to the network infrastructure were made to improve security, performance, reliability, and growth potential. Established as the first ARM research facility in 1992, the SGP site was running on essentially the same network architecture since site inception. Now handling approximately 1GB of data from numerous sources every day, the Central Facility computer network was in need of restructuring. The new network architecture isolated the various functional groups of instruments, data systems, site operations, visitors, and globally accessible services onto separate networks. Installation of higher-performance firewall and logging systems also better supports implementation of the ACRF cyber security policy.

As part of this effort, new network switches were installed throughout the site, both to improve performance for local users and to provide the ability to administer the network down to the individual port level. This level of administration is vital to supporting reliable network operation and site visitors in a secure manner. A higher-performance router was also installed as a gateway to the site to improve performance over both the T1 (internet) link with the Data Archive and several lines of Voice Over Internet Protocol (VOIP). The new gateway supports increasing bandwidth with the Data Archive, if needed, in addition to allowing for growth in the use of VOIP in support of communications among SGP data systems operations staff, the AMF, and ACRF sites in the TWP.

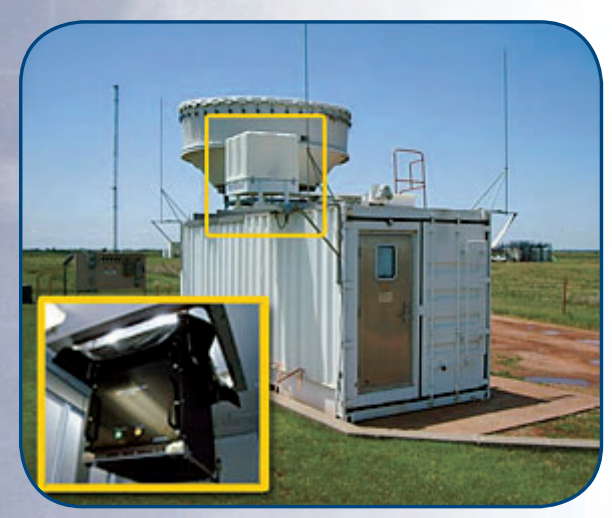

The WACR provides improved sensitivity for detecting tiny objects in the atmosphere to an altitude of $5 \mathrm{~km}$. The instrument's antenna is located adjacent to the MMCR antenna on top of the MMCR shelter; the rest of the unit is located inside (inset).

\section{Instrument Enhancements}

\section{Battle with Bugs Nearly Over Thanks to New Radar}

For a great portion of the year at the SGP site, data from the millimeter wavelength cloud radar (MMCR) are often contaminated by "atmospheric plankton" (tiny bugs and dust particles) at altitudes up to $5 \mathrm{~km}$. Because MMCR data are used to measure cloud boundaries (i.e., cloud tops and bottoms) and to record the reflectivity profile of the atmosphere up to $20 \mathrm{~km}$, this contamination issue poses data quality issues. Researchers analyzing MMCR data from several experiments concluded that trying to differentiate between the clouds and atmospheric plankton with the current set of instruments was extremely time consuming and inexact. To solve this dilemma, a new W-band ARM cloud radar (WACR) was designed and built over the course of a year, and was installed in the MMCR instrument shelter at the SGP Central Facility.

The WACR is a Doppler radar that returns signals of reflectivity, velocity, and spectral width (which corresponds to turbulence). Both the WACR and MMCR have co-polarization and cross-polarization channels to differentiate between spheri- 
cal (e.g., raindrops) and nonspherical (e.g., insects and ice crystals) atmospheric objects, but the new radar operates at $95 \mathrm{GHz}$, whereas the MMCR operates at 35 GHz. The new radar complements the existing MMCR by differentiating between clouds and spurious radar returns due to insects and other detritus in the lower atmosphere. By collocating these two radars and their various modes of operation, researchers will now have the data to explore dual wavelength techniques such as retrieval of drizzle parameters. Deployment of the WACR represents a key milestone for user enhancements at the SGP Central Facility.

\section{New Microwave Radiometer Makes Water Vapor Measurements in the Arid Cold a Snap}

Typical instruments for measuring water vapor struggle to obtain accurate moisture readings in highly arid conditions like the Arctic. Using a DOE Small Business Innovative Research grant, ACRF pursued the development of a microwave radiometer that could operate near $183 \mathrm{GHz}$-a rate as much as 100 times more sensitive to water vapor than other ACRF microwave radiometers. In March, ACRF operations staff and developers from ProSensing deployed a prototype of the new $183 \mathrm{GHz}$ microwave radiometer at the ACRF NSA site in Barrow.

The new radiometer actually measures at $183.31 \mathrm{GHz} \pm 1, \pm 3, \pm 7$, and $\pm 14 \mathrm{GHz}$. The $183.31 \pm 1 \mathrm{GHz}$ channel is useful when conditions are very cold and very dry, but as the Arctic winter gives way to spring and then summer, the amount of water vapor increases and the $\pm 1 \mathrm{GHz}$ channel saturates (i.e., the signal no longer increases as the water vapor amount increases). The \pm 3 and $\pm 7 \mathrm{GHz}$ channels allow the radiometer to still provide useful water vapor data while the $\pm 14 \mathrm{GHz}$ channel permits the amount of liquid water in the thin Arctic clouds to be accurately determined. Although similar microwave radiometers have been demonstrated in Barrow for short periods, this prototype will operate through the 2005-2006 winter. This long-term deployment will permit refinements to the design based on actual Arctic conditions and will allow ARM scientists to have access to accurate water vapor measurements over an entire annual cycle.

\section{Infrared Thermometers Complete Cloud Pictures}

Six new infrared thermometers (IRTs) were installed at Extended Facilities throughout the SGP locale this year, to help ARM scientists analyze cloud temperatures and infer cloud heights over the SGP site. Having the additional IRT retrieval points for comparison and testing will allow the ARM science team to refine the retrievals by cloud situation and to test and compare them with satellite data. While satellite data affords good spatial coverage, it only provides a "snapshot" every half hour, and has known weaknesses, especially in inferring such quantities as low cloud base heights, low cloud amounts, and detection of few or smaller clouds. By using both the IRT and satellite data, ARM researchers can paint a more complete picture of the temporal and spatial resolution of the entire SGP domain.

New features for the IRT include a mirror surface hardened with a thin coating of silicone dioxide, and a prototype automatic mirror washing/drying system to keep the IRT mirror surfaces clean and free of dew or frost, thereby providing more accurate measurements of sky brightness temperature. In addition, a new

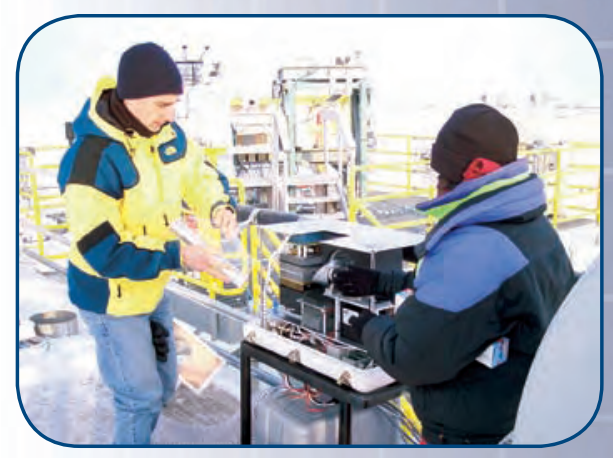

The $183 \mathrm{GHz}$ radiometer, protected inside an insulated enclosure (inset), is installed on the roof of the primary instrument shelter at Barrow. To prevent snow from accumulating on the mylar window, a blower mounted beneath the radiometer directs air through a duct to a standard Y-shaped fitting mounted on top of the radiometer.

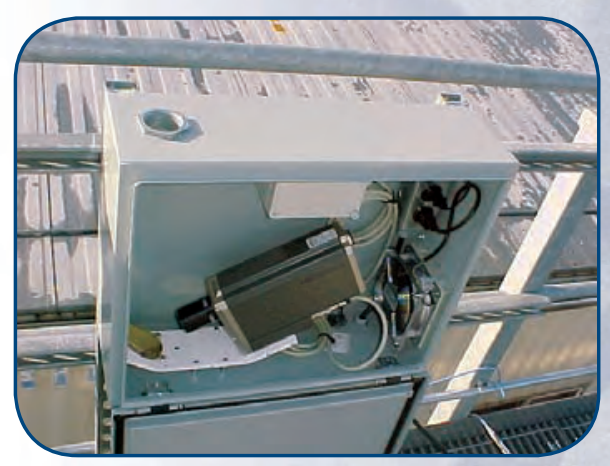

A filtered fan keeps moisture from building up on the mirror surface (bottom left) by circulating air up through the optical port (top left) of the IRT enclosure.

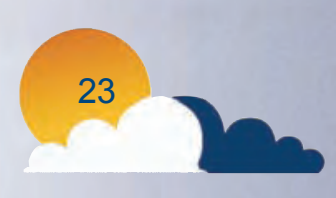




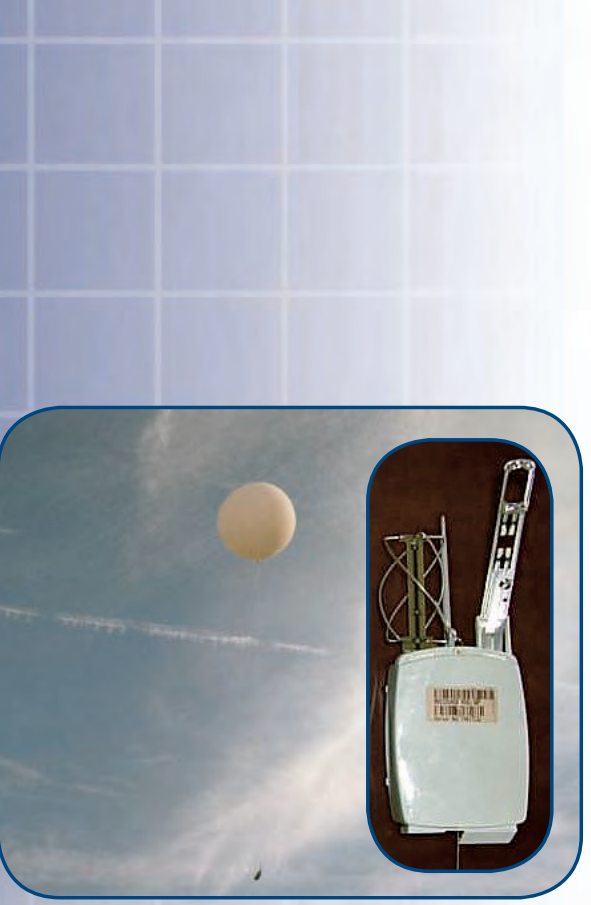

At the end of a string tied to the weather balloon, a small sensor package, called a radiosonde, contains the "brains" for measuring atmospheric temperature, pressure, and humidity.

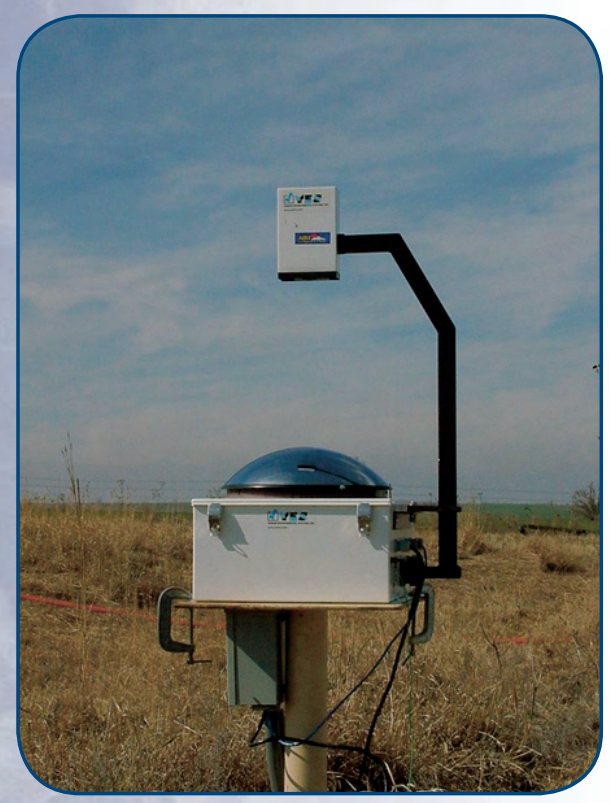

Data from the TSI measurements are presented as individual images and retrievals, including daily "movies" of sky conditions above the site. data acquisition and display system is capable of logging the IRT serial data at a minimum of $5 \mathrm{~Hz}$. This system was tested for compatibility with Linux computers like those at the SGP Extended Facilities, as well as with the Windows operating systems planned for installation at the TWP and NSA locales.

\section{Improved Radiosonde Sensor Ready for Launch}

The radiosonde system was one of the first instruments deployed by ACRF; the first launch was conducted in 1992, from the SGP site, using a then state-of-theart ground system known as the PC-CORA. Since then, ACRF pioneered the use of three subsequent generations of radiosonde ground systems, as technological advances led to the Digi-CORA I, II, and III models. Vaisala, one of the market leaders of this technology, began phasing out production of their RS90 radiosondes at the end of calendar year 2004 in favor of their new RS92 model. With the transition to the RS92 radiosondes, the PC-CORA was retired after nearly 13 years of continuous service, and ACRF operations personnel worked to upgrade the various firmware and hardware systems at the radiosonde ground stations for compatibility with the new sondes.

The new RS92 version has an improved global positioning system processor that will increase the accuracy of the wind speed and direction measurements made during the balloon flight. It also uses a new digital telemetry system to reduce the potential for data loss, and includes a system for restoring the temperature and humidity sensors to their factory-calibrated condition before flight to improve the measurement of these important variables. Launches with the new sondes began at the SGP site, followed by the AMF deployment in Point Reyes, California. Launches for the TWP and NSA locales will be phased in as they exhaust their stocks of RS90 sondes.

\section{New Total Sky Imager Improves Reliability Picture in Tropics}

Instruments that collect climate data at the TWP locale are continually subjected to adverse operating conditions that can impact their reliability. As part of an ongoing effort to add and upgrade instruments to meet these challenges, total sky imagers (TSI) were redesigned to improve their reliability at remote sites like those at the TWP. The TSI measures the horizontal distributions of clouds in its field of view, providing real-time processing and display in a visual record of daytime sky conditions. The instrument's software computes both the fractional cloud cover and sunshine duration, which are useful for interpreting other ARM measurements and important elements in understanding climate change. The TSI design modifications - including remote operating and troubleshooting capability, and streamlined internal electronics - will reduce the potential for system failure and resulting downtime, while also making it easier to maintain and repair.

The newly redesigned TSI was installed for the first time at the TWP Manus site in Papua New Guinea. The TSI at Manus provides additional measurement capability to the suite of instruments already at that site. With similar instruments installed this year at Darwin, Australia, and at Nauru Island, all the TWP sites now have the new TSIs. Completion of this effort greatly improves ACRF's routine data collection capabilities in the tropics. 


\section{Data Delivery}

\section{Data Quality Application Gives Data Browsers a New View}

ACRF's Data Quality Office developed a web application to quickly and easily view diagnostic data quality plots, without making multiple selections to see just one plot. The new Plot Browser-a part of the Data Quality Health and Status (DQ HandS) application - helps data quality analysts, instrument mentors, and site scientists view all the daily plots (around 1000 per day) from the ACRF sites by producing custom, highly-browsable lists or thumbnail images of data streams suitable for monitoring data quality.

By using DQ HandS and the Plot Browser to perform visual data quality inspections, the Data Quality Office inspects and assesses ARM data on a near-real-time basis (daily to weekly) and submits requests to initiate troubleshooting and/or corrective maintenance activities, based on guidelines provided by the instrument mentors. If a problem is identified, mentors, site operators, and site scientists are notified to start the problem resolution process and/or continue to investigate. This level of vigilance helps the ACRF deliver a data stream of reasonable quality to the scientific community.

\section{History Tool Records Changes to Data Streams}

Each day, the Data Management Facility (DMF) processes approximately 1875 data streams from 287 instrument systems and delivers them to the Data Archive. Occasionally, modifications are needed to update or correct a data stream structure. Information about the history of changes made to a data stream can be a critical issue for ACRF data users. Historically, the metadata within the data object design (DOD) files were revised and overwritten whenever a change occurred, with no record of the change saved for reference. (The DOD manages ARM netCDF, or network Common Data Form, file structure - the standard file format for ACRF measurement collection for each ARM data stream.) Recognizing this dilemma, the DMF created a tool to record the history of every data stream for every instrument from every ACRF site since the beginning of the ARM Program.

In March, the History of Data Stream tool began providing information on changes to the metadata, and when the changes occurred — a historical record — for all the data streams available at the DMF. Once a week, the tool scans the current DOD files, identifies any changes, and adds a link to "history" in the netCDF File Header Description web page by selecting the instrument or value-added product's DOD. Plans are in place to use the tool at the Data Archive and XDC to help build a historical record of data stream changes since the sites first began collecting data, and to maintain a history of data stream changes in the future.

\section{Radiosonde Data Distribution in Place for Modeling During M-PACE}

To support the M-PACE in October 2004 at the NSA locale, radiosonde systems were deployed at Atqasuk, Toolik Lake, and Oliktok Point. The ability to transmit radiosonde data—as well as routine data from the NSA site in Barrow-to the Global Telecommunications System (GTS) with minimal delay after completion of

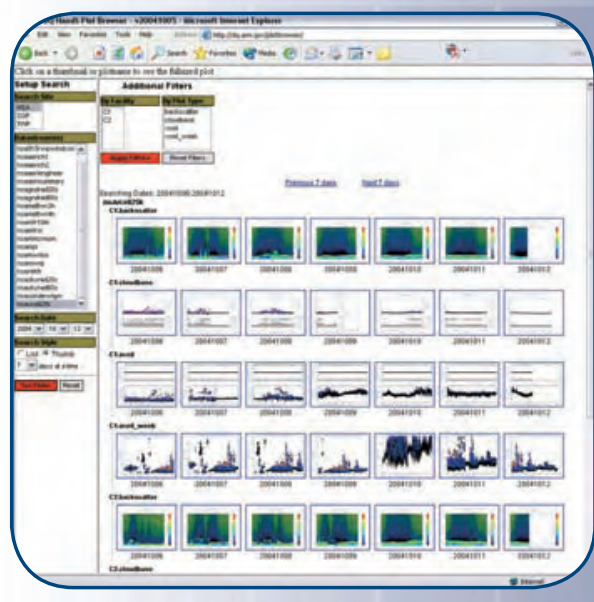

ARM data are inspected daily to weekly using the "Plot Browser," which supplies data plots by providing lists or thumbnail images of selected data streams. 


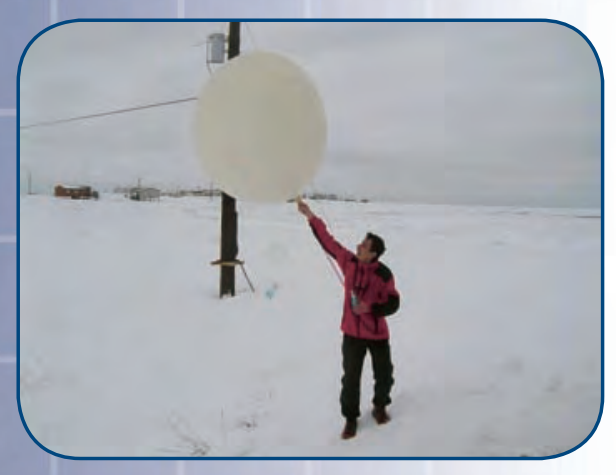

During several 5-day launch periods throughout the field campaign, M-PACE researchers released four radiosondes per day from all four experimental sites (Barrow, Oliktok Point, Atqasuk and Tulik Lake).

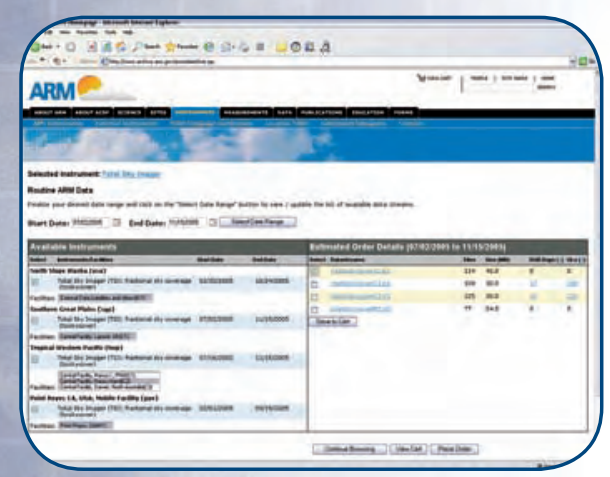

The ARM website was upgraded with a new capability in September; ARM data users now have the ability to order data using the data cart. the sounding was critical to the success of the experiment. Early in October, ACRF data coordination staff completed the necessary revisions to the radiosonde data collection software to enable distribution to GTS via a server-or gateway-sponsored by the NOAA. This allowed the data to be used in near-real-time in forecasting models used during the experiment.

GTS is the World Meteorological Organization integrated network of point-topoint circuits and multi-point circuits, which interconnect meteorological telecommunication centers. Its purpose is to enable an efficient exchange of meteorological data and products in a timely and reliable way to meet the needs of world, regional, and national meteorological centers. The European Centre for Medium-Range Weather Forecasting_-reknown for its forecasting models—acquires the data from the GTS and integrates it into some of their modeling products. Researchers involved in M-PACE used these modeling products to plan aircraft operations for cloud and atmospheric sampling during the campaign. Based upon this success, plans to distribute radiosonde data from the TWP Manus and Nauru sites through the NOAA gateway have been made.

\section{Website Integration Effort Delivers One-Stop Shopping for Data}

A new way to browse and order ARM data from the ARM website was published following 9 months of careful development. ACRF infrastructure staff across the United States teamed together to integrate the ARM web pages with the Data Archive, creating the ability to order data while also learning about it. By adding a data "shopping" cart, users can now browse instruments, measurements, and data pages to find data streams to place in the cart. After all the desired data streams are in the cart, the Data Archive processes the order and delivers the data to an ftp site for pickup. The cart was designed to be intuitive and easy to use, especially for new users. In addition, the Data Archive website was updated to match the ARM website design and navigation, providing a smoother visual transition for users.

A number of other data-related website renovations were also completed. Web page content was augmented to include the XDC and field campaign instruments and data streams in the instruments, measurements, and data pages. The field campaign web area improved its design and navigation for past campaigns, including moving all information from 1992-2001 campaigns into the background database, and adding links for ordering available data. As a result, ordering data from the Data Archive is now easier and more seamless from the ARM website.

\section{Communication, Education, and Outreach}

\section{ACRF Communications Products Receive High Honors}

Several ACRF communications products were recognized for excellence this year in two communication award competitions: the 2005 Communicator Awards print-media competition and the Seventeenth Annual Awards for Publication Excellence (APEX) competition. The 2004 ACRF Annual Report received high honors in both competitions. The annual report received the prestigious Crystal 
Award of Excellence from the Communicator Awards, which is awarded to those entrants "whose ability to communicate places them among the best in the field." The annual report also received the Award of Excellence in the "Writing" category in the APEX competition. Out of 267 annual reports evaluated, only 9 Awards of Excellence were given in this category.

The ARM website, featuring its extensive homepage redesign, was also recognized in both competitions. From the Communicator Awards, the website received the Award of Distinction, which was awarded to approximately $19 \%$ of entrants. The Award of Distinction is given for work that "exceeds industry standards in communicating a message or idea." In addition, the ARM website won an award under the category of "Most Improved Web and Intranet Sites" in the APEX competition. The ARM website was evaluated against 565 websites in 10 categories. Two additional ACRF communications products received Awards of Distinction from the Communicator Awards: the ACRF student activity book, Climate, Coloring, Crosswords... and Other Fun Stuff!, and the online, bimonthly newsletter, the ACRF Operations Update.

\section{ARM Climate Research Facility Increases Outreach Efforts}

As part of its effort to increase outreach and visibility, the ACRF exhibited for the first time at two conferences this year. The added exposure allowed ACRF staff to promote the ACRF as a world-class national user facility to new audiences and potential users. In December 2004, ACRF exhibited at the American Geophysical Union's fall meeting in San Francisco, California. More than 10,000 geophysicists attended the meeting. Because the emphasis of the meeting was geophysical rather than weather related, explaining the Program's mission and goals to attendees represented a challenge. However, several inquiries about how other research could be conducted at the ACRF sites resulted from the meeting.

ACRF also exhibited for the first time at the 98th Annual Air \& Waste Management Association Conference in Minneapolis, Minnesota, in June 2005. Approximately 2500 environmental professionals attended the conference. Representatives from such countries as Jamaica, Taiwan, Mexico, Canada, Australia, New Zealand, Korea, Russia, and Japan asked questions about the ACRF and the upcoming AMF deployment in Africa in 2006. Dr. Sylvia Edgerton, ACRF Science Liaison, also gave an overview presentation in the exhibit hall describing ACRF.

\section{Web Improvements Ease Searching}

To improve usability and quality, the ARM Image Library was significantly redesigned this year. Approximately 200 new, high-resolution images with detailed captions were added to the library, and all photos were reviewed for resolution (dots per inch, or dpi). This information is now displayed along with the image to allow users to identify high-quality images for large posters and presentations. In addition, the Image Library's new search capabilities eliminate the need for scrolling through images; users can now search by resolution or keyword, or by using newly structured navigation categories.

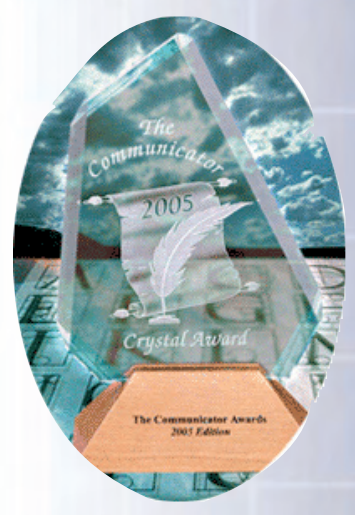

Of approximately 5,000 international entries, only $13 \%$ receive the Crystal Award of Excellence. 


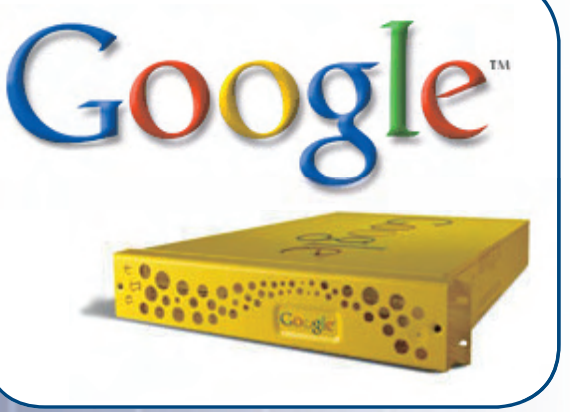

Users now have the power of Google at their disposal to search www.arm.gov.
In another much-anticipated upgrade, the ARM website search engine was replaced by the industry leader, Google. The new search engine has greatly improved the efficiency and accuracy of ARM website search results. Google was chosen because it is easy to use, indexes PDFs, and can index multiple servers. Because of this capability, users can now see results from all the arm.gov servers, including the Data Archive and the XDC. Furthermore, specialized subject area collections were created to allow users to search a specified area of the website, including education, news, data quality reports, or field campaigns.

\begin{tabular}{|c|c|c|c|}
\hline Dates & Name & Status & Description \\
\hline \multicolumn{4}{|r|}{ North Slope of Alaska } \\
\hline September - October 2004 & $\begin{array}{l}\text { Mixed-Phase Arctic Cloud } \\
\text { Experiment (M-PACE) }\end{array}$ & Completed & $\begin{array}{l}\text { The purpose of the M-PACE was to understand the dynamics of mixed-phase arctic clouds. } \\
\text { The main objectives of M-PACE were to (a) understand the microphysical processes and radia- } \\
\text { tive transfer, (b) develop retrieval algorithms to provide critical measurements, and (c) provide } \\
\text { the physical understanding necessary to parameterize mixed-phase arctic cloud processes. M- } \\
\text { PACE took place at four sites, which included the NSA sites at Barrow and Atqasuk, and sites } \\
\text { at Oliktok Point and Toolik Lake. }\end{array}$ \\
\hline September - October 2004 & M-PACE - Sassen Lidar & Completed & $\begin{array}{l}\text { As part of the M-PACE field campaign, a polarization diversity lidar system, provided through } \\
\text { the University of Alaska Fairbanks, was used to capture arctic cirrus cloud properties at two } \\
\text { laser wavelengths }(1.06 \text { and } 0.532 \mu \mathrm{m}) \text {. }\end{array}$ \\
\hline September - October 2004 & $\begin{array}{l}\text { M-PACE - High Spectral } \\
\text { Resolution Lidar (HSRL) }\end{array}$ & Completed & $\begin{array}{l}\text { To measure calibrated optical depth and backscatter during M-PACE, an HSRL was provided } \\
\text { through the University of Wisconsin. It was used to obtain vertical and calibrated profiles, } \\
\text { backscatter cross sections, and depolarization at a 532-nm wavelength. }\end{array}$ \\
\hline September - October 2004 & Spectral Water Phase & Completed & $\begin{array}{l}\text { The goal of this experiment was to better understand the radiative properties of clouds and } \\
\text { infer liquid and ice paths. Spectral measurements of scattered sunlight at visible and near-infra- } \\
\text { red wavelengths were used to remotely estimate liquid and ice amounts in clouds. Techniques } \\
\text { and liquid and ice-retrieval measurements were compared to those taken with the ARM micro- } \\
\text { wave radiometer and AERI during M-PACE. These comparisons will increase the understanding } \\
\text { of the radiative properties of clouds. }\end{array}$ \\
\hline $\begin{array}{l}\text { January } 2005 \text { - January } \\
2006\end{array}$ & $\begin{array}{l}\text { High-Latitude Optical Tur- } \\
\text { bulence Characterization }\end{array}$ & In Progress & $\begin{array}{l}\text { The goals of this effort are to improve the NOAA Air Resources Laboratory Surface Layer Sta- } \\
\text { bility Transition Forecast Model and characterize the near-surface atmospheric optical turbu- } \\
\text { lence over a flat, dry, high-latitude location. A scintillometer will measure solar effects through } \\
\text { radiation sensors to help determine any latitudinal dependencies in the model. The results will } \\
\text { be used to compare a low-humidity, high-latitude site to a low-humidity, mid-latitude site. }\end{array}$ \\
\hline April - September 2005 & $\begin{array}{l}\text { Atmospheric Infrared } \\
\text { Sounder Validation } \\
\text { Soundings, Phase IV } \\
\text { (Also at TWP and SGP) }\end{array}$ & $\begin{array}{l}\text { Completed; } \\
\text { awaiting data }\end{array}$ & $\begin{array}{l}\text { The aim of this ongoing experiment is to (a) provide in situ validation data for the develop- } \\
\text { ment and testing of water vapor retrievals obtained from the Atmospheric Infrared Sounder } \\
\text { (AIRS) sensor aboard NASA's Aqua satellite and (b) demonstrate and quantify the accuracy of } \\
\text { water vapor retrieval algorithms. Because global water vapor distributions are important in the } \\
\text { study of climate, passes from the AIRS instrument will be timed to coincide with additional } \\
\text { radiosonde launches from TWP sites. This is a user support activity with funding provided by } \\
\text { the user. }\end{array}$ \\
\hline February - May 2005 & $\begin{array}{l}\text { Studies of the Northern } \\
\text { Alaskan Coastal System }\end{array}$ & Completed & $\begin{array}{l}\text { The objective of this NSF-funded experiment was to understand how halogen oxide concen- } \\
\text { trations change in the atmosphere and affect changes in ozone and mercury deposition. Dif- } \\
\text { ferential optical absorption spectroscopy was used at the Atqasuk site to measure atmospheric } \\
\text { concentrations of the reactive halogen gas, bromine monoxide. Data obtained through this } \\
\text { experiment will be correlated with meteorological information from the ARM Data Archive } \\
\text { and will be compared to a similar instrument installed in Barrow (at NSF/BASC facilities). }\end{array}$ \\
\hline July - August 2005 & Boundary Layer Cloud IOP & $\begin{array}{l}\text { Completed; } \\
\text { awaiting data }\end{array}$ & $\begin{array}{l}\text { To test summertime arctic cloud climate models, rawinsondes will be launched every } 4 \text { hours } \\
\text { at the Barrow and Atqasuk sites during this field campaign. Measurements will be taken to } \\
\text { determine how the surface of the arctic land (a) changes the way low clouds absorb, reflect, and } \\
\text { transmit solar and infrared radiation, and (b) controls the liquid water, droplet size, and physi- } \\
\text { cal dimensions of arctic clouds. This experiment will ultimately improve the understanding of } \\
\text { the physical processes between clouds and the ground, and how that relationship influences } \\
\text { climate change. }\end{array}$ \\
\hline
\end{tabular}




\begin{tabular}{|c|c|c|c|}
\hline \multicolumn{4}{|r|}{ Southern Great Plains } \\
\hline $\begin{array}{l}\text { September - December } \\
2004\end{array}$ & $\begin{array}{l}\text { Precision Gas Sampling } \\
\text { (PGS) Validation }\end{array}$ & Completed & $\begin{array}{l}\text { The purpose of the ongoing PGS validation study is to study the carbon cycle by measuring } \\
\text { the carbon dioxide, water, and energy fluxes near the SGP Central Facility near Lamont, Okla- } \\
\text { homa. Information obtained from this study will help quantify the } \mathrm{CO}_{2} \text { exchange between } \\
\text { the atmosphere and two previously unobserved crop types (pasture and sorghum) during the } \\
\text { dormant season. }\end{array}$ \\
\hline October 2004 & Surface Albedo IOP & $\begin{array}{l}\text { Completed; } \\
\text { awaiting data }\end{array}$ & $\begin{array}{l}\text { The purpose of this field campaign was to (a) collect surface albedo spectra for representative } \\
\text { surface types in the SGP site area, (b) gather information useful for conducting surface type } \\
\text { classification from aerial/satellite remote sensing data, and (c) develop the detailed spectral } \\
\text { model of surface reflectance over the SGP site for fall conditions. This information is required } \\
\text { as boundary conditions for radiative transfer modeling, cloud and atmospheric dynamics } \\
\text { modeling, and remote sensing, carbon, and hydrological studies. }\end{array}$ \\
\hline $\begin{array}{l}\text { March } 2005 \text { - February } \\
2006\end{array}$ & PGS Validatation & In Progress & $\begin{array}{l}\text { In an extension of the earlier study on crop systems, this field campaign will investigate the } \\
\text { effects of burning on the cycles of carbon, water, and energy in an example of grazed land at } \\
\text { the SGP site. Because the exchange of carbon, water, and energy varies with climate, soil, and } \\
\text { land management, measurements of different land-cover types and management treatments are } \\
\text { necessary to calibrate and test model predictions. }\end{array}$ \\
\hline $\begin{array}{l}\text { Summer } 2005 \text { - December } \\
2008\end{array}$ & Aircraft Carbon & In Progress & $\begin{array}{l}\text { The goals of this field campaign are to acquire the ability to measure } \mathrm{CO}_{2} \text { concentrations and } \\
\text { sample for a suite of trace gases, such as } \mathrm{CO}, \mathrm{CH}_{4},{ }^{13} \mathrm{CO}_{2} \text {, and }{ }^{14} \mathrm{CO}_{2} \text {, from the surface to mid- } \\
\text { troposphere. Airborne measurements of trace gases will (a) provide valuable data for addressing } \\
\text { carbon cycle questions that have been identified by the U.S. Climate Change Research } \\
\text { Program and the North American Carbon Program, (b) facilitate the calibration of the NASA } \\
\text { Orbiting Carbon Observatory, and (c) provide a basis from which to develop inverse methods } \\
\text { to infer ecosystem carbon exchange and quantify anthropogenic combustion emissions. }\end{array}$ \\
\hline June 2005 & $\begin{array}{l}\text { ARM Atmospheric Com- } \\
\text { pensation }\end{array}$ & Completed & $\begin{array}{l}\text { For this study, five panels were deployed to gather data for atmospheric compensation studies } \\
\text { of hyperspectral images. Overflight data collected from DC } 3 \text { aircraft with hyperspectral sensors } \\
\text { will be used to characterize the atmosphere and compensate related imagery. }\end{array}$ \\
\hline September 2005 & $\begin{array}{l}\text { Aerosol Lidar Validation } \\
\text { Experiment (ALIVE) }\end{array}$ & $\begin{array}{l}\text { Completed; } \\
\text { awaiting data }\end{array}$ & $\begin{array}{l}\text { In this field campaign the NASA Ames airborne tracking } 14 \text {-channel sun photometer (AATS- } \\
\text { 14) was used to validate aerosol extinction profiles obtained from the Raman and micropulse } \\
\text { lidar at SGP. The AATS-14 was flown aboard the Jetstream- } 31 \text { aircraft to obtain the extinction } \\
\text { vertical profiles and further validate the integrity of the historical Raman lidar aerosol extinc- } \\
\text { tion record. These measurements will also help evaluate the (In Situ Aerosol Profiling) IAP } \\
\text { measurements after the IAP instruments are moved to a new aircraft. }\end{array}$ \\
\hline \multicolumn{4}{|r|}{ Tropical Western Pacific } \\
\hline $\begin{array}{l}\text { December } 2004 \text { - Febru- } \\
\text { ary } 2006\end{array}$ & $\begin{array}{l}\text { Darwin Lightning Detec- } \\
\text { tion }\end{array}$ & In Progress & $\begin{array}{l}\text { The objective of this IOP is to characterize convection produced from lightning by using } \\
\text { a VHF broadband digital interferometer (VHF BDITF) at the TWP Darwin site. Because } \\
\text { electrical storms are common in the Darwin area and lightning is a useful indicator of convec- } \\
\text { tive strength, the instrument would (a) monitor the evolution and activity of a thunderstorm } \\
\text { system, (b) add to the convective characterization component of lightning, and (c) comple- } \\
\text { ment the existing scanning centimeter radars. The VHF BDITF will enable the characteriza- } \\
\text { tion of the lightning at a high resolution ( } 1 \text { microsecond) and will provide a new convective } \\
\text { characteristic component that will complement existing measurements. }\end{array}$ \\
\hline May - November 2005 & Darwin Aerosol IOP II & In Progress & $\begin{array}{l}\text { A CIMEL sun/sky radiometer deployed over the } 2005 \text { dry season will allow further inter- } \\
\text { comparisons and validation of aerosol optical depths obtained from the multi-filter rotating } \\
\text { shadowband radiometer operating at the Darwin site. Sky radiance retrievals will also be used } \\
\text { to infer the microphysical aerosol properties needed to evaluate aerosol radiative forcing. }\end{array}$ \\
\hline $\begin{array}{l}\text { September } 2005 \text { - Febru- } \\
\text { ary } 2006\end{array}$ & $\begin{array}{l}\text { Orbiting Carbon Observa- } \\
\text { tory-Fourier Transform } \\
\text { Spectrometer (FTS) } \\
\text { Validation }\end{array}$ & In Progress & $\begin{array}{l}\text { This field campaign involves deployment of a solar-viewing Bruker } 125 \mathrm{HR} \text { FTS at the Dar- } \\
\text { win site to (a) validate space-based column } \mathrm{CO}_{2} \text { retrievals, (b) validate space-based measure- } \\
\text { ments using a combination of in situ and remote sensing techniques, and (c) use a ground- } \\
\text { based, solar-viewing, high-resolution FTS to retrieve atmospheric } \mathrm{O}_{2}, \mathrm{CO}_{2}, \mathrm{CH}_{4}, \mathrm{CO}, \mathrm{HF} \text {, and } \\
\mathrm{H}_{2} \mathrm{O} \text { measurements. The data from this field campaigns will yield better surface-pressure maps } \\
\text { and aerosol climatologies, and aid in the validation of a high-profile NASA satellite mission. }\end{array}$ \\
\hline \multicolumn{4}{|r|}{ ARM Mobile Facility } \\
\hline March - September 2005 & $\begin{array}{l}\text { Marine Stratus Radiation } \\
\text { Aerosol and Drizzle (MAS- } \\
\text { RAD) IOP }\end{array}$ & $\begin{array}{l}\text { Completed; } \\
\text { awaiting data }\end{array}$ & $\begin{array}{l}\text { The AMF was deployed at Point Reyes National Seashore in California, to study the micro- } \\
\text { physical and radiative characteristics of marine stratus clouds, one of the most prevalent cloud } \\
\text { types on the planet. Because marine stratus clouds are known to be susceptible to infusions } \\
\text { of anthropogenic (human-produced) aerosols, the focus of this campaign was to investigate } \\
\text { (a) the general relationships between cloud mesoscale structure, aerosols, cloud microphysics, } \\
\text { drizzle, and radiation, and (b) the specific effect of aerosols on the discrepancy between the } \\
\text { measured and modeled amount of solar radiation absorbed by these clouds. }\end{array}$ \\
\hline
\end{tabular}




\begin{tabular}{|c|c|c|c|}
\hline June - September 2005 & $\begin{array}{l}\text { Cloud Study from the } \\
\text { 2-Channel Narrow Field of } \\
\text { View (2-NFOV) Radiom- } \\
\text { eter at Point Reyes }\end{array}$ & $\begin{array}{l}\text { Completed; } \\
\text { awaiting data }\end{array}$ & $\begin{array}{l}\text { In conjunction with the MASRAD field campaign, a ground-based 2NFOV radiometer will } \\
\text { be used to validate an algorithm and capture local, rapid changes in 3D cloud structures at } \\
\text { a 1-second time resolution. The ability to retrieve cloud optical depth in fully 3D situations } \\
\text { will help cloud-radiation parameterizations and advance the understanding of cloud statistics } \\
\text { with high temporal resolution. Extensive comparisons will be made with larger data sets from } \\
2 \text { NFOV measurements at the SGP and Point Reyes sites. }\end{array}$ \\
\hline June - August 2005 & $\begin{array}{l}\text { MASRAD - Aerosol Optical } \\
\text { Properties }\end{array}$ & $\begin{array}{l}\text { Completed; } \\
\text { awaiting data }\end{array}$ & $\begin{array}{l}\text { In conjunction with the MASRAD field campaign, this field campaign will deploy a suite of } \\
\text { instruments, including a counter-flow virtual impactor (CVI), to measure the chemical, physi- } \\
\text { cal, and optical properties of cloud-free summertime aerosol. A number of different types of } \\
\text { models, covering processes ranging from radiative transfer to marine aerosol microphysics to } \\
\text { cloud droplet formation, will be used to interpret the measurements. Results from this study } \\
\text { will be relevant to improving the parameterization of aerosol forcing (direct and indirect effect) } \\
\text { in climate models. }\end{array}$ \\
\hline June - August 2005 & $\begin{array}{l}\text { MASRAD: Sub-Micron } \\
\text { Aerosol Measurements }\end{array}$ & $\begin{array}{l}\text { Completed; } \\
\text { awaiting data }\end{array}$ & $\begin{array}{l}\text { In conjunction with the MASRAD field campaign, the objective of this field campaign is to } \\
\text { carry out submicron aerosol (10-500-nm) size distribution measurement. A suite of instru- } \\
\text { ments, which includes a counter-flow virtual impactor (CVI), will be deployed to Point Reyes, } \\
\text { one of the foggiest places, to continuously sample cloud-free summertime aerosol. A number } \\
\text { of different types of models, covering processes ranging from radiative transfer to marine } \\
\text { aerosol microphysics to cloud droplet formation, will be used to interpret the measurements. } \\
\text { Results from this study will be relevant to improving the parameterization of aerosol forcing } \\
\text { (direct and indirect effect) in climate models. }\end{array}$ \\
\hline June - July 2005 & $\begin{array}{l}\text { MASRAD: Marine Aerosol } \\
\text { Properties }\end{array}$ & $\begin{array}{l}\text { Completed; } \\
\text { awaiting data }\end{array}$ & $\begin{array}{l}\text { The purpose of this experiment is to measure the aerosol optical, physical, and chemical } \\
\text { properties during cloud-free conditions at a marine site. A suite of instruments, which includes } \\
\text { a CVI, will be deployed to the Point Reyes site, one of the foggiest places, to continuously } \\
\text { sample cloud-free summertime aerosol. A number of different models, covering processes rang- } \\
\text { ing from radiative transfer to marine aerosol microphysics to cloud droplet formation, will be } \\
\text { used to interpret the measurements. Results from this study will be relevant to improving the } \\
\text { parameterization of aerosol forcing (direct and indirect effect) in climate models. }\end{array}$ \\
\hline July 2005 & $\begin{array}{l}\text { MASRAD: Cloud Con- } \\
\text { densation Nuclei (CCN) } \\
\text { Chemistry Measurements }\end{array}$ & $\begin{array}{l}\text { Completed; } \\
\text { awaiting data }\end{array}$ & $\begin{array}{l}\text { The objective of this campaign is to measure the chemical compositional differences between } \\
\text { interstitial particles and cloud droplet kernels of fog or stratus by (a) measuring the fraction of } \\
\text { cloud droplet kernels that are CCN-active over a range of super-saturations, and (b) obtaining } \\
\text { data on composition and single particles to determine elemental composition and morphology. } \\
\text { The information on aerosol chemical characterization and its relationship to CCN activity } \\
\text { could be used to develop better parameterizations for cloud modeling. }\end{array}$ \\
\hline July 2005 & $\begin{array}{l}\text { Pt. Reyes Stratus Cloud and } \\
\text { Drizzle Study }\end{array}$ & $\begin{array}{l}\text { Completed; } \\
\text { awaiting data }\end{array}$ & $\begin{array}{l}\text { The goals of this study are to (a) compare a newly installed micropulse lidar with the ARM } \\
\text { micropulse lidar, (b) determine the effectiveness of the micropulse lidar in detecting aerosol } \\
\text { movement below and into stratus clouds, and (c) use a radar wind profiler and sodar to con- } \\
\text { tinuously measure wind profiles and mixed layer height and development. Wind profiles will } \\
\text { be measured in situ with aircraft to aid in determining the modifications of aerosols by cloud } \\
\text { processes. The sodar and profiler will provide continuous knowledge of the processes affecting } \\
\text { cloud development. }\end{array}$ \\
\hline \multicolumn{4}{|r|}{ Off-Site Campaigns } \\
\hline February - October 2005 & Loan of Filters & Completed & $\begin{array}{l}\text { In this campaign, Service d'Aeronomie of Paris, France, conducted a series of tests on a Raman } \\
\text { lidar system to develop a mobile Raman lidar for the remote sensing of water vapor in the } \\
\text { troposphere during the daytime. Water vapor measurements of cumulus cloud formations and } \\
\text { aerosol-water vapor interactions were made at the French experimental site for atmospheric } \\
\text { research. These measurements provide reference humidity observations for the validation of } \\
\text { various ground-based and spaceborne remote sensing techniques. }\end{array}$ \\
\hline April - June 2005 & $\begin{array}{l}\text { Rain Microphysics Study } \\
\text { with Disdrometer and } \\
\text { Polarization Radar }\end{array}$ & Completed & $\begin{array}{l}\text { The NCAR video disdrometer was installed at the Kessler farm near the Purcell Bound- } \\
\text { ary Facility at the SGP to (a) verify KOUN polarimeteric radar measurements, (b) develop } \\
\text { retrieval algorithms for raindrop size distribution, (c) study rain microphysics, and (d) derive } \\
\text { improved parameterization schemes for numerical weather prediction (NWP) models. Because } \\
\text { understanding rain microphysics is important for accurate rainfall rate estimation and for } \\
\text { improving parameterization in NWP models, these data will be utilized to improve rainfall } \\
\text { estimation, make numerical weather forecasts, and help in the understanding of microphysical } \\
\text { processes. }\end{array}$ \\
\hline \multicolumn{4}{|c|}{ Special Data Set Requests } \\
\hline Fall 2005 & $\begin{array}{l}\text { Study of Environmental } \\
\text { Arctic Change (SEARCH) } \\
\text { Data Archival }\end{array}$ & In Progress & $\begin{array}{l}\text { NOAA is deploying a climate-monitoring site in Eureka, Canada, as part of the SEARCH } \\
\text { Program in an effort to duplicate the Barrow site at the NSA in terms of instruments, data } \\
\text { streams, and data formats. Because data sets would be similar to those in the ARM and } \\
\text { SEARCH data sets, a combined archive would be used to create a comparison to facilitate } \\
\text { arctic research. }\end{array}$ \\
\hline
\end{tabular}




\section{FY 2005 Publications}

\section{Journal Articles}

Abdul-Razzak, H, and SJ Ghan. 2005. "Influence of slightly soluble organics on aerosol activation.” Journal of Geophysical Research 110, D06206, doi:10.1029/2004JD005324.

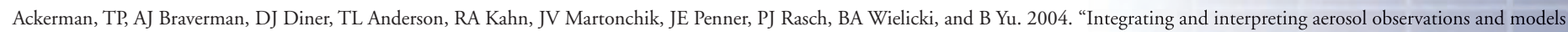
within the PARAGON framework.” Bulletin of the American Meteorological Society 85(10):1523-1533.

Alexandrov, MD, BE Carlson, AA Lacis, and B Cairns. 2005. “Separation of fine and coarse aerosol modes in MFRSR data sets.” Journal of Geophysical Research 110, D13204, doi:10.1029/ 2004JD005226.

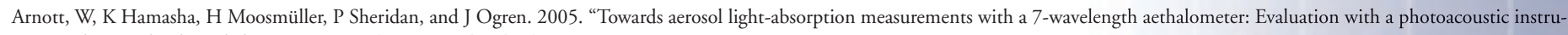
ment and 3-wavelenth nephelometer." Aerosol Science and Technology 39:17-29.

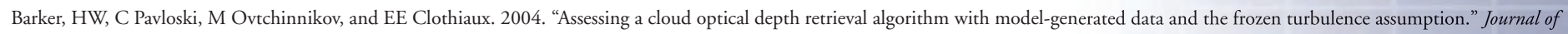
the Atmospheric Sciences 61:2951-2956.

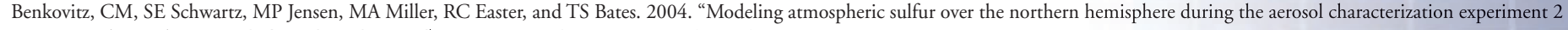
experimental period.” Journal of Geophysical Research 109, D22207, doi:10.1029/2004JD004939.

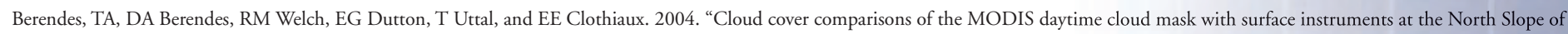
Alaska ARM site." IEEE Transactions on Geoscience and Remote Sensing 42:2584 2593.

Berg, LK, and R Stull. 2005. “A simple parameterization coupling the convective daytime boundary layer and fair-weather cumuli.” Journal of the Atmospheric Sciences 62:1976 1988.

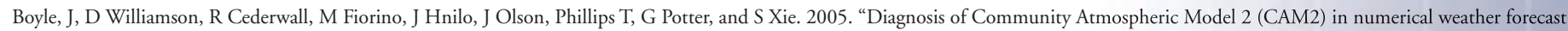
configuration at Atmospheric Radiation Measurement sites.” Journal of Geophysical Research 110, D15S15, doi:10.1029/2004JD005042.

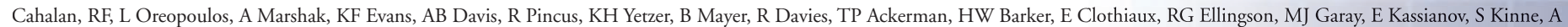

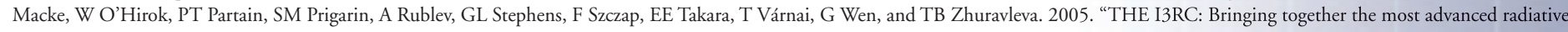
transfer tools for cloudy atmospheres." Bulletin of the American Meteorological Society 86:1275-1293.

Cheng, A. 2005. "Organization of mesoscale convective systems: 1. Numerical experiments.” Journal of Geophysical Research 110, D15S11, doi:10.1029/2004JD005444.

Cheng, A. 2005. "Organization of mesoscale convective systems: 2. Linear theory.” Journal of Geophysical Research 110, D15S12, doi:10.1029/2004JD005450.

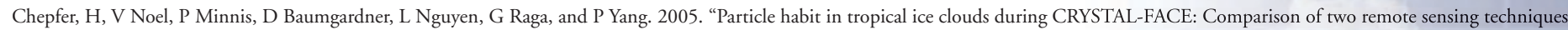
with in situ observations." Journal of Geophysical Research 110, D16204, doi:10.1029/2004JD005455.

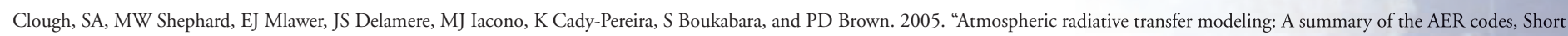
Communication.” Journal of Quantitative Spectroscopy Radiative Transfer 91:233 244.

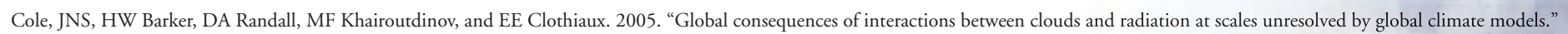
Geophysical Research Letters 32, L06703, doi:10.1029/2004GL020945.

Curry, JA, JM Maslanik, GJ Holland, and JO Pinto. 2004. “Applications of aerosondes in the Arctic.” Bulletin of the American Meteorological Society 85:1855-1861.

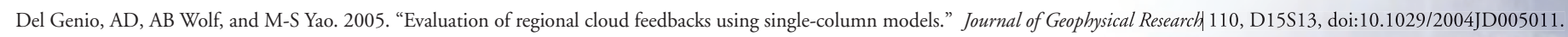

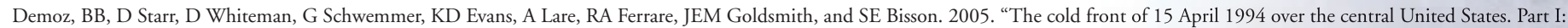
Observations." Monthly Weather Review 133:1525-1543.

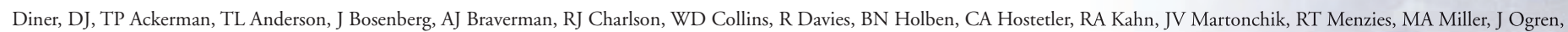

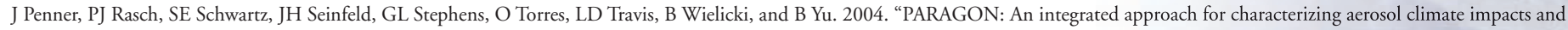
environmental interactions." Bulletin of the American Meteorological Society 85:1491-1501.

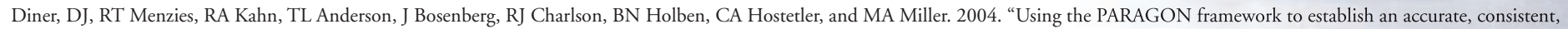
and cohesive long-term aerosol record." Bulletin of the American Meteorological Society 85:1535-1548.

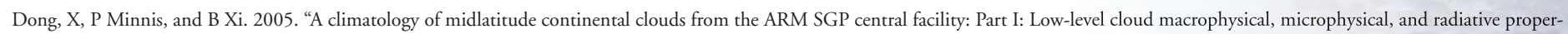
ties." Journal of Climate 18:1391-1410.

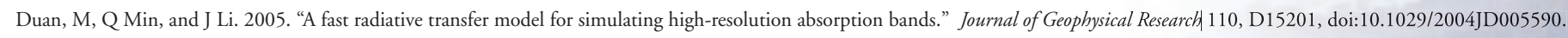

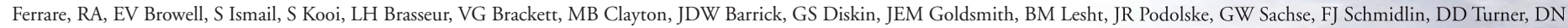

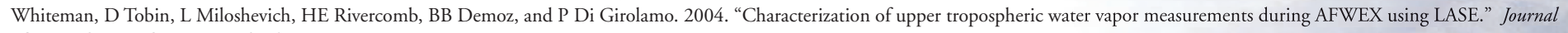
of Atmospheric and Oceanic Technology 21:1790-1808.

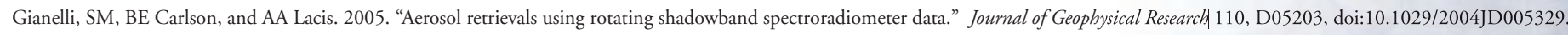

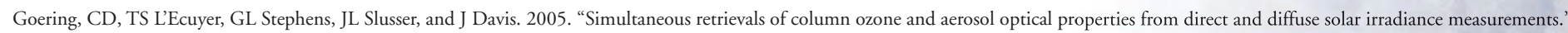
Journal of Geophysical Research 110, D05204, doi:10.1029/2004JD005330.

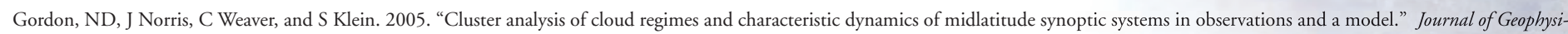
cal Research 110, D15S17, doi:10.1029/2004JD005027.

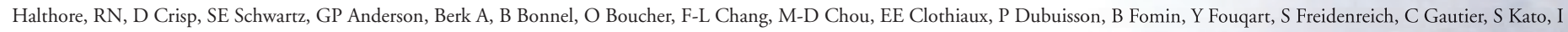

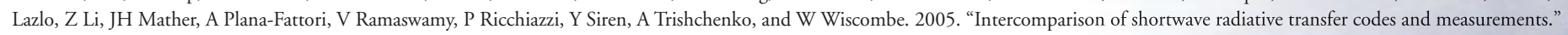
Journal of Geophysical Research 110, D11206, doi:10.1029/2004JD005293.

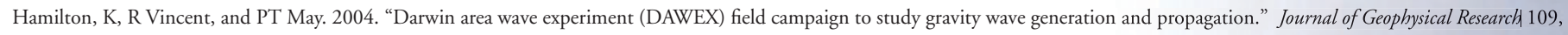
D20S01, doi:10.1029/2003JD004393. 
Hartmann, CM, and JY Harrington. 2005. "Radiative impacts on the growth of drops within simulated marine stratocumulus. Part I: Maximum solar heating." Journal of the Atmospheric Sciences 62:2323-2338

Hartman, CM, and JY Harrington. 2005. "Radiative impacts on the growth of drops within simulated marine stratocumulus. Part II: Solar zenith angle variations." Journal of the Atmospheric Sciences 62:2339-2351

Hinkelman, L, B Stevens, and K Franklin. 2005. "A large-eddy simulation study of anisotropy in fair-weather cumulus cloud fields." Journal of the Atmospheric Sciences 62:2155-2171.

Huang, J, P Minnis, B Lin, Y Yi, MH Khaiyer, RF Arduini, A Fan, and G Mace. 2005. "Advanced retrievals of multilayered cloud properties using multispectral measurements." Journal of Geophysical Research 110, D15S18, doi:10.1029/2004JD005101.

Hume, T, and C Jakob. 2005. “Ensemble single column modeling (ESCM) in the tropical western Pacific: Forcing data sets and uncertainty analysis.” Journal of Geophysical Research 110, D13109, doi:10.1029/2004JD005704.

Jakob, C, G Tselioudis, and T Hume. 2005. “The radiative, cloud, and thermodynamic properties of the major Tropical Western Pacific cloud regimes.” Journal of Climate 18:1203 1215.

Kahn, RA, JA Ogren, TP Ackerman, J Bosenberg, RJ Charlson, DJ Diner, BN Holben, RT Menzies, MA Miller, and JH Seinfeld. 2004. "Aerosol data sources and their roles within PARAGON." Bulletin of the American Meteorological Society 85:1511-1522.

Kassianov, E, TP Ackerman, and P Kollias. 2005. “The role of cloud-scale resolution on radiative properties of oceanic cumulus clouds." Journal of Quantitative Spectroscopy and Radiative Transfer 91:211-226.

Kassianov, EI, J Barnard, and TP Ackerman. 2005. "Retrieval of aerosol microphysical properties using surface multifilter rotating shadowband radiometer (MFRSR) data: Modeling and observations." Journal of Geophysical Research 110, D09201, doi:10.1029/2004JD005337.

Kassianov, EI, CN Long, and J Christy. 2005. “Cloud-base-height estimation from paired ground-based hemispherical observations.” Journal of Applied Meteorology 44:1221-1233.

Kassianov, E, CN Long, and M Ovtchinnikov. 2005. "Cloud sky cover versus cloud fraction: Whole-sky simulations and observations.” Journal of Applied Meteorology 44:86-98.

Khvorostyanov, VI, and JA Curry. 2004. "The theory of ice nucleation by heterogeneous freezing of deliquescent mixed CCN. Part I: Critical radius, energy, and nucleation rate." Journal of the Atmospheric Sciences 61:2676-2691.

Kiehl, JT, and PR Gent. 2004. “The community climate system model, Version 2.” Journal of Climate 17:3666-3682.

Knuteson, RO, FA Best, NC Ciganovich, RG Dedecker, TP Dirkx, S Ellington, WF Feltz, RK Garcia, RA Herbsleb, HB Howell, HE Revercomb, WL Smith, and JF Short. 2004. "Atmospheric emitted radiance interferometer (AERI): Part I: Instrument design." Journal of the Atmospheric Oceanic Technology 21:1763-1777.

Knuteson, RO, FA Best, NC Ciganovich, RO Dedecker, TP Dirkx, S Ellington, WF Feltz, RK Garcia, RA Herbsleb, HB Howell, HE Revercomb, WL Smith, and JF Short. 2004. “Atmospheric emitted radiance interferometer (AERI): Part II: Instrument performance." Journal of Atmospheric Oceanic Technology 21:1777-1789.

Knyazikhin, Y, RB Myneni, A Marshak, WJ Wiscombe, ML Larsen, and JV Martonchik. 2005. “Small-scale drop size variability: Impact on estimation of cloud optical properties.” Journal of the Atmospheric Sciences 62:2555-2567.

Kogan, ZN, DB Mechem, and YL Kogan. 2005. "Assessment of variability in continental low stratiform clouds based on observations of radar reflectivity." Journal of Geophysical Research 110, D18205, doi:10.1029/2005JD006158.

Kollias, P, EE Clothiaux, BA Albrecht, MA Miller, KP Moran, and KL Johnson. 2005. "The Atmospheric Radiation Measurement Program cloud profiling radars: An evaluation of signal processing and sampling strategies." Journal of Applied Meteorology (in press).

Kratz, DP, MG Mlynczak, CJ Mertins, H Brindley, LL Gordley, J Martin-Torres, FM Miskolczi, and DD Turner. 2004. "An inter-comparison of far-infrared line-by-line radiative transfer models." Journal of Quantitative Spectroscopic Radiative Transfer 90:323-341.

Leung, LR, and WI Gustafson Jr. 2005. "Potential regional climate change and implications to U.S. air quality.” Geophysical Research Letters 32, L16711, doi:10.1029/2005GL022911.

Li, J, and HW Barker. 2005. “A radiation algorithm with correlated-k distribution. Part I: Local thermal equilibrium." Journal of the Atmospheric Sciences 62:286-309.

Li, Z, MC Cribb, F-L Chang, AP Trishchenko, and Y Luo. 2005. "Natural variability and sampling errors in solar radiation measurements for model validation over the Atmospheric Radiation Measurement Southern Great Plains region.” Journal of Geophysical Research 110(D15):D15S19, doi:10.1029/2004JD005028.

Lin, WY, and MH Zhang. 2004. "Evaluation of clouds and their radiative effects simulated by the NCAR Community Atmospheric Model CAM2 against satellite observations." Journal of Climate $17: 3302-3318$

Liu, G. 2004. "Approximation of single scattering properties of ice and snow particles for high microwave frequencies." Journal of the Atmospheric Sciences 61:2441-2456.

Liu, X, J Penner, and M Herzog. 2005. "Global modeling of aerosol dynamics: Model description, evaluation, and interactions between sulfate and nonsulfate aerosols." Journal of Geophysical Research 110, D18206, doi:10.1029/2004JD005674

Liu, Y, P Daum, and RL McGraw. 2005. "Size truncation effect, threshold behavior, and a new type of autoconversion parameterization." Geophysical Research Letters 32, L11811, doi:10.1029/ 2005 GL022636.

Luo, Y, A Trishchenko, R Latifovic, and Z Li. 2005. "Surface bidirectional reflectance and albedo properties derived using a land cover-based approach with moderate resolution imaging spectroradiometer observations." Journal of Geophysical Research 110, D01106, doi:10.1029/2004JD004741.

Mace, GG, Y Zhang, S Platnick, MD King, P Minnis, and P Yang. 2005. "Evaluation of cirrus cloud properties derived from MODIS radiances using cloud properties derived from ground-based data collected at the ARM SGP site." Journal of Applied Meteorology 44:221-240.

Marchand, RT, and TP Ackerman. 2004. "Evaluation of radiometric measurements from the NASA multiangle imaging spectroradiometer (MISR): Two- and three-dimensional radiative transfer modeling of an inhomogeneous stratocumulus cloud deck." Journal of Geophysical Research 109, D18208, doi:10.1029/2004JD004710.

Marshak, A, Yu Knyazikhin, KD Evans, and WJ Wiscombe. 2004. “The 'RED versus NIR' plane to retrieve broken-cloud optical depth from ground-based measurements.” Journal of the Atmospheric Sciences 61:1911-1925.

Mather, JM. 2005. "Seasonal variability in clouds and radiation at the Manus ARM site." Journal of Climate 18:2417-2428.

Mattioli, V, ER Westwater, SI Gutman, and VR Morris. 2005. "Forward model studies of water vapor using scanning microwave radiometers, global positioning system, and radiosondes during the Cloudiness Intercomparison Experiment." IEEE Transactions on Geoscience and Remote Sensing 43:1012-1021. 
May, PT, and TD Keenan. 2005. "Evaluation of microphysical retrievals from polarimetric radar with wind profiler data." Journal of Applied Meteorology 44:827-838.

McFarlane, SA, and KF Evans. 2004. “Clouds and shortwave fluxes at Nauru. Part II: Shortwave flux closure.” Journal of the Atmospheric Sciences 61:2602-2615.

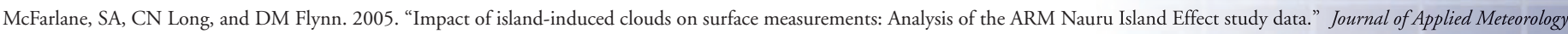
44:1045-1065.

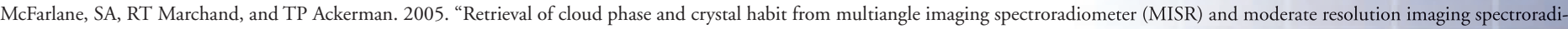
ometer (MODIS) data.” Journal of Geophysical Research 110, D14201, doi:10.1029/2004JD004831.

McFarquhar, GM, and SG Cober. 2004. "Single-scattering properties of mixed-phase arctic clouds at solar wavelengths: Impacts on radiative transfer." Journal of Climate 17:3799-3813.

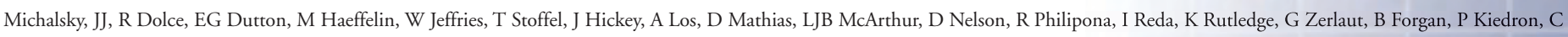

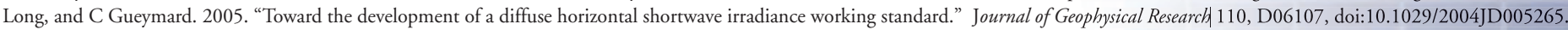

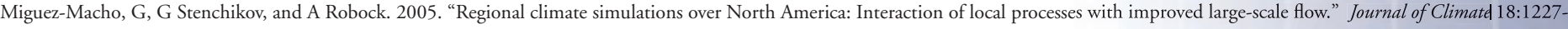
1246 .

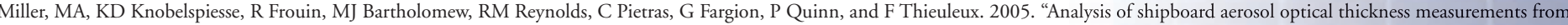
multiple sun photometers aboard the R/V Ronald H. Brown during ACE-Asia.” Journal of Applied Optics (accepted).

Min, Q. 2005. “Impacts of aerosols and clouds on forest-atmosphere carbon exchange.” Journal of Geophysical Research 110, D06203, doi:10.1029/2004JD004858.

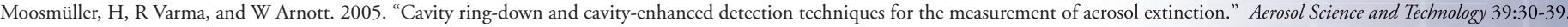

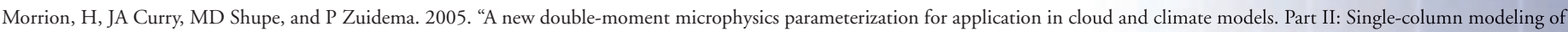
arctic clouds." Journal of the Atmospheric Sciences 62:1678-1693.

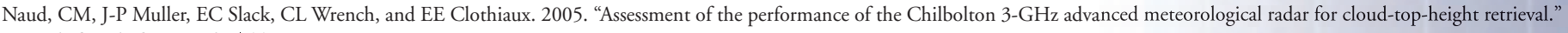
Journal of Applied Meteorology 44:876-887.

Noel, V, and K Sassen. 2005. "Study of planar ice crystal orientations in ice clouds from scanning polarization lidar observations." Journal of Applied Meteorology 44:653-664.

Nousiainen, T, and GM McFarquhar. 2004. "Light scattering by quasi-spherical ice crystals.” Journal of the Atmospheric Sciences 61:2229-2248.

Ovtchinnikov, M, and SJ Ghan. 2005. "Parallel simulations of aerosol influence on clouds using cloud-resolving and single-column models.” Journal of Geophysical Research 110(D15):D15S10.

Pavolonis, MJ, AK Heidinger, and T Uttal. 2005. "Daytime global cloud typing from AVHRR and VIIRS: Algorithm description, validation, and comparisons." Journal of Applied Meteorology 44:804-826.

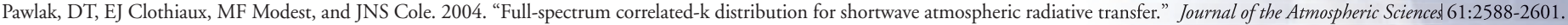

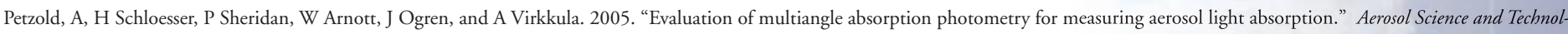
ogy 39:40-51.

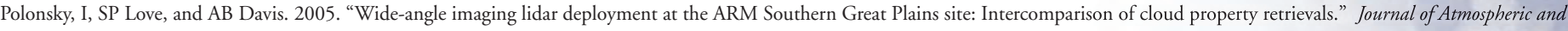
Oceanic Technology 22:628-648.

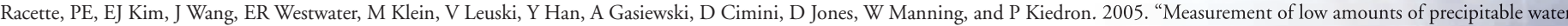
vapor using ground-based millimeterwave radiometry." Journal of Atmospheric and Oceanic Technology 22:317-337.

Rotstayn, LD, and Y Liu. 2005. "A smaller global estimate of the second indirect aerosol effect." Geophysical Research Letters 32, L05708, doi:10.1029/2004GL021922.

Sabburg, JM, and CN Long. 2004. "Improved sky imaging for studies of enhanced UV irradiances." Atmospheric Chemistry and Physics 4:2543-2552.

Sassen, K. 2005. "Dusty ice clouds over Alaska." Nature 434(7032):456-459.

Schmitt, C, and A Heymsfield. 2005. "Total surface area estimates for individual ice particles and particle populations." Journal of Applied Meteorology 44:467-474.

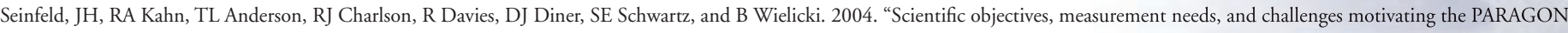
aerosol initiative." Bulletin of the American Meteorological Society 85:1503-1509.

Sengupta, M, E Clothiaux, and TP Ackerman. 2004. "Climatology of warm boundary layer clouds at the ARM SGP site and their comparison to models." Journal of Climate 17:4760-4782.

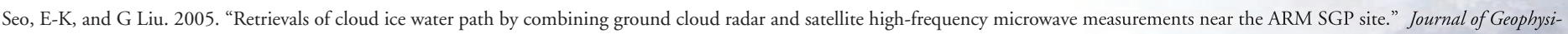
cal Research 110, D14203, doi:10.1029/2004JD005727.

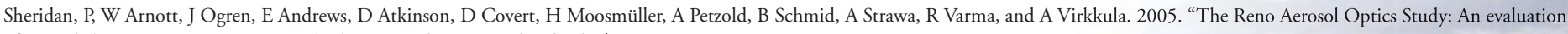
of aerosol absorption measurement methods." Aerosol Science and Technology 39:1-16.

Stephens, GL. 2005. “Cloud feedback in the climate system: A critical review.” Journal of Climate 18:237-273.

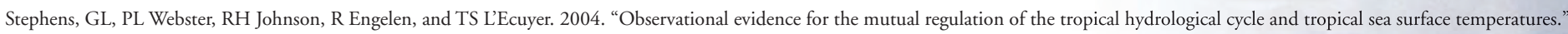
Journal of Climate 17:2213-2224.

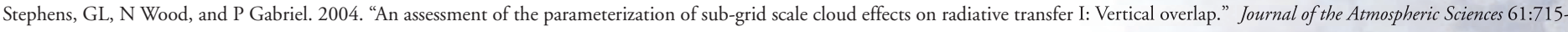
732 .

Tian, B, I Held, N-C Lau, and BJ Soden. 2005. “Diurnal cycle of summertime deep convection over North America: A satellite perspective.” Journal of Geophysical Research 110, D08108, doi: $10.1029 / 2004 J D 005275$.

Turner, DD. 2005. “Arctic mixed-phase cloud properties from AERI-lidar observations: Algorithm and results from SHEBA.” Journal of Applied Meteorology 44:427-444.

Turner, DD, and RE Holz. 2005. "Retrieving cloud fraction in the field-of-view of a high-spectral resolution infrared radiometer." IEEE Geoscience and Remote Sensing Letters, 2(3):287-291.

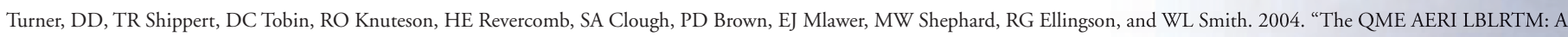
closure experiment for downwelling high spectral resolution infrared radiance." Journal of the Atmospheric Sciences 61:2657-2675. 
Virkkula, A, N Ahlquist, D Covert, W Arnott, P Sheridan, P Quinn, and D Coffman. 2005. "Modification, calibration and a field test of an instrument for measuring light absorption by particles." Aerosol Science and Technology 39:68-83.

Virkkula, A, N Ahlquist, D Covert, P Sheridan, W Arnott, and J Ogren. 2005. "A three-wavelength optical extinction call for measuring aerosol light extinction and its application to determining light absorption coefficient." Aerosol Science and Technology 39:52-67.

Weaver, CP, JR Norris, ND Gordon, and SA Klein. 2005. "Dynamical controls on sub-global climate model grid-scale cloud variability for Atmospheric Radiation Measurement Program (ARM) case 4." Journal of Geophysical Research 110, D15S05, doi:10.1029/2004JD005022.

Westwater, ER. 2005. "Surface-based microwave and millimeter wave radiometric remote sensing of the troposphere: A tutorial." IEEE Geoscience and Remote Sensing Newsletter \#134:16-33.

Whiteway, J, C Cook, T Choularton, J Harries, P Connolly, R Busen, K Bower, M Flynn, P May, R Aspey, and J HackeWr. 2004. "Anatomy of cirrus clouds: Results from the Emerald airborne campaigns." Geophysical Research Letters 31, L24102, doi:10.1029/2004GL021201.

Wild, MF, H Gilgen, A Roesch, A Ohmura, CN Long, EG Dutton, BW Forgan, A Kallis, V Russak, and A Tsvetkov. 2005. "From dimming to brightening: Decadal changes in solar radiation at earth's surface." Science 308:847-850.

Williamson, DL, J Boyle, R Cederwall, M Fiorino, J Hnilo, J Olson, T Phillips, G Potter, and SC Xie. 2005. "Moisture and temperature balances at the Atmospheric Radiation Measurement Southern Great Plains Site in forecasts with the Community Atmosphere Model (CAM2)." Journal of Geophysical Research 110, D15S16, doi:10.1029/2004JD005109.

Wood, N, PM Gabriel, and GL Stephens. 2005. "An assessment of the parameterization of subgrid-scale cloud effects on radiative transfer. Part II: Horizontal inhomogeneity." Journal of the Atmospheric Sciences 62:2895-2909.

Xie, S, M Zhang, M Branson, RT Cederwall, AD Del Genio, ZA Eitzen, SJ Ghan, SF Iacobellis, KL Johnson, M Khairoutdinov, SA Klein, SK Krueger, W Lin, U Lohmann, M Miller, DA Randall, RCJ Somerville, YC Sud, GK Walker, A Wolf, X Wu, K-M Xu, JJ Yio, G Zhang, and J Zhang. 2005. "Simulations of midlatitude frontal clouds by single-column and cloud-resolving models during the Atmospheric Radiation Measurement March 2000 cloud intensive operational period." Journal of Geophysical Research 110, D15S03, doi:10.1029/2004JD005119.

Xu, K-M. 2005. "The sensitivity of diagnostic radiative properties to cloud microphysics among cloud-resolving model simulations." Journal of the Atmospheric Sciences 62:1241 1254.

Xu, K-M, M Zhang, Z Eitzen, S Ghan, S Klein, X Wu, S Xie, M Branson, A Del Genio, S Iacobellis, M Khairoutdinov, W Lin, U Löhmann, DA Randall, RJ Somerville, Y Sud, G Walker, AB Wolf, J Yio, and J Zhang. 2005. "Modeling springtime shallow frontal clouds with cloud-resolving and single-column models." Journal of Geophysical Research 110, D15S04, doi:10.1029/2004JD005153.

Zamora, R, E Dutton, M Trainer, S McKeen, JM Wilczak, and Y-T Hou. 2005. "The accuracy of solar irradiance calculations used in mesoscale numerical weather prediction." Monthly Weather Review 133:783-792.

Zhang, J, U Lohmann, and P Stier. 2005. "A microphysical parameterization for convective clouds in the ECHAM5 climate model: Single-column model results evaluated at the Oklahoma Atmospheric Radiation Measurement Program site." Journal of Geophysical Research 110, D15S07, doi:10.1029/2004JD005128.

Zhang, M, W Lin, SA Klein, J Bacmeister, S Bony, RT Cederwall, AD Del Genio, J Hack, NG Loeb, U Lohmann, P Minnis, I Musat, R Pincus, P Stier, MJ Suarez, MJ Webb, JB Wu, SC Xie, M-S Yao, and JH Zhang. 2005. "Comparing clouds and their seasonal variations in 10 atmospheric general circulation models with satellite measurements." Journal of Geophysical Research 110, D15S02, doi:10.1029/2004JD005021.

\section{Conference Proceedings}

Ackerman, TP, SJ Ghan, RT Marchand, M Ovtchinnikov, and AS Koontz. 2005. "Comparison of the multi-scale modeling framework and the NCAR CAM with observations along a Pacific Ocean transect." In Proceedings of the 85th American Meteorological Society (AMS) Annual Meeting, American Meteorological Society, San Diego, California.

Ackerman, TP, and CN Long. 2005. "A surface based climatology of irradiance, cloud effect and cloud amount at the ARM sites." In Proceedings of the 85th American Meteorological Society (AMS) Annual Meeting, American Meteorological Society, San Diego, California.

Alexandrov, M, B Cairns, BE Carlson, and AA Lacis. 2005. "Fine and coarse mode aerosols in Southern Great Plains multi-filter rotating shadowband radiometer data sets." In Proceedings of the Fiffeenth Atmospheric Radiation Measurement (ARM) Science Team Meeting, U.S. Department of Energy, DOE/SC-ARM-0503, Richland, Washington.

Arduini, RT, P Minnis, JK Ayers, MM Khaiyer, WL Smith Jr., and PW Heck. 2005. “Sensitivity of satellite-retrieved cloud properties to the spectral dispersion of cloud droplet distribution." In Proceedings of the Fiffeenth Atmospheric Radiation Measurement (ARM) Science Team Meeting, U.S. Department of Energy, DOE/SC-ARM-0503, Richland, Washington.

Avramov, A, VT Yannuzzi, PQ Olsson, CP Bahrmann, JY Harrington, and J Verlinde. 2005. “Mesoscale modeling during MPACE.” In Proceedings of the 85th American Meteorological Society (AMS) Annual Meeting, American Meteorological Society, San Diego, California.

Ayers, JK, P Minnis, R Palikonda, P Heck, and R Arduini. 2005. "Evaluation of cloud properties derived from dual-view satellite data over the continental United States." In Proceedings of the Atmospheric Radiation Measurement (ARM) Science Team Meeting, U.S. Department of Energy, DOE/SC-ARM-0503, Richland, Washington.

Bauer, M, and AD Del Genio. 2005. "Composite analysis of winter cyclones in a general circulation model: influence on climatological humidity." In Proceedings of the Fifteenth Atmospheric Radiation Measurement (ARM) Science Team Meeting, U.S. Department of Energy, DOE/SC-ARM-0503, Richland, Washington.

Berg, LK, and RB Stull. 2005. "A new parameterization framework for boundary-layer cumuli." In Proceedings of the Fifteenth Atmospheric Radiation Measurement (ARM) Science Team Meeting, U.S. Department of Energy, DOE/SC-ARM-0503, Richland, Washington.

Cairns, B, A Lacis, B Carlson, and M Alexandrov. 2005. "Inversion of multi-angle radiation measurements." In Proceedings of the Atmospheric Radiation Measurement (ARM) Science Team Meeting, U.S. Department of Energy, DOE/SC-ARM-0503, Richland, Washington.

Chang, F-L, and Z Li. 2005. "A comparison of the global surveys of high, mid, and low clouds from satellites and general circulation models." In Proceedings of the Fifteenth Atmospheric Radiation Measurement (ARM) Science Team Meeting, U.S. Department of Energy, DOE/SC-ARM-0503, Richland, Washington.

Chang, F-L, Z Li, and E Clothiaux. 2005. "Comparing the overlapped cloud top altitudes deduced from a satellite-based retrieval scheme with atmospheric radiation measurement ground-based measurement." In Proceedings of the Fiffeenth Atmospheric Radiation Measurement (ARM) Science Team Meeting, U.S. Department of Energy, DOE/SC-ARM-0503, Richland, Washington.

Charlock, TP, FG Rose, DA Rutan, DA Coleman, LH Caldwell, T Caldwell, and S Zentz. 2005. "Global, multi-year analysis of clouds and earth's radiant energy system Terra observations and radiative transfer calculations." In Proceedings of the Fifteenth Atmospheric Radiation Measurement (ARM) Science Team Meeting, U.S. Department of Energy, DOE/SC-ARM-0503, Richland, Washington.

Chiriaco, M, M Haeffelin, Y Wanherdrick, H Chepfer, R Vautard, Y Morille, A Protat, and J Dudhia. 2005. "The ability of MM5 to simulate ice clouds: systematic comparison between simulated and measured fluxes and lidar/radar profiles at SIRTA Atmospheric Observatory." In Proceedings of the Fifteenth Atmospheric Radiation Measurement (ARM) Science Team Meeting, U.S. Department of Energy, DOE/SC-ARM-0503, Richland, Washington.

Cimini, D, M Klein, ER Westwater, V Leuski, A Gasiewski, and S Dowlatshahi. 2005. "Ground-based scanning radiometer measurements during the water vapor intensive operational period 2004: A valuable new data set for the study of the Arctic Atmosphere." In Proceedings of the Fiffeenth Atmospheric Radiation Measurement (ARM) Science Team Meeting, U.S. Department of Energy, DOE/SCARM-0503, Richland, Washington. 


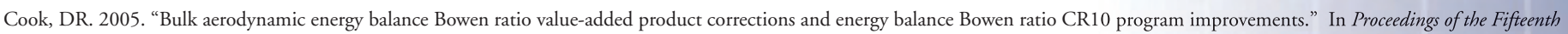
Atmospheric Radiation Measurement (ARM) Science Team Meeting, U.S. Department of Energy, DOE/SC-ARM-0503, Richland, Washington.

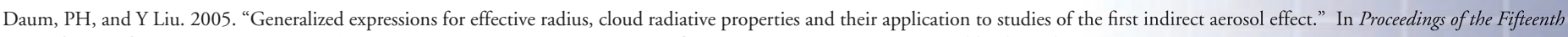
Atmospheric Radiation Measurement (ARM) Science Team Meeting, U.S. Department of Energy, DOE/SC-ARM-0503, Richland, Washington.

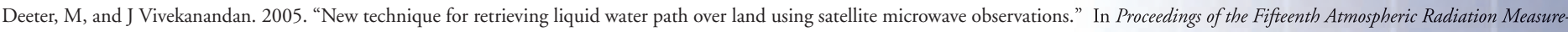
ment (ARM) Science Team Meeting, U.S. Department of Energy, DOE/SC-ARM-0503, Richland, Washington.

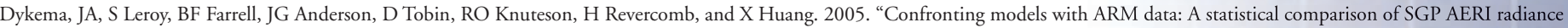

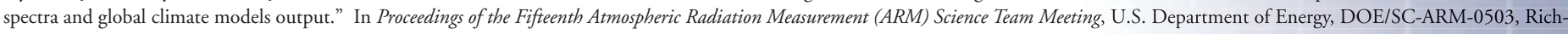
land, Washington.

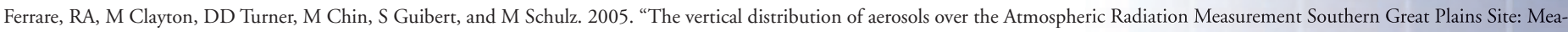
sured vs. modeled." In Proceedings of the Fifteenth Atmospheric Radiation Measurement (ARM) Science Team Meeting, U.S. Department of Energy, DOE/SC-ARM-0503, Richland, Washington.

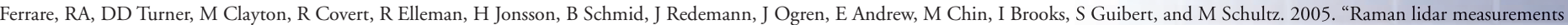

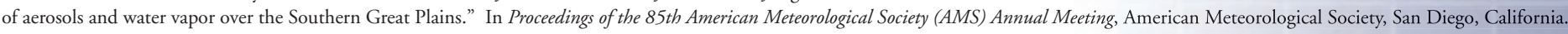

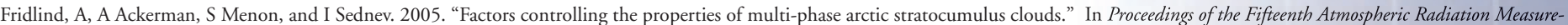
ment (ARM) Science Team Meeting, U.S. Department of Energy, DOE/SC-ARM-0503, Richland, Washington.

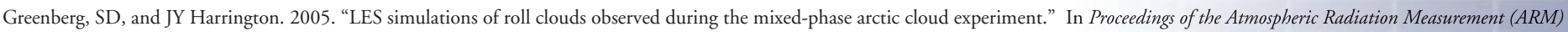
Science Team Meeting, U.S. Department of Energy, DOE/SC-ARM-0503, Richland, Washington.

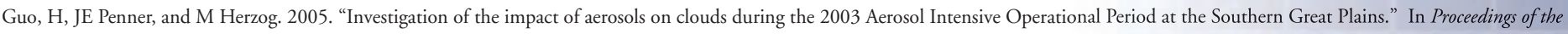
Atmospheric Radiation Measurement (ARM) Science Team Meeting, U.S. Department of Energy, DOE/SC-ARM-0503, Richland, Washington.

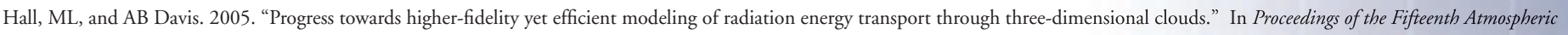
Radiation Measurement (ARM) Science Team Meeting, U.S. Department of Energy, DOE/SC-ARM-0503, Richland, Washington.

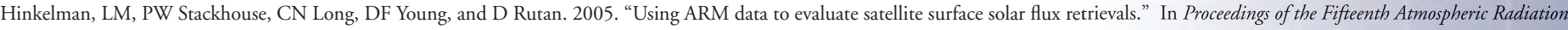
Measurement (ARM) Science Team Meeting, U.S. Department of Energy, DOE/SC-ARM-0503, Richland, Washington.

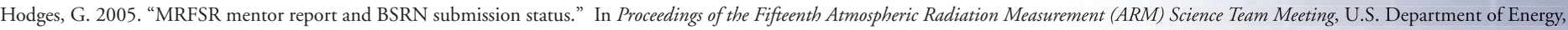
DOE/SC-ARM-0503, Richland, Washington.

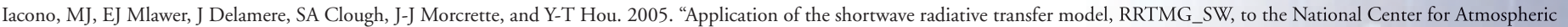

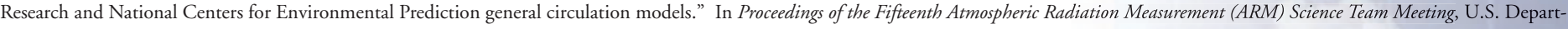
ment of Energy, DOE/SC-ARM-0503, Richland, Washington.

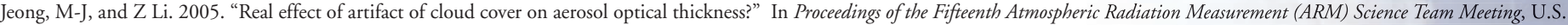
Department of Energy, DOE/SC-ARM-0503, Richland, Washington.

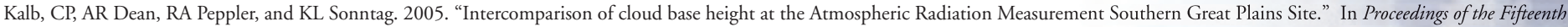
Atmospheric Radiation Measurement (ARM) Science Team Meeting, U.S. Department of Energy, DOE/SC-ARM-0503, Richland, Washington.

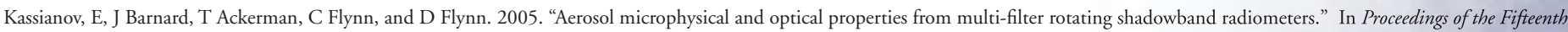
Atmospheric Radiation Measurement (ARM) Science Team Meeting, U.S. Department of Energy, DOE/SC-ARM-0503, Richland, Washington.

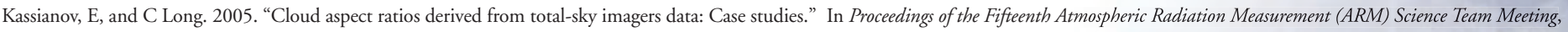
U.S. Department of Energy, DOE/SC-ARM-0503, Richland, Washington.

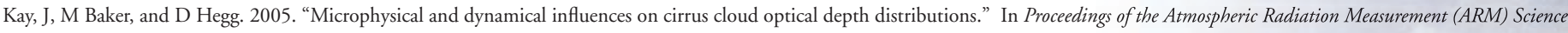
Team Meeting, U.S. Department of Energy, DOE/SC-ARM-0503, Richland, Washington.

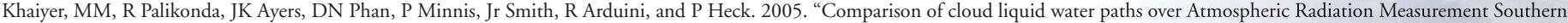

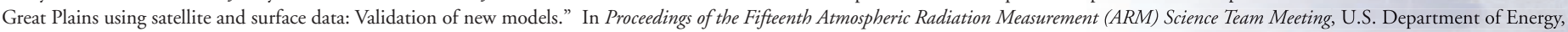
DOE/SC-ARM-0503, Richland, Washington.

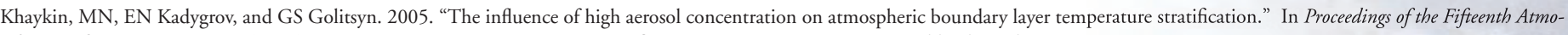
spheric Radiation Measurement (ARM) Science Team Meeting, U.S. Department of Energy, DOE/SC-ARM-0503, Richland, Washington.

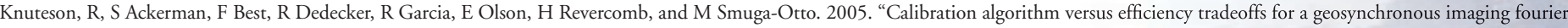
transform spectrometer." In Proceedings of the 85th American Meteorological Society (AMS) Annual Meeting, American Meteorological Society, San Diego, California.

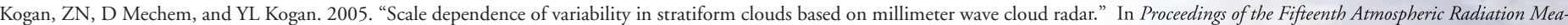
surement (ARM) Science Team Meeting, U.S. Department of Energy, DOE/SC-ARM-0503, Richland, Washington.

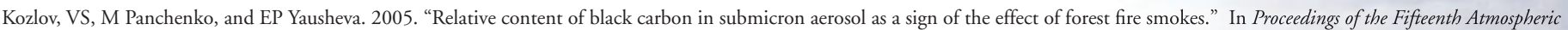
Radiation Measurement (ARM) Science Team Meeting, U.S. Department of Energy, DOE/SC-ARM-0503, Richland, Washington.

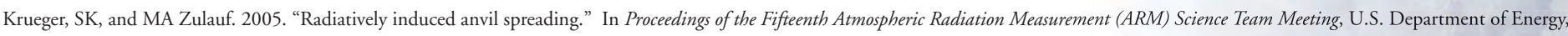
DOE/SC-ARM-0503, Richland, Washington.

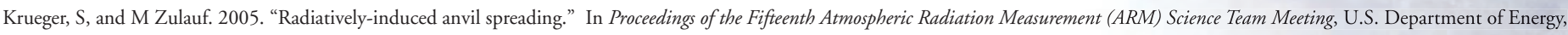
DOE/SC-ARM-0503, Richland, Washington.

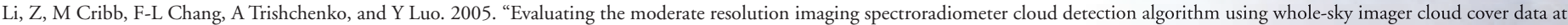

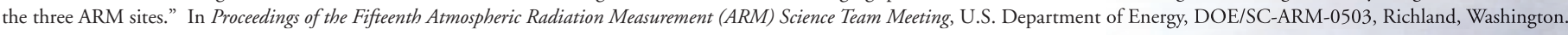

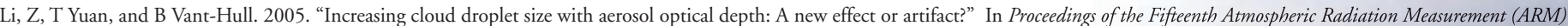
Science Team Meeting, U.S. Department of Energy, DOE/SC-ARM-0503, Richland, Washington. 
Liu, L, AA Lacis, BE Carlson, MI Mishchenko, and B Cairns. 2005. "Improving GCM aerosol climatology using satellite and ground-based measurements." In Proceedings of the Fifteenth Atmospheric Radiation Measurement (ARM) Science Team Meeting, U.S. Department of Energy, DOE/SC-ARM-0503, Richland, Washington.

Liu, Y, PH Daum, and RL McGraw. 2005. “Parameterization of the autoconversion process: Kessler-type, Sundqvist-type, and unification.” In Proceedings of the Fifteenth Atmospheric Radiation Measurement (ARM) Science Team Meeting, U.S. Department of Energy, DOE/SC-ARM-0503, Richland, Washington.

Long, CN. 2005. "On the estimation of clear-sky upwelling shortwave and longwave." In Proceedings of the Fiffeenth Atmospheric Radiation Measurement (ARM) Science Team Meeting, U.S. Department of Energy, DOE/SC-ARM-0503, Richland, Washington.

Macduff, MC, and RC Eagan. 2005. "ACRF data collection and processing infrastructure." In Proceedings of the 85th American Meteorological Society (AMS) Annual Meeting, American Meteorological Society, San Diego, California.

Maestas, AM. 2005. “Tools for teaching climate studies." In Proceedings of the Fiffeenth Atmospheric Radiation Measurement (ARM) Science Team Meeting, U.S. Department of Energy, DOE/SC-ARM0503, Richland, Washington.

Marchand, RT, SJ Ghan, M Ovtchinnikov, TP Ackerman, and M Khairoutdinov. 2005. "Comparison of the multi-scale modeling framework and NCAR community atmospheric model (CAM) with ISCCP and CERES retrievals." In Proceedings of the 85th American Meteorological Society (AMS) Annual Meeting, American Meteorological Society, San Diego, California.

Matrosov, S. 2005. "An approach to estimate rainfall rates aloft from MMCR measurements." In Proceedings of the Fifteenth Atmospheric Radiation Measurement (ARM) Science Team Meeting, U.S. Department of Energy, Richland, Washington.

Mattioli, V, ER Westwater, D Cimini, JS Liljegren, BM Lesht, S Gutman, and F Schmidlin. 2005. "Analysis of radiosonde and precipitable water vapor data from the 2004 North Slope of Alaska arctic winter radiometric experiment." In Proceedings of the Fifteenth Atmospheric Radiation Measurement (ARM) Science Team Meeting, U.S. Department of Energy, DOE/SC-ARM-0503, Richland, Washington.

McComiskey, A, P Ricchiazzi, JA Ogren, and E Dutton. 2005. “SGPGET: AN SBDART Module for Aerosol Radiative Transfer." In Proceedings of the Fifteenth Atmospheric Radiation Measurement (ARM) Science Team Meeting, U.S. Department of Energy, DOE/SC-ARM-0503, Richland, Washington.

McComiskey, A, SE Schwartz, ER Lewis, P Ricchiazzi, JA Ogren, and JJ Michalsky. 2005. "Direct aerosol forcing: Calculations from observables and sensitivities to inputs." In Proceedings of the Fifteenth Atmospheric Radiation Measurement (ARM) Science Team Meeting Proceedings, U.S. Department of Energy, DOE/SC-ARM-0503, Richland, Washington.

McFarlane, SA, JH Mather, and TP Ackerman. 2005. "Radiative heating profiles in the convective tropics: A comparison of observations and models." In Proceedings of the 85th American Meteorological Society (AMS) Annual Meeting, American Meteorological Society, San Diego, California.

McFarquhar, GM, M Freer, J Um, R McCoy, and W Bolton. 2005. "Remote sensing and in-situ observations of arctic mixed-phase and cirrus clouds acquired during M-PACE.” In Proceedings of the Fifteenth Atmospheric Radiation Measurement (ARM) Science Team Meeting, U.S. Department of Energy, DOE/SC-ARM-0503, Richland, Washington.

McFarquhar, GM, MS Timlin, T Nousianen, and P Yang. 2005. "A new representation of the single-scattering properties for mid-latitude clouds and its impacts." In Proceedings of the Fifteenth Atmospheric Radiation Measurement (ARM) Science Team Meeting, U.S. Department of Energy, DOE/SC-ARM-0503, Richland, Washington.

McFarquhar, GM, G Zhang, J Verlinde, M Poellot, A Heymsfield, and G Kok. 2005. "Assessing current parameterization of mixed-phase clouds using in situ profiles measured during the mixed-phase cloud experiment." In Proceedings of the Fifteenth Atmospheric Radiation Measurement (ARM) Science Team Meeting, U.S. Department of Energy, DOE/SC-ARM-0503, Richland, Washington.

McGraw, RL, and Y Liu. 2005. "Parameterizations for clouds and precipitation based on the kinetic potential theory for drizzle formation." In Proceedings of the Atmospheric Radiation Measurement (ARM) Science Team Meeting, U.S. Department of Energy, DOE/SC-ARM-0503, Richland, Washington.

Mechem, DB, YL Kogan, M Childers, and KM Donner. 2005. "Toward a diurnal climatology of cold-season turbulence statistics in continental stratucumulus as observed by the Atmospheric Radiation Measurement millimeter wavelength cloud radar." In Proceedings of the Fifteenth Atmospheric Radiation Measurement (ARM) Science Team Meeting, U.S. Department of Energy, DOE/SC-ARM0503, Richland, Washington.

Mechem, D, and YL Kogan. 2005. "Representing cloud processing of aerosol in numerical models." In Proceedings of the Fiffeenth Atmospheric Radiation Measurement (ARM) Science Team Meeting, U.S. Department of Energy, DOE/SC-ARM-0503, Richland, Washington.

Moore, S, and G Hughes. 2005. "Instrument cross-comparisons and automated quality control of atmospheric radiation measurement data." In Proceedings of the Fifteenth Atmospheric Radiation Measurement (ARM) Science Team Meeting, U.S. Department of Energy, DOE/SC-ARM-0503, Richland, Washington.

Musat, IC, and RG Ellingson. 2005. "Short-term variability of extinction by broadband steller photometry." In Proceedings of the Fifteenth Atmospheric Radiation Measurement (ARM) Science Team Meeting, U.S. Department of Energy, DOE/SC-ARM-0503, Richland, Washington.

Nordeen, ML, P Minnis, M Khaiyer, D Doelling, and D Phan. 2005. "Comparison of surface and satellite-derived cloud and radiation properties at the ARM Southern Great Plains and Tropical Western Pacific sites." In Proceedings of the Fiffeenth Atmospheric Radiation Measurement (ARM) Science Team Meeting, U.S. Department of Energy, DOE/SC-ARM-0503, Richland, Washington.

O'Hirok, W, M Miller, E Mlawer, P Ricchiazzi, and C Gautier. 2005. "Assessing the impact of the plane-parallel cloud assumption used in computing shortwave heating rate profiles for the broadband heating rate profile project." In Proceedings of the Fifteenth Atmospheric Radiation Measurement (ARM) Science Team Meeting, U.S. Department of Energy, DOE/SC-ARM-0503, Richland, Washington.

O'Hirok, W, P Ricchiazzi, and C Gautier. 2005. "Incorporations of 3D shortwave radiative effects within the weather research and forecasting model." In Proceedings of the Fifteenth Atmospheric Radiation Measurement (ARM) Science Team Meeting, U.S. Department of Energy, Richland, Washington.

Palikonda, R, P Minnis, MM Khaiyer, P Heck, DR Doelling, L Nguyen, AK Ayers, DA Spangenberg, ML Nordeen, R Arduini, QZ Trepte, S Sun-Mack, and DN Pham. 2005. "Overview of Atmospheric Radiation Measurement satellite cloud and radiation products from Langley Research Center." In Proceedings of the Fifteenth Atmospheric Radiation Measurement (ARM) Science Team Meeting, U.S. Department of Energy, DOE/SC-ARM-0503, Richland, Washington.

Polonsky, IN, AB Davis, and MA Box. 2005. "Radiative transfer in 3D clouds: A perturbation theoretical approach." In Proceedings of the Fifteenth Atmospheric Radiation Measurement (ARM) Science Team Meeting, U.S. Department of Energy, DOE/SC-ARM-0503, Richland, Washington.

Ricchiazzi, P, W O'Hirok, and C Gautier. 2005. "The effect of non-Lambertian surface reflectance on aerosol radiative forcing." In Proceedings of the Fiffeenth Atmospheric Radiation Measurement (ARM) Science Team Meeting, U.S. Department of Energy, DOE/SC-ARM-0503, Richland, Washington.

Ritsche, M, D Holdridge, and R Pearson. 2005. "New and improved data logging and collection system for ACRF TWP and NSA SKYRAD, GNDRAD and MET systems." In Proceedings of the Atmospheric Radiation Measurement (ARM) Science Team Meeting, U.S. Department of Energy, DOE/SC-ARM-0503, Richland, Washington.

Roeder, LR, and R Jundt. 2005. "Photography in the field: Faux pas to phenomenal." In Proceedings of the Fifteenth Atmospheric Radiation Measurement (ARM) Science Team Meeting, U.S. Department of Energy, DOE/SC-ARM-0503, Richland, Washington.

Rutan, D, F Rose, and TP Charlock. 2005. "Improvement in clouds and the earth's radiant energy system/surface and atmospheric radiation budget dust aerosol properties, effects on surface validation of clouds and radiative swath." In Proceedings of the Fiffeenth Atmospheric Radiation Measurement (ARM) Science Team Meeting, U.S. Department of Energy, DOE/SC-ARM-0503, Richland, Washington.

Sakerin, S, T Zhuravleva, and I Nasrtdinov. 2005. "Regularities of angular distribution of near-horizon sky brightness in the cloudless atmosphere." In Proceedings of the Fifteenth Atmospheric Radia- 
tion Measurement (ARM) Science Team Meeting, U.S. Department of Energy, DOE/SC-ARM-0503, Richland, Washington.

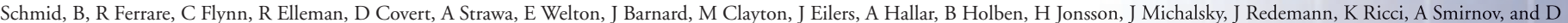

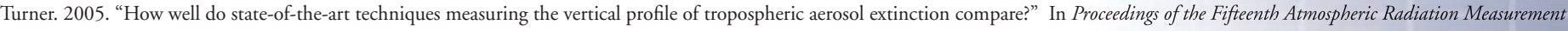
(ARM) Science Team Meeting, U.S. Department of Energy, DOE/SC-ARM-0503, Richland, Washington.

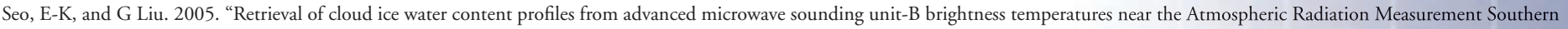
Great Plains site." In Proceedings of the Fifteenth Atmospheric Radiation Measurement (ARM) Science Team Meeting, U.S. Department of Energy, DOE/SC-ARM-0503, Richland, Washington.

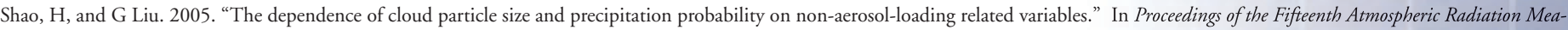
surement (ARM) Science Team Meeting, U.S. Department of Energy, DOE/SC-ARM-0503, Richland, Washington.

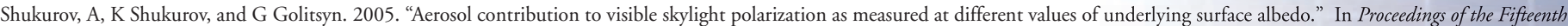
Atmospheric Radiation Measurement (ARM) Science Team Meeting, U.S. Department of Energy, DOE/SC-ARM-0503, Richland, Washington.

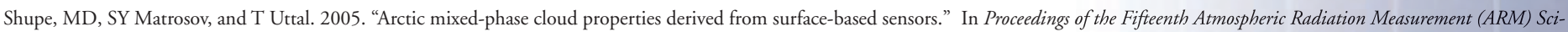
ence Team Meeting, U.S. Department of Energy, DOE/SC-ARM-0503, Richland, Washington.

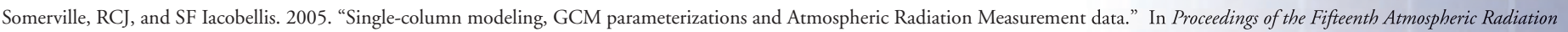
Measurement (ARM) Science Team Meeting, U.S. Department of Energy, DOE/SC-ARM-0503, Richland, Washington.

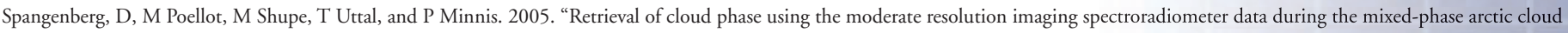
experiment." In Proceedings of the Fifteenth Atmospheric Radiation Measurement (ARM) Science Team Meeting, U.S. Department of Energy, DOE/SC-ARM-0503, Richland, Washington.

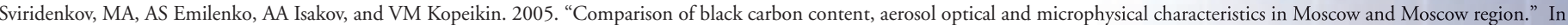
Proceedings of the Fifteenth Atmospheric Radiation Measurement (ARM) Science Team Meeting, U.S. Department of Energy, DOE/SC-ARM-0503, Richland, Washington.

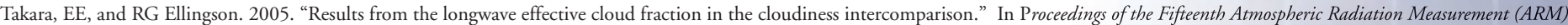
Science Team Meeting, U.S. Department of Energy, DOE/SC-ARM-0503, Richland, Washington.

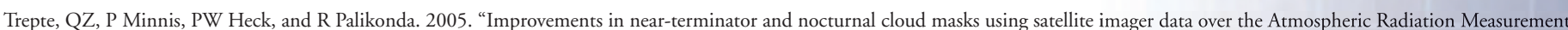
sites." In Proceedings of the Fifteenth Atmospheric Radiation Measurement (ARM) Science Team Meeting, U.S. Department of Energy, DOE/SC-ARM-0503, Richland, Washington.

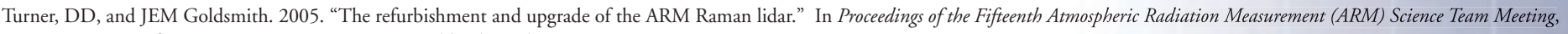
U.S. Department of Energy, DOE/SC-ARM-0503, Richland, Washington.

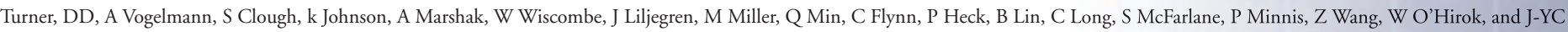

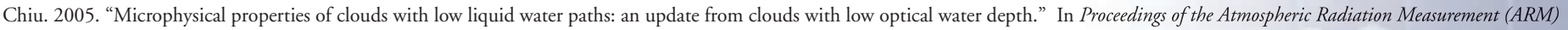
Science Team Meeting, U.S. Department of Energy, DOE/SC-ARM-0503, Richland, Washington.

Um, J. 2005. “Aggregation effects on single-scattering properties of ice crystals." In Proceedings of the Fifteenth Atmospheric Radiation Measurement (ARM) Science Team Meeting Proceedings, U.S. Department of Energy, DOE/SC-ARM-0503, Richland, Washington.

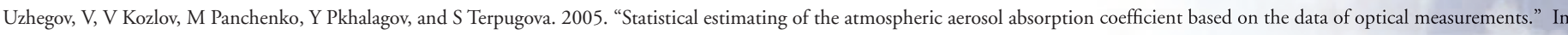
Proceedings of the Fifteenth Atmospheric Radiation Measurement (ARM) Science Team Meeting, U.S. Department of Energy, DOE/SC-ARM-0503, Richland, Washington.

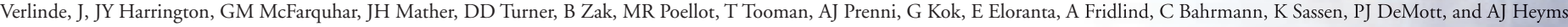

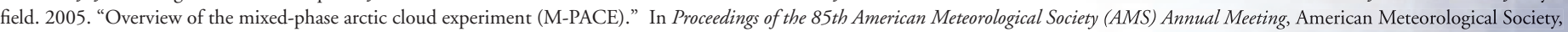
San Diego, California.

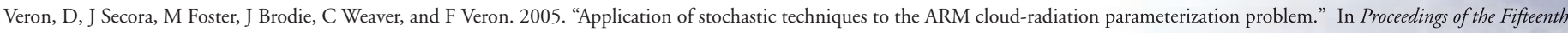
Atmospheric Radiation Measurement (ARM) Science Team Meeting, U.S. Department of Energy, DOE/SC-ARM-0503, Richland, Washington.

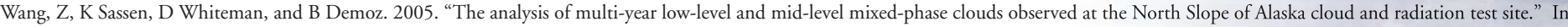
Proceedings of the Fifteenth Atmospheric Radiation Measurement (ARM) Science Team Meeting, U.S. Department of Energy, DOE/SC-ARM-0503, Richland, Washington.

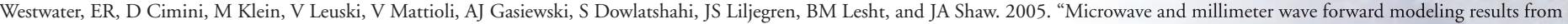

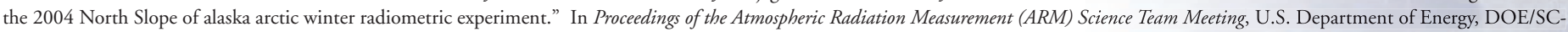
ARM-0503, Richland, Washington.

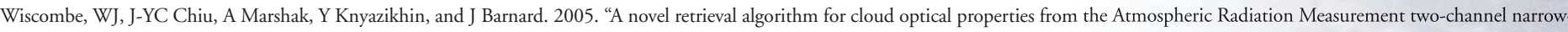

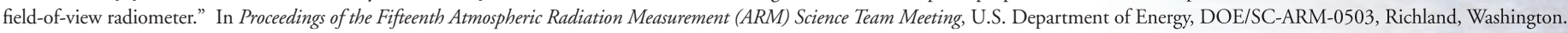

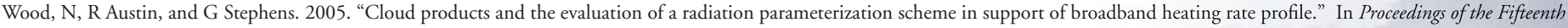
Atmospheric Radiation Measurement (ARM) Science Team Meeting, U.S. Department of Energy, DOE/SC-ARM-0503, Richland, Washington.

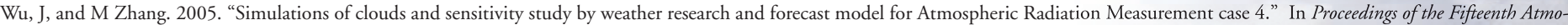
spheric Radiation Measurement (ARM) Science Team Meeting, U.S. Department of Energy, DOE/SC-ARM-0503, Richland, Washington.

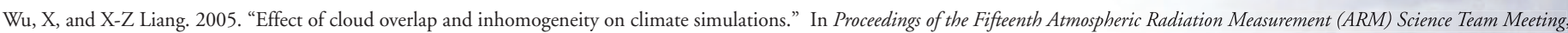
U.S. Department of Energy, DOE/SC-ARM-0503, Richland, Washington.

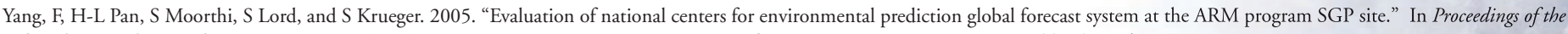
Fifteenth Atmospheric Radiation Measurement (ARM) Science Team Meeting, U.S. Department of Energy, DOE/SC-ARM-0503, Richland, Washington.

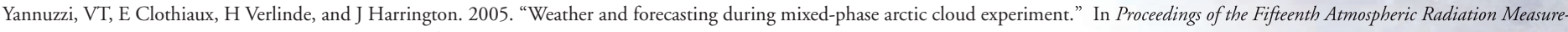
ment (ARM) Science Team Meeting, U.S. Department of Energy, DOE/SC-ARM-0503, Richland, Washington.

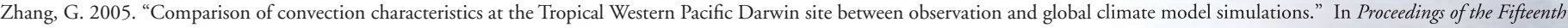
Atmospheric Radiation Measurement (ARM) Science Team Meeting, U.S. Department of Energy, DOE/SC-ARM-0503, Richland, Washington.

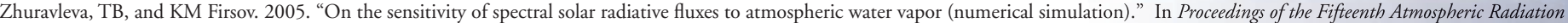
Measurement (ARM) Science Team Meeting, U.S. Department of Energy, DOE/SC-ARM-0503, Richland, Washington.

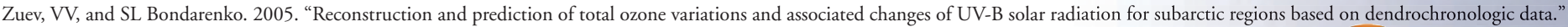


In Proceedings of the Fifteenth Atmospheric Radiation Measurement (ARM) Science Team Meeting, U.S. Department of Energy, DOE/SC-ARM-0503, Richland, Washington.

\section{Conference Presentation Abstracts}

Ackerman, TP, SJ Ghan, RT Marchand, M Ovtchinnikov, and AS Koontz. 2005. "Comparison of the multi-scale modeling framework and the NCAR CAM with observations along a Pacific Ocean transect." Presented at the 85th American Meteorological Society (AMS) Annual Meeting. San Diego, California.

Ackerman, TP, and CN Long. 2005. "A surface based climatology of irradiance, cloud effect and cloud amount at the ARM sites." Presented at the 85th American Meteorological Society (AMS) Annual Meeting. San Diego, California.

Albrecht, B, P Kollias, L Jo, V Ghate, E Serpetzoglou, P Minnis, and S Sun-Mack. 2005. "Observations of natural variability in marine stratocumulus clouds." Presented at the Fifteenth Atmospheric Radiation Measurement (ARM) Science Team Meeting. Daytona Beach, Florida.

Alexandrov, M. 2005. "Fine and coarse mode aerosols in Southern Great Plains multi-filter rotating shadowband radiometer data sets." Presented at the Fifteenth Atmospheric Radiation Measurement (ARM) Science Team Meeting. Daytona Beach, Florida.

Arduini, R, P Minnis, and J Ayers. 2005. "Sensitivity of satellite-retrieved cloud properties to the spectral dispersion of cloud droplet distribution." Presented at the Fifteenth Atmospheric Radiation Measurement (ARM) Science Team Meeting. Daytona Beach, Florida.

Avramov, A, J Harrington, and J Verlinde. 2005. “Mesoscale modeling during M-PACE: Influences of ice nuclei on simulated mesoscale cloud fields." Presented at the Fifteenth Atmospheric Radiation Measurement (ARM) Science Team Meeting. Daytona Beach, Florida.

Avramov, A, VT Yannuzzi, PQ Olsson, CP Bahrmann, JY Harrington, and J Verlinde. 2005. “Mesoscale modeling during MPACE.” Presented at the 85th American Meteorological Society (AMS) Annual Meeting. San Diego, California.

Ayers, J, P Minnis, R Palikonda, P Heck, and R Arduini. 2005. "Evaluation of cloud properties derived from dual-view satellite data over the Continental United States." Presented at the Fifteenth Atmospheric Radiation Measurement (ARM) Science Team Meeting. Daytona Beach, Florida.

Barker, H, J Cole, E Clothiaux, J Li, J-J Morcrette, R Pincus, P Raisanen, and G Stephens. 2005. "Assessing the response of several GCMs to the McICA radiative transfer methodology." Presented at the Fifteenth Atmospheric Radiation Measurement (ARM) Science Team Meeting. Daytona Beach, Florida.

Barker, H, J Cole, A Marshak, J Strapp, P Raisanen, and Y Knyazikhin. 2005. "Response of a GCM to subgrid-scale variations in cloud droplet size distribution." Presented at the Fifteenth Atmospheric Radiation Measurement (ARM) Science Team Meeting. Daytona Beach, Florida.

Barker, H, J Cole, P Raisanen, E Clothiaux, D Randall, and M Khairoutdinov. 2005. "Radiative forcing and response of a GCM to maximum-random overlap of homogeneous clouds." Presented at the Fifteenth Atmospheric Radiation Measurement (ARM) Science Team Meeting. Daytona Beach, Florida.

Bartholomew, MJ, M Miller, A Bucholtz, B Albrecht, P Kollias, D Sisterson, K Widener, L Jones, and K Nitschke. 2005. "The first deployment of the ARM mobile facility; investigating marine stratus at Pt. Reyes, California." Presented at the Fifteenth Atmospheric Radiation Measurement (ARM) Science Team Meeting. Daytona Beach, Florida.

Bauer, M, and A Del Genio. 2005. "Composite analysis of GCM winter cyclones: Influence on climatological humidity." Presented at the Fifteenth Atmospheric Radiation Measurement (ARM) Science Team Meeting. Daytona Beach, Florida.

Berg, L, and R Stull. 2005. "A new parameterization framework for boundary-layer cumuli.” Presented at the Fifteenth Atmospheric Radiation Measurement (ARM) Science Team Meeting. Daytona Beach, Florida.

Biraud, S, W Riley, M Fischer, M Torn, J Berry, and H Cooley. 2005. "Spatially distributed CO2, sensible, and latent heat fluxes over the Southern Great Plains." Presented at the Fifteenth Atmospheric Radiation Measurement (ARM) Science Team Meeting. Daytona Beach, Florida.

Bond, D. 2005. "Soil water and temperature system (SWATS) measurements in the Southern Great Plains." Presented at the Fifteenth Atmospheric Radiation Measurement (ARM) Science Team Meeting. Daytona Beach, Florida.

Cairns, B, A Lacis, B Carlson, and M Alexandrov. 2005 "Inversion of multi-angle radiation measurements." Presented at the Fifteenth Atmospheric Radiation Measurement (ARM) Science Team Meeting. Daytona Beach, Florida.

Cess, R, and M Sun. 2005. "Interpretation of cloud structure anomalies over the tropical pacific during the 1997/98 El Niño." Presented at the Fifteenth Atmospheric Radiation Measurement (ARM) Science Team Meeting. Daytona Beach, Florida.

Chang, F-L and Z Li. 2005 "A comparison of the global surveys of high, mid, and low clouds from satellites and GCMs." Presented at the Fifteenth Atmospheric Radiation Measurement (ARM) Science Team Meeting. Daytona Beach, Florida.

Chang, F-L, Z Li, and E Clothiaux. 2005. "Comparing the overlapped cloud top altitudes deduced from MODIS with ARM ground-based measurements." Presented at the Fifteenth Atmospheric Radiation Measurement (ARM) Science Team Meeting. Daytona Beach, Florida.

Charlock, T, F Rose, D Rutan, L Coleman, T Caldwell, and S Zentz. 2005. "Global, multi-year analysis of CERES terra observations and radiative transfer calculations.” Presented at the Fifteenth Atmospheric Radiation Measurement (ARM) Science Team Meeting. Daytona Beach, Florida.

Chen, Y, A Hall, and K-N Liou. 2005. “Application of 3D radiative transfer to mountains.” Presented at the Fifteenth Atmospheric Radiation Measurement (ARM) Science Team Meeting. Daytona Beach, Florida.

Childers, M, K Donner, and D Mechem. 2005. "Diurnal climatology of cold-season turbulence statistics in continental stratocumulus as observed by the ARM MMCR." Presented at the Fifteenth Atmospheric Radiation Measurement (ARM) Science Team Meeting. Daytona Beach, Florida.

Chiriaco, M, M Haeffelin, H Chepfer, R Vautard, and J Dudhia. 2005. "The ability of MM5 to simulate ice clouds: Systematic comparison between simulated and measured fluxes and lidar/radar profiles at SIRTA atmospheric observatory." Presented at the Fifteenth Atmospheric Radiation Measurement (ARM) Science Team Meeting. Daytona Beach, Florida.

Chiu, J-YC, A Marshak, W Wiscombe, Y Knyazikhin, and J Barnard. 2005. "A novel retrieval algorithm for cloud optical properties from the ARM Program's two-channel narrow-field-of-view radiometer." Presented at the Fifteenth Atmospheric Radiation Measurement (ARM) Science Team Meeting. Daytona Beach, Florida.

Chuang, C, and S Chin. 2005. "Modeling the vertical profiles of aerosol characteristics and radiative impacts over the ARM sites." Presented at the Fifteenth Atmospheric Radiation Measurement (ARM) Science Team Meeting. Daytona Beach, Florida.

Cimini, D, M Klein, E Westwater, V Leuskiy, AJ Gasiewski, and S Dowlatshahi. 2005. "Ground-based scanning radiometer measurements during the water vapor IOP 2004: A valuable new data set for the study of the arctic atmosphere." Presented at the Fifteenth Atmospheric Radiation Measurement (ARM) Science Team Meeting. Daytona Beach, Florida.

Clough, S, M Shepard, E Mlawer, J Delamere, K Cady-Pereira, D Tobin, H Revercomb, R Knuteson, and D Turner. 2005. "ARM radiative transfer modeling and remote sensing." Presented at the 
Fifteenth Atmospheric Radiation Measurement (ARM) Science Team Meeting. Daytona Beach, Florida.

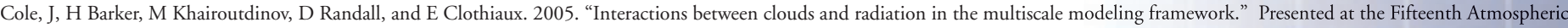
Radiation Measurement (ARM) Science Team Meeting. Daytona Beach, Florida.

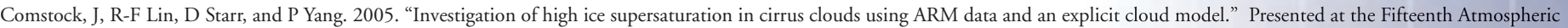
Radiation Measurement (ARM) Science Team Meeting. Daytona Beach, Florida.

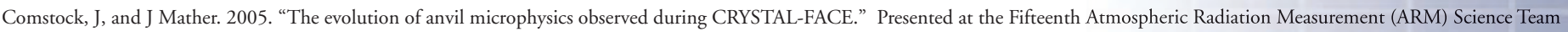
Meeting. Daytona Beach, Florida.

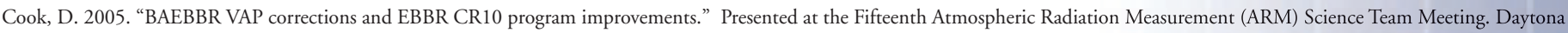
Beach, Florida.

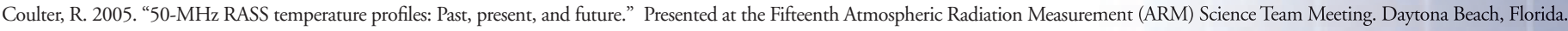

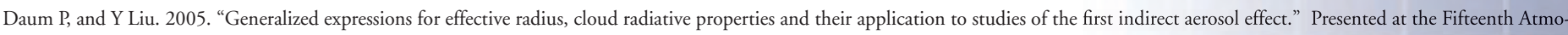
spheric Radiation Measurement (ARM) Science Team Meeting. Daytona Beach, Florida.

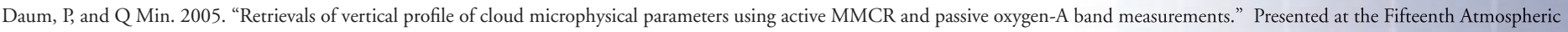
Radiation Measurement (ARM) Science Team Meeting. Daytona Beach, Florida.

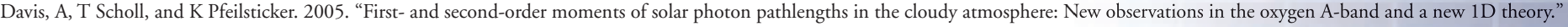
Presented at the Fifteenth Atmospheric Radiation Measurement (ARM) Science Team Meeting. Daytona Beach, Florida.

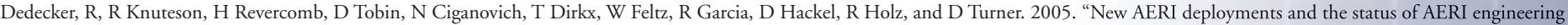
changes." Presented at the Fifteenth Atmospheric Radiation Measurement (ARM) Science Team Meeting. Daytona Beach, Florida.

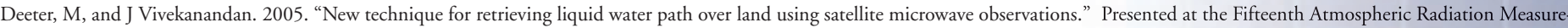
ment (ARM) Science Team Meeting. Daytona Beach, Florida.

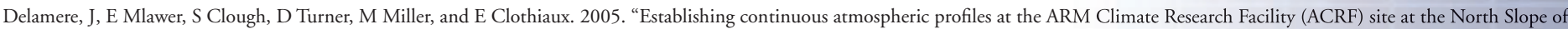
Alaska (NSA).” Presented at the Fifteenth Atmospheric Radiation Measurement (ARM) Science Team Meeting. Daytona Beach, Florida.

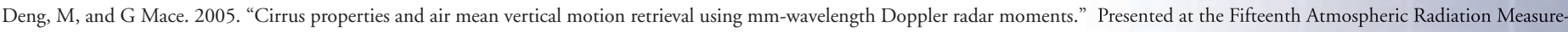
ment (ARM) Science Team Meeting. Daytona Beach, Florida.

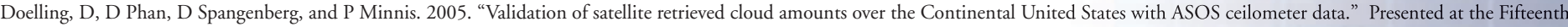
Atmospheric Radiation Measurement (ARM) Science Team Meeting. Daytona Beach, Florida.

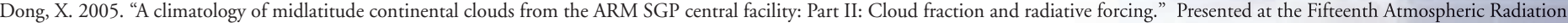
Measurement (ARM) Science Team Meeting. Daytona Beach, Florida.

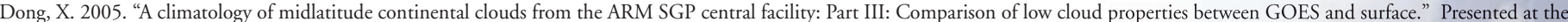
Fifteenth Atmospheric Radiation Measurement (ARM) Science Team Meeting. Daytona Beach, Florida.

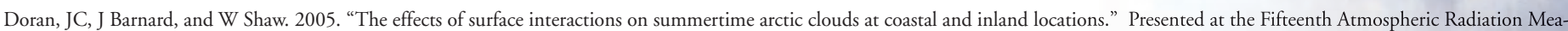
surement (ARM) Science Team Meeting. Daytona Beach, Florida.

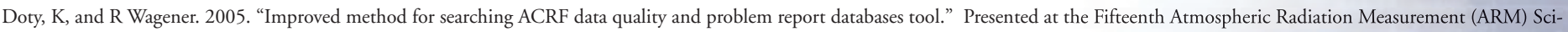
ence Team Meeting. Daytona Beach, Florida.

Duan, M, and Q Min. 2005. "Effects of aerosol size distribution and vertical profile on the polarization in the oxygen A-band.” Presented at the Fifteenth Atmospheric Radiation Measurement (ARM) Science Team Meeting. Daytona Beach, Florida.

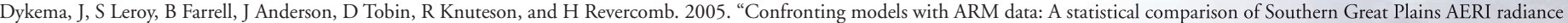
spectra and GCM output.” Presented at the Fifteenth Atmospheric Radiation Measurement (ARM) Science Team Meeting. Daytona Beach, Florida

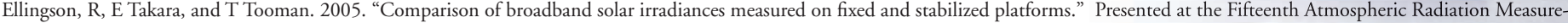
ment (ARM) Science Team Meeting. Daytona Beach, Florida.

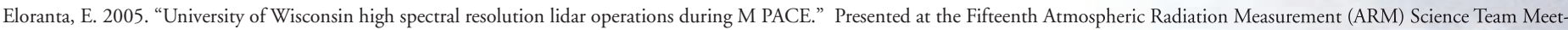
ing. Daytona Beach, Florida.

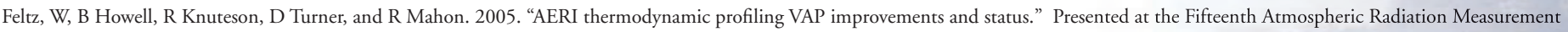
(ARM) Science Team Meeting. Daytona Beach, Florida.

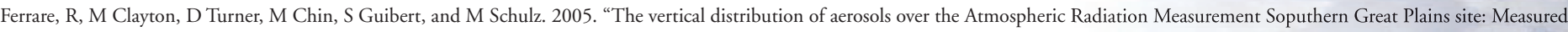
vs. modeled." Presented at the Fifteenth Atmospheric Radiation Measurement (ARM) Science Team Meeting. Daytona Beach, Florida.

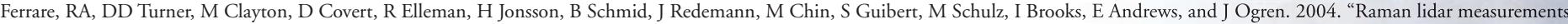
of aerosol profiles over the Southern Great Plains.” Presented at the 2004 American Geophysical Union (AGU) Fall Meeting. San Francisco, California.

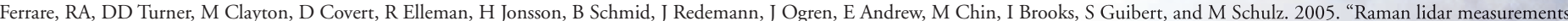
of aerosols and water vapor over the Southern Great Plains.” Presented at the 85th American Meteorological Society (AMS) Annual Meeting. San Diego, California.

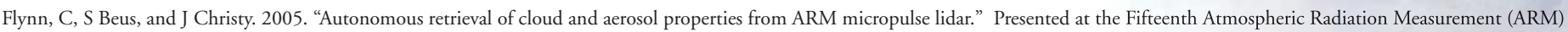
Science Team Meeting. Daytona Beach, Florida.

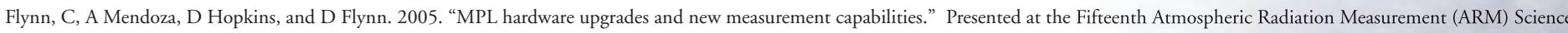
Team Meeting. Daytona Beach, Florida.

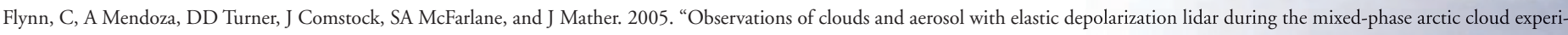
ment." Presented at the 85th American Meteorological Society (AMS) Annual Meeting. San Diego, California.

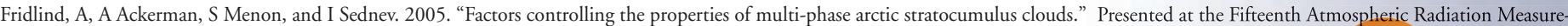


ment (ARM) Science Team Meeting. Daytona Beach, Florida.

Gasiewski, AJ, S Dowlatshahi, M Klein, V Leuskiy, E Westwater, D Cimini, and T Uttal. 2005. "The potential for retrieving integrated cloud ice water content using ground-based submillimeter-wave radiometry." Presented at the Fifteenth Atmospheric Radiation Measurement (ARM) Science Team Meeting. Daytona Beach, Florida.

Genkova, I, C Long, P Minnis, P Heck, and M Khaiyer. 2005. "Clouds over the ARM SGP network area-3D Prospective.” Presented at the Fifteenth Atmospheric Radiation Measurement (ARM) Science Team Meeting. Daytona Beach, Florida.

Genkova, I, C Long, and D Turner. 2005. “Day and night cloud fraction-cloud inter-comparison IOP results." Presented at the Fifteenth Atmospheric Radiation Measurement (ARM) Science Team Meeting. Daytona Beach, Florida.

Gianelli, S, B Carlson, and A Lacis. 2005. "Using EOF analysis to uncover inhomogeneities in data from ground-based aerosol monitoring devices." Presented at the Fifteenth Atmospheric Radiation Measurement (ARM) Science Team Meeting. Daytona Beach, Florida.

Greenberg, S, and J Harrington. 2005. "LES simulations of roll clouds observed during M PACE." Presented at the Fifteenth Atmospheric Radiation Measurement (ARM) Science Team Meeting. Daytona Beach, Florida.

Grosdidier, Y, S Lovejoy, B Watson, and D Schertzer. 2005. "Single and multiple scattering in optically thick multifractal clouds." Presented at the Fifteenth Atmospheric Radiation Measurement (ARM) Science Team Meeting. Daytona Beach, Florida.

Guo, H, J Penner, and M Herzog. 2005. “Investigation of the impact of aerosols on clouds during the 2003 aerosol IPO at the SGP.” Presented at the Fifteenth Atmospheric Radiation Measurement (ARM) Science Team Meeting. Daytona Beach, Florida.

Haeffelin, M, A Protat, Y Morille, V Noel, and H Chepfer. 2005. "Characterization of mid-latitude clouds at SIRTA.” Presented at the Fifteenth Atmospheric Radiation Measurement (ARM) Science Team Meeting. Daytona Beach, Florida.

Hall, M, and A Davis. 2005. "Progress towards higher-fidelity yet efficient modeling of radiation energy transport through three-dimensional clouds." Presented at the Fifteenth Atmospheric Radiation Measurement (ARM) Science Team Meeting. Daytona Beach, Florida.

Hallar, A, A Strawa, B Schmid, B Andrews, J Ogren, R Ferrare, D Covert, and R Elleman. 2005. "Comparison study of optical properties during the aerosol IOP from multiple aircraft platforms." Presented at the Fifteenth Atmospheric Radiation Measurement (ARM) Science Team Meeting. Daytona Beach, Florida.

Harder, J, J Fontenla, G Kopp, G Rottman, E Richard, and P Pilewskie. 2005. "Measuring solar irradiance from space: The solar radiation and climate experiment." Presented at the Fifteenth Atmospheric Radiation Measurement (ARM) Science Team Meeting. Daytona Beach, Florida.

Heck, P, P Minnis, M Khairer, and R Palikonda. 2005. "Improved techniques for deriving thin cirrus cloud heights from daytime GOES data." Presented at the Fifteenth Atmospheric Radiation Measurement (ARM) Science Team Meeting. Daytona Beach, Florida.

Henderson, P, and A Slingo. 2005. "Using ARM data to evaluate the dependence of surface downward longwave radiation on near-surface temperature and water vapour path, in both ARM observations and the Met Office NWP model." Presented at the Fifteenth Atmospheric Radiation Measurement (ARM) Science Team Meeting. Daytona Beach, Florida.

Hinkelman, L, P Stackhouse, D Young, and C Long. 2005. "Using ARM data to evaluate satellite surface solar flux retrievals.” Presented at the Fifteenth Atmospheric Radiation Measurement (ARM) Science Team Meeting. Daytona Beach, Florida.

Hodges, G. 2005. "MFRSR mentor report and BSRN submission status." Presented at the Fifteenth Atmospheric Radiation Measurement (ARM) Science Team Meeting. Daytona Beach, Florida.

Hoffman, F, W Hargrove, and A Del Genio. 2005. "From measurements to models: Cross-comparison of measured and simulated behavioral states of the atmosphere." Presented at the Fifteenth Atmospheric Radiation Measurement (ARM) Science Team Meeting. Daytona Beach, Florida.

Holz, R, D DeSlover, H Revercomb, D Tobin, R Knuteson, D Turner, and E Eloranta. 2005. "Validation of infrared cloud radiative transfer simulations and spectral cloud properties retrievals using S-HIS, AERI and HSRL measurements from M-PACE.” Presented at the Fifteenth Atmospheric Radiation Measurement (ARM) Science Team Meeting. Daytona Beach, Florida.

Huang, A, J Li, K Baggett, X Wu, H Revercomb, D Tobin, and R Knuteson. 2005. "Cloud property retrievals using AIRS data during M-PACE.” Presented at the Fifteenth Atmospheric Radiation Measurement (ARM) Science Team Meeting. Daytona Beach, Florida.

Hume, T, and C Jakob. 2005. "Ensemble single-column modeling (ESCM) in the Tropical Western Pacific." Presented at the Fifteenth Atmospheric Radiation Measurement (ARM) Science Team Meeting. Daytona Beach, Florida.

Iacono, MJ, E Mlawer, J Delamere, S Clough, and J-J Morcrette. 2005. "Application of the shortwave radiative transfer model, RRTMG_SW, to NCAR, ECMWF, and NCEP general circulation models." Presented at the Fifteenth Atmospheric Radiation Measurement (ARM) Science Team Meeting. Daytona Beach, Florida.

Inoue, T. 2005. "Retrieval of optical thickness of low-level water cloud using the MSG multi-channel data." Presented at the Fifteenth Atmospheric Radiation Measurement (ARM) Science Team Meeting. Daytona Beach, Florida.

Inoue, T. 2005. "The life stage of deep convection defined by the MSG multi-channel data and rainfall type observed by PR/TRMM." Presented at the Fifteenth Atmospheric Radiation Measurement (ARM) Science Team Meeting. Daytona Beach, Florida.

Ivanova, K, N Shirer, E Clothiaux, and M Ausloos. 2005. "Internal variability dependence on cirrus cloud structure." Presented at the Fifteenth Atmospheric Radiation Measurement (ARM) Science Team Meeting. Daytona Beach, Florida.

Jakob, C. 2005. "Identifying regime-dependent model errors in the Tropical Western Pacific - an ERA40 example.” Presented at the Fifteenth Atmospheric Radiation Measurement (ARM) Science Team Meeting. Daytona Beach, Florida.

Jakob, C, and S Hoeglund. 2005. "Clouds in the Darwin area and their relation to large-scale conditions." Presented at the Fifteenth Atmospheric Radiation Measurement (ARM) Science Team Meeting. Daytona Beach, Florida.

Jensen, M, and A Del Genio. 2005. "An observational analysis of cumulus congestus at Nauru." Presented at the Fifteenth Atmospheric Radiation Measurement (ARM) Science Team Meeting. Daytona Beach, Florida.

Jeong, M-J, and Z Li. 2005. "The effects of humidity and cloud contamination on aerosol retrievals from ground and satellite observations." Presented at the Fifteenth Atmospheric Radiation Measurement (ARM) Science Team Meeting. Daytona Beach, Florida.

Johnson, N, A Avramov, E Clothiaux, N Shirer, J Harrington, and J Verlinde. 2005. "Advantages of T-mode decomposition in rotated principal component analysis: Applications to the Arctic." Presented at the Fifteenth Atmospheric Radiation Measurement (ARM) Science Team Meeting. Daytona Beach, Florida. 


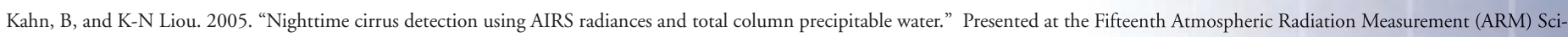
ence Team Meeting. Daytona Beach, Florida.

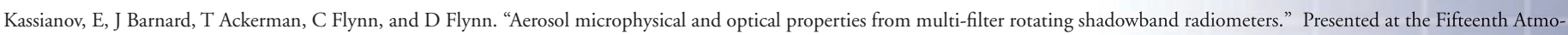
spheric Radiation Measurement (ARM) Science Team Meeting. Daytona Beach, Florida.

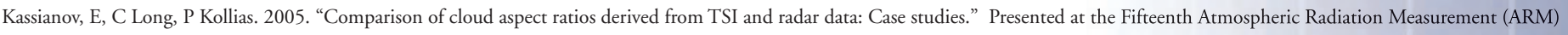
Science Team Meeting. Daytona Beach, Florida.

Kehoe, K, K Sonntag, M Zaman, B Burkholder, C Shafer, R Peppler, S Moore, G Hughes, and K Doty. 2005. "Improvements to and Status of the Data Quality Health and Status (DQ HandS) system." Presented at the Fifteenth Atmospheric Radiation Measurement (ARM) Science Team Meeting. Daytona Beach, Florida.

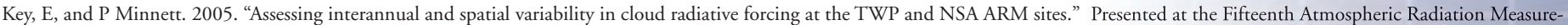
ment (ARM) Science Team Meeting. Daytona Beach, Florida.

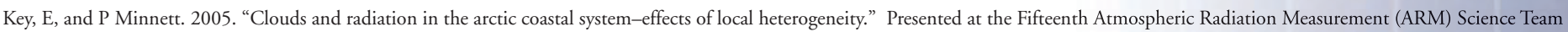
Meeting. Daytona Beach, Florida.

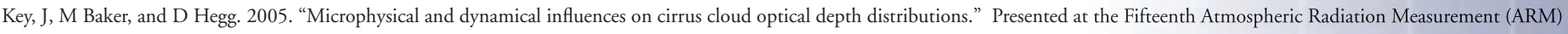
Science Team Meeting. Daytona Beach, Florida.

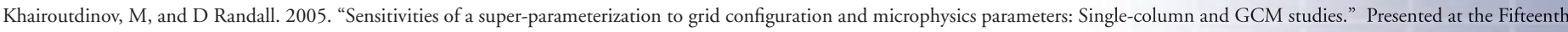
Atmospheric Radiation Measurement (ARM) Science Team Meeting. Daytona Beach, Florida.

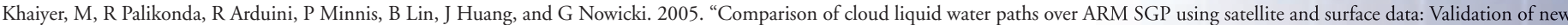
models.” Presented at the Fifteenth Atmospheric Radiation Measurement (ARM) Science Team Meeting. Daytona Beach, Florida.

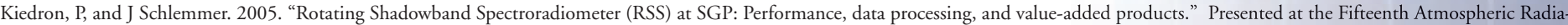
tion Measurement (ARM) Science Team Meeting. Daytona Beach, Florida.

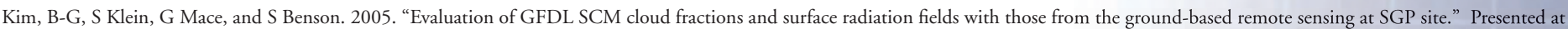
the Fifteenth Atmospheric Radiation Measurement (ARM) Science Team Meeting. Daytona Beach, Florida.

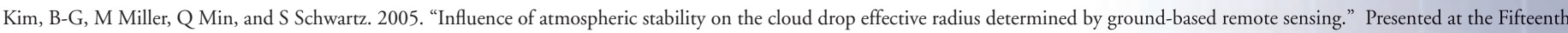
Atmospheric Radiation Measurement (ARM) Science Team Meeting. Daytona Beach, Florida.

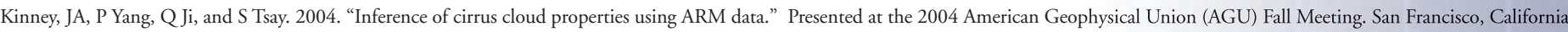

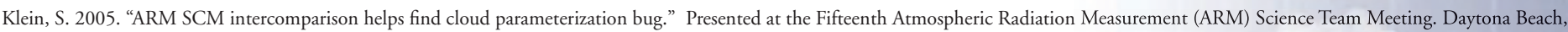
Florida.

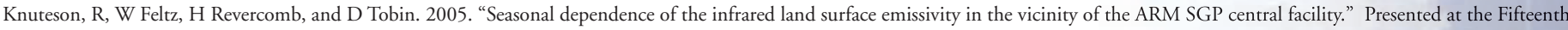
Atmospheric Radiation Measurement (ARM) Science Team Meeting. Daytona Beach, Florida.

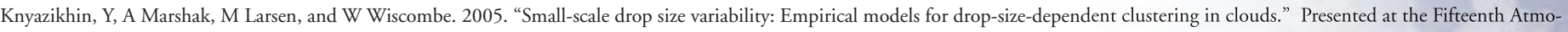
spheric Radiation Measurement (ARM) Science Team Meeting. Daytona Beach, Florida

Kogan, Z, D Mechem, and Y Kogan. 2005. "Analysis of scale dependence of stratiform clouds variability based on milimeter-wave radar data." Presented at the Fifteenth Atmospheric Radiation Measurement (ARM) Science Team Meeting. Daytona Beach, Florida.

Kollias, P, and B Albrecht. 2005. "Atmospheric modes of drizzling stratus at the ARM SGP site.” Presented at the Fifteenth Atmospheric Radiation Measurement (ARM) Science Team Meeting. Daytona Beach, Florida.

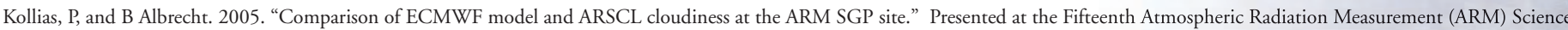
Team Meeting. Daytona Beach, Florida.

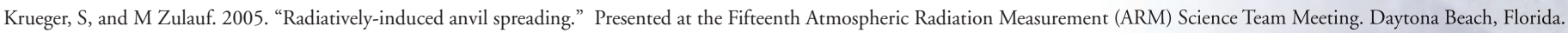

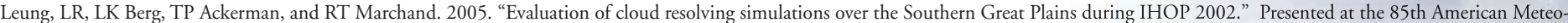
rological Society (AMS) Annual Meeting. San Diego, California.

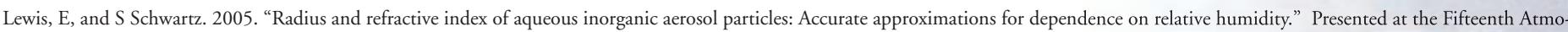
spheric Radiation Measurement (ARM) Science Team Meeting. Daytona Beach, Florida.

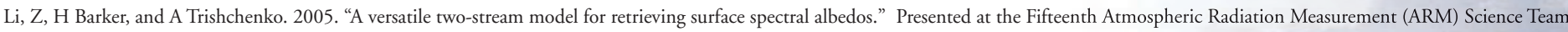
Meeting. Daytona Beach, Florida.

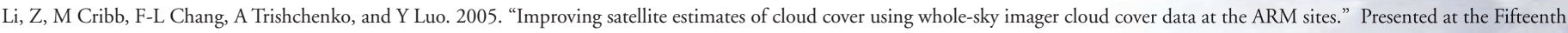
Atmospheric Radiation Measurement (ARM) Science Team Meeting. Daytona Beach, Florida.

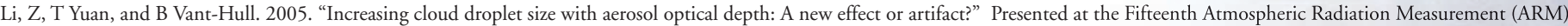
Science Team Meeting. Daytona Beach, Florida.

Liu, L, A Lacis, B Carlson, M Mishchenko, and B Cairns. 2005. "Improving GCM aerosol climatology using satellite and ground-based measurements." Presented at the Fifteenth Atmospheric Radiation Measurement (ARM) Science Team Meeting. Daytona Beach, Florida.

Liu, Y. 2005. "A climatology of clouds and radiative forcing.” Presented at the Fifteenth Atmospheric Radiation Measurement (ARM) Science Team Meeting. Daytona Beach, Florida.

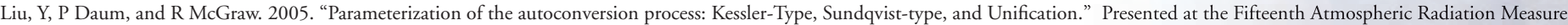
ment (ARM) Science Team Meeting. Daytona Beach, Florida.

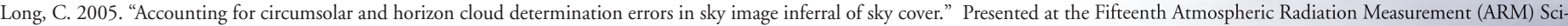
ence Team Meeting. Daytona Beach, Florida.

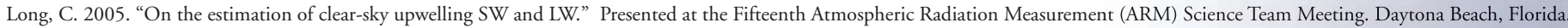


Long, CN, M Wild, and EG Dutton. 2005. "From dimming to brightening: trends in solar radiation inferred from surface observations." Presented at the 85th American Meteorological Society (AMS) Annual Meeting. San Diego, California.

Lubin, D, and A Vogelmann. 2004. "Radiation budget over the Arctic Ocean: Influence of aerosols and clouds.” Presented at the 2004 American Geophysical Union (AGU) Fall Meeting. San Francisco, California.

Lubin, D, and A Vogelmann. 2005. "Determination of the Arctic indirect aerosol effect from AERI and multispectral radiometer data." Presented at the Fifteenth Atmospheric Radiation Measurement (ARM) Science Team Meeting. Daytona Beach, Florida.

Macduff, MC, and RC Eagan. 2005. "ACRF data collection and processing infrastructure." Presented at the 85th American Meteorological Society (AMS) Annual Meeting. San Diego, California.

Mace, G, S Benson, and S Kato. 2005. "Cloud radiative forcing at the ARM climate research facility: Part 2. The vertical redistribution of radiant energy by clouds." Presented at the Fifteenth Atmospheric Radiation Measurement (ARM) Science Team Meeting. Daytona Beach, Florida.

Mace, G, S Benson, K Sonntag, S Kato, Q Min, P Minnis, C Twohy, M Poellot, X Dong, Q Zhang, and C Long. 2005. "Cloud radiative forcing at the ARM climate research facility: Part 1. Technique, validation, and comparison to satellite-derived diagnostic quantities." Presented at the Fifteenth Atmospheric Radiation Measurement (ARM) Science Team Meeting. Daytona Beach, Florida.

Mace, G, M Den, B Soden, and E Zipser. 2005. "On the association of tropical cirrus in the $1015 \mathrm{~km}$ layer with deep convective source regions; an observational study combining millimeter radar data and satellite-derived trajectories.” Presented at the Fifteenth Atmospheric Radiation Measurement (ARM) Science Team Meeting. Daytona Beach, Florida.

Maetas, A, and L Jones. 2005. "Tools for teaching climate studies." Presented at the Fifteenth Atmospheric Radiation Measurement (ARM) Science Team Meeting. Daytona Beach, Florida.

Marchand, R, and T Ackerman. 2005. "An assessment of multi-angle imaging spectroradiometer (MISR) stereo-derived cloud top heights using cloud optical depths derived from ARM Data." Presented at the Fifteenth Atmospheric Radiation Measurement (ARM) Science Team Meeting. Daytona Beach, Florida.

Marchand, R, N Beagley, and T Ackerman. 2005. "A bootstrap technique for testing the relationship between local-scale radar observations of cloud occurrence and large-scale atmospheric fields." Presented at the Fifteenth Atmospheric Radiation Measurement (ARM) Science Team Meeting. Daytona Beach, Florida.

Marchand, RT, SJ Ghan, M Ovtchinnikov, TP Ackerman, and M Khairoutdinov. 2005. "Comparison of the multi-scale modeling framework and NCAR community atmospheric model (CAM) with ISCCP and CERES retrievals." Presented at the 85th American Meteorological Society (AMS) Annual Meeting. San Diego, California.

Martonchik, J, D Diner, R Kahn, W Abdou, and B Gaitley. 2005. "Determination of aerosol and surface reflectance characteristics at the ARM SGP site using MISR observations." Presented at the Fifteenth Atmospheric Radiation Measurement (ARM) Science Team Meeting. Daytona Beach, Florida.

Mather, J, and J Comstock. 2005. “Analysis of ground-based radiation and cloud measurements from CRYSTAL-FACE.” Presented at the Fifteenth Atmospheric Radiation Measurement (ARM) Science Team Meeting. Daytona Beach, Florida.

Matrosov, S. 2005. "An approach to estimate rainfall rates aloft from MMCR measurements." Presented at the Fifteenth Atmospheric Radiation Measurement (ARM) Science Team Meeting. Daytona Beach, Florida.

Mattioli, V, E Westwater, D Cimini, J Liljegren, BM Lesht, S Gutman, and F Schmidlin. 2005. "Analysis of radiosonde and PWV data from the 2004 North Slope of Alaska arctic winter radiometeric experiment." Presented at the Fifteenth Atmospheric Radiation Measurement (ARM) Science Team Meeting. Daytona Beach, Florida.

May, P. 2005. "The height distribution of tropical convective clouds." Presented at the Fifteenth Atmospheric Radiation Measurement (ARM) Science Team Meeting. Daytona Beach, Florida.

May, P, J Mather, and C Jakob. 2005. “Tropical warm pool-international cloud experiment.” Presented at the Fifteenth Atmospheric Radiation Measurement (ARM) Science Team Meeting. Daytona Beach, Florida.

McComiskey, A, P Ricchiazzi, J Ogren, and E Dutton. 2005. "SGPGET: An SBDART module for aerosol radiative transfer." Presented at the Fifteenth Atmospheric Radiation Measurement (ARM) Science Team Meeting. Daytona Beach, Florida.

McComiskey, A, S Schwartz, E Lewis, J Ogren, J Michalsky, and P Ricchiazzi. 2005. "Direct aerosol forcing: Calculation from observables and sensitivities to inputs." Presented at the Fifteenth Atmospheric Radiation Measurement (ARM) Science Team Meeting. Daytona Beach, Florida.

McCoy, R, and T Tooman. 2005. "ARM-UAV instrumentation used on the proteus aircraft during the M-PACE experiment." Presented at the Fifteenth Atmospheric Radiation Measurement (ARM) Science Team Meeting. Daytona Beach, Florida.

McFarlane, S, J Mather, and T Ackerman. 2005. "Radiative heating profiles in the tropics-an evaluation of model output using ARM observations." Presented at the Fifteenth Atmospheric Radiation Measurement (ARM) Science Team Meeting. Daytona Beach, Florida.

McFarlane, SA, JH Mather, and TP Ackerman. 2005. "Radiative heating profiles in the convective tropics: A comparison of observations and models." Presented at the 85th American Meteorological Society (AMS) Annual Meeting. San Diego, California.

McFarquhar, G. 2005. "Investigation of ice crystal shapes using multi-resolution techniques." Presented at the Fifteenth Atmospheric Radiation Measurement (ARM) Science Team Meeting. Daytona Beach, Florida.

McFarquhar, G, M Timlin, T Nousiainen, and P Yang. 2005. "A new representation for the solar and infrared single-scattering properties of mid-latitude clouds and its impacts." Presented at the Fifteenth Atmospheric Radiation Measurement (ARM) Science Team Meeting. Daytona Beach, Florida.

McFarquhar, G, T Tooman, R McCoy, and W Bolton. 2005. "Remote sensing and in situ observations of arctic mixed-phase and cirrus clouds acquired during M-PACE." Presented at the Fifteenth Atmospheric Radiation Measurement (ARM) Science Team Meeting. Daytona Beach, Florida.

McFarquhar, G, G Zhang, J Verlinde, M Poellot, A Heymsfield, and G Kok. 2005. "Assessing current parameterizations of mixed-phase clouds using in situ profiles measured during the mixed-phase cloud experiment (M-PACE)." Presented at the Fifteenth Atmospheric Radiation Measurement (ARM) Science Team Meeting. Daytona Beach, Florida.

McGraw, R, and Y Liu. 2005. "Parameterizations for clouds and precipitation based on the kinetic potential theory for drizzle formation." Presented at the Fifteenth Atmospheric Radiation Measurement (ARM) Science Team Meeting. Daytona Beach, Florida.

Mead, J, and K Widener. 2005. "W-band ARM cloud radar system.” Presented at the Fifteenth Atmospheric Radiation Measurement (ARM) Science Team Meeting. Daytona Beach, Florida.

Mechem, D, and Y Kogan. 2005. "Representing cloud processing of aerosol in numerical models." Presented at the Fifteenth Atmospheric Radiation Measurement (ARM) Science Team Meeting. Daytona Beach, Florida

Michalsky, JJ, GP Anderson, J Barnard, C Gueymard, S Kato, P Kiedron, and A McComiskey. 2004. "Radiation closure studies for clear-sky conditions during the ARM 2003 aerosol intensive observation period." Presented at the 2004 American Geophysical Union (AGU) Fall Meeting. San Francisco, California.

Miller, M, K Johnson, P Michael, and G Mace. 2005. "MICROBASE, a continuous baseline microphysical retrieval: Status and future plans." Presented at the Fifteenth Atmospheric Radiation Measurement (ARM) Science Team Meeting. Daytona Beach, Florida. 


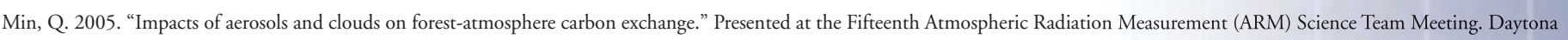
Beach, Florida.

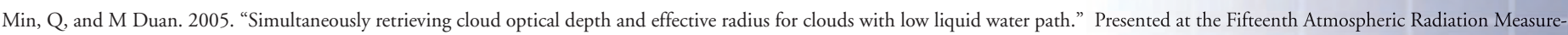
ment (ARM) Science Team Meeting. Daytona Beach, Florida.

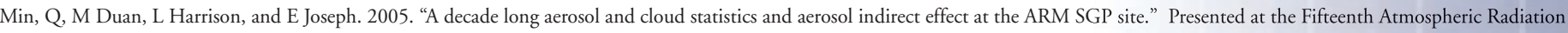
Measurement (ARM) Science Team Meeting. Daytona Beach, Florida.

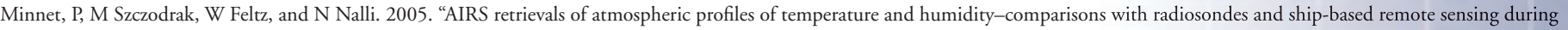
AEROSE.” Presented at the Fifteenth Atmospheric Radiation Measurement (ARM) Science Team Meeting. Daytona Beach, Florida.

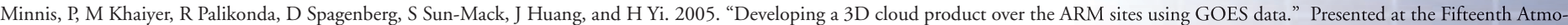
spheric Radiation Measurement (ARM) Science Team Meeting. Daytona Beach, Florida.

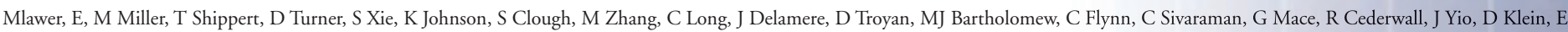

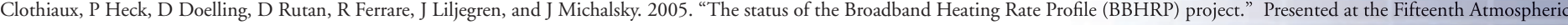
Radiation Measurement (ARM) Science Team Meeting. Daytona Beach, Florida.

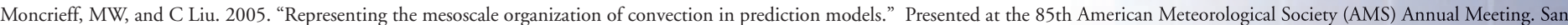
Diego, California.

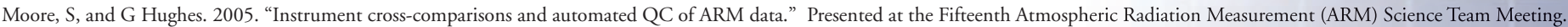
Daytona Beach, Florida.

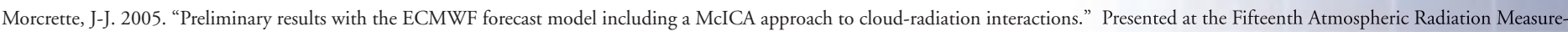
ment (ARM) Science Team Meeting. Daytona Beach, Florida.

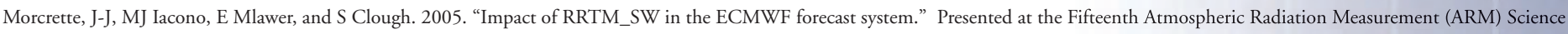
Team Meeting. Daytona Beach, Florida.

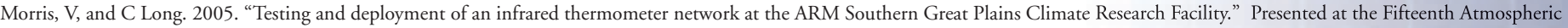
Radiation Measurement (ARM) Science Team Meeting. Daytona Beach, Florida.

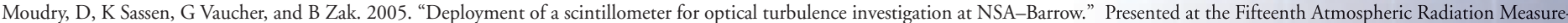
ment (ARM) Science Team Meeting. Daytona Beach, Florida.

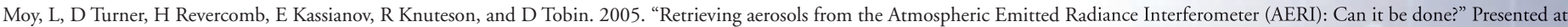
the Fifteenth Atmospheric Radiation Measurement (ARM) Science Team Meeting. Daytona Beach, Florida.

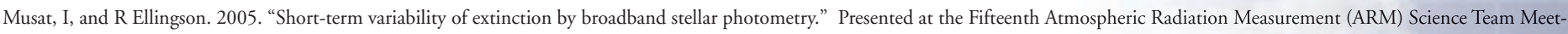
ing. Daytona Beach, Florida.

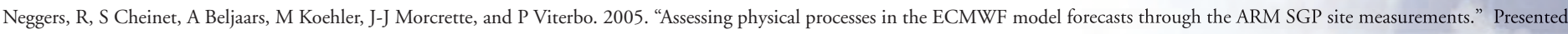
at the Fifteenth Atmospheric Radiation Measurement (ARM) Science Team Meeting. Daytona Beach, Florida.

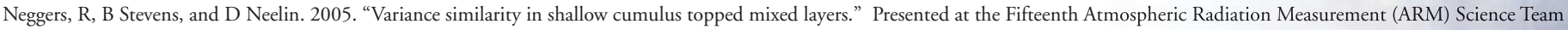
Meeting. Daytona Beach, Florida.

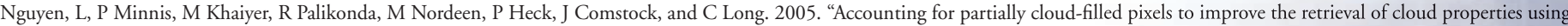
high-resolution data.” Presented at the Fifteenth Atmospheric Radiation Measurement (ARM) Science Team Meeting. Daytona Beach, Florida.

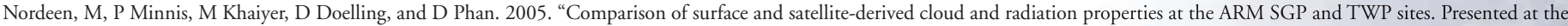
Fifteenth Atmospheric Radiation Measurement (ARM) Science Team Meeting. Daytona Beach, Florida.

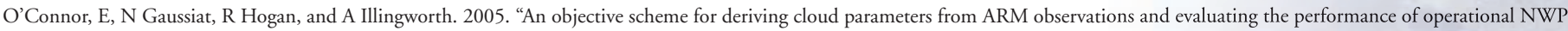
models.” Presented at the Fifteenth Atmospheric Radiation Measurement (ARM) Science Team Meeting. Daytona Beach, Florida.

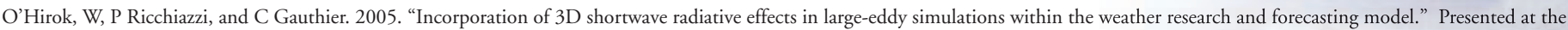
Fifteenth Atmospheric Radiation Measurement (ARM) Science Team Meeting. Daytona Beach, Florida.

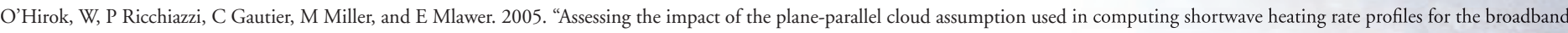
heating rate profile project." Presented at the Fifteenth Atmospheric Radiation Measurement (ARM) Science Team Meeting. Daytona Beach, Florida.

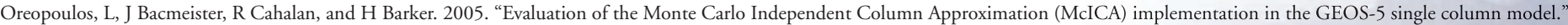
Presented at the Fifteenth Atmospheric Radiation Measurement (ARM) Science Team Meeting. Daytona Beach, Florida.

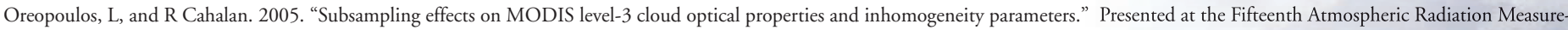
ment (ARM) Science Team Meeting. Daytona Beach, Florida.

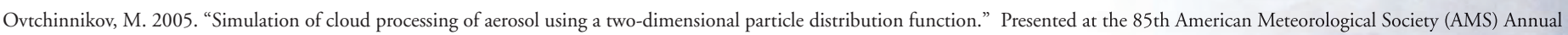
Meeting. San Diego, California.

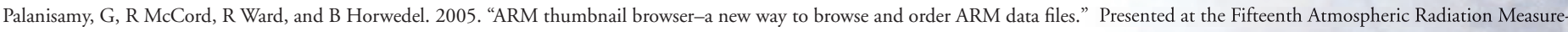
ment (ARM) Science Team Meeting. Daytona Beach, Florida.

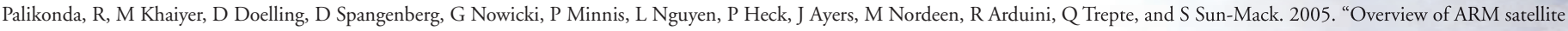
cloud and radiation products from LaRC.” Presented at the Fifteenth Atmospheric Radiation Measurement (ARM) Science Team Meeting. Daytona Beach, Florida.

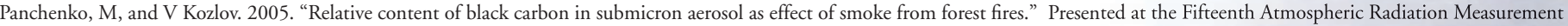
(ARM) Science Team Meeting. Daytona Beach, Florida.

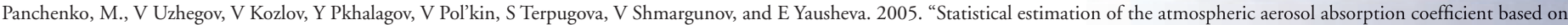
the data of optical measurements.” Presented at the Fifteenth Atmospheric Radiation Measurement (ARM) Science Team Meeting. Daytona Beach, Florida. 
Pazmany, A. 2005. "Millimeter-wave (183 GHz) radiometer for high sensitivity water vapor measurements at the North Slope of Alaska ARM site." Presented at the Fifteenth Atmospheric Radiation Measurement (ARM) Science Team Meeting. Daytona Beach, Florida.

Pincus, R, R Neale, C Batstone, and S Klein. 2005. “Linking subgrid-scale variability in temperature and humidity to convection.” Presented at the Fifteenth Atmospheric Radiation Measurement (ARM) Science Team Meeting. Daytona Beach, Florida.

Pinto, J, and H Morrison. 2005. “On modeling the persistence of cold clouds observed during M-PACE.” Presented at the Fifteenth Atmospheric Radiation Measurement (ARM) Science Team Meeting. Daytona Beach, Florida.

Polonsky, I, A Davis, and M Box. 2005. "Radiative transfer in 3D clouds: A perturbation theoretical approach.” Presented at the Fifteenth Atmospheric Radiation Measurement (ARM) Science Team Meeting. Daytona Beach, Florida.

Pommier, J, W Gore, and P Pilewskie. 2005. "A new shortwave spectrometer for SGP site." Presented at the Fifteenth Atmospheric Radiation Measurement (ARM) Science Team Meeting. Daytona Beach, Florida.

Popham, J. 2005. "The impact of cloud and radiation on the Great Plains climate change during 1981-2003.” Presented at the Fifteenth Atmospheric Radiation Measurement (ARM) Science Team Meeting. Daytona Beach, Florida.

Potter, G, J Boyle, S Klein, T Phillips, S Xie, and G Zhang. 2005. “Update on activities of the CAPT project." Presented at the Fifteenth Atmospheric Radiation Measurement (ARM) Science Team Meeting. Daytona Beach, Florida.

Revercomb, H, D Tobin, R Knuteson, F Best, D Laporte, S Ellington, M Werner, R Dedecker, R Garcia, N Ciganovich, B Howell, S Dutcher, J Taylor, H Huang, J Li, and R Holz. 2005. “Scanning high-resolution interferometer sounder (S-HIS) participation in the mixed-phase arctic cloud experiment (M-PACE) on the ARM-UAV proteus aircraft." Presented at the Fifteenth Atmospheric Radiation Measurement (ARM) Science Team Meeting. Daytona Beach, Florida.

Ricchiazzi, P, W O'Hirok, and C Gautier. 2005. "The effect of non-lambertian surface reflectance on aerosol radiative forcing." Presented at the Fifteenth Atmospheric Radiation Measurement (ARM) Science Team Meeting. Daytona Beach, Florida.

Ritsche, M, D Holdridge, and R Pearson. 2005. "New and improved data logging and collection system for ACRF TWP and NSA SKYRAD, GNDRAD, and MET systems." Presented at the Fifteenth Atmospheric Radiation Measurement (ARM) Science Team Meeting. Daytona Beach, Florida.

Roeder, L, and R Jundt. 2005. "Photography in the field: Faux pas to phenomenal.” Presented at the Fifteenth Atmospheric Radiation Measurement (ARM) Science Team Meeting. Daytona Beach, Florida.

Roskovensky, J, and K-N Liou. 2005. "Simultaneous retrieving of aerosol and thin cirrus optical depths over the Tropical Western Pacific ARM site from MODIS data." Presented at the Fifteenth Atmospheric Radiation Measurement (ARM) Science Team Meeting. Daytona Beach, Florida.

Rutan, D, F Rose, and T Charlock. 2005. "Improvement in CERES SARB dust aerosols, effects on surface validation of CRS data product." Presented at the Fifteenth Atmospheric Radiation Measurement (ARM) Science Team Meeting. Daytona Beach, Florida.

Sakerin, S, T Zhuravleva, and I Nasttdinov. 2005. "Regularities of angular distribution of near-horizon sky brightness in the cloudless atmosphere." Presented at the Fifteenth Atmospheric Radiation Measurement (ARM) Science Team Meeting. Daytona Beach, Florida.

Sassen, K, R Tiruchirapalli, D Daneva, and V Khovorostyanov. 2005. "Aerosol research at the arctic facility for atmospheric remote sensing (AFARS): In search of indirect cloud effects." Presented at the Fifteenth Atmospheric Radiation Measurement (ARM) Science Team Meeting. Daytona Beach, Florida.

Sassen, K, and J Zhu. 2005. "Cirrus cloud measurements by the UAF polarization diversity lidar during M-PACE." Presented at the Fifteenth Atmospheric Radiation Measurement (ARM) Science Team Meeting. Daytona Beach, Florida.

Schmid, B, K Ricci, R Ferrare, M Clayton, C Flynn, J Barnard, D Turner, R Elleman, D Covert, A Strawa, J Eilers, E Welton, A Hallar, B Holben, H Jonsson, J Michalsky, J Redemann, and A Smirnov. 2005. "How well can we measure the vertical profile of tropospheric aerosol extinction?" Presented at the Fifteenth Atmospheric Radiation Measurement (ARM) Science Team Meeting. Daytona Beach, Florida.

Seo, E-K, and G Liu. 2005. "Retrieval of cloud ice water content profiles from AMSU-B brightness temperatures near the ARM SGP site." Presented at the Fifteenth Atmospheric Radiation Measurement (ARM) Science Team Meeting. Daytona Beach, Florida.

Shao, H, and G Liu. 2005. "The dependence of cloud particle size and precipitation probability on non-aerosol-loading related variables." Presented at the Fifteenth Atmospheric Radiation Measurement (ARM) Science Team Meeting. Daytona Beach, Florida.

Shephard, MW, SA Clough, JS Delamere, KE Cady-Pereira, SS Kulawik, and JA Logan. 2004. “Tropospheric ozone retrievals for TES validations at the ARM sites." Presented at the 2004 American Geophysical Union (AGU) Fall Meeting. San Francisco, California.

Shi, Y, and C Long. 2005. "Examples of detecting measurement errors with the QCRad VAP.” Presented at the Fifteenth Atmospheric Radiation Measurement (ARM) Science Team Meeting. Daytona Beach, Florida.

Shupe, M, S Matrosov, and T Uttal. 2005. "Arctic mixed-phase cloud properties derived from ground-based remote sensors." Presented at the Fifteenth Atmospheric Radiation Measurement (ARM) Science Team Meeting. Daytona Beach, Florida.

Soden, B. 2005. "An assessment of clear-sky radiative damping rates and their implications for climate feedbacks." Presented at the Fifteenth Atmospheric Radiation Measurement (ARM) Science Team Meeting. Daytona Beach, Florida.

Somerville, R, and S Iacobellis. 2005. "Single-column modeling, GCM parameterizations, and ARM data." Presented at the Fifteenth Atmospheric Radiation Measurement (ARM) Science Team Meeting. Daytona Beach, Florida.

Spangenberg, D, Q Trepte, S Sun-Mack, T Uttal, and P Minnis. 2005. "Retrieval of cloud properties using MODIS and AVHRR data during M-PACE." Presented at the Fifteenth Atmospheric Radiation Measurement (ARM) Science Team Meeting. Daytona Beach, Florida.

Stephens, G, N Wood, and P Gabriel. 2005. “ARM data as a source of validation of GCM physics.” Presented at the Fifteenth Atmospheric Radiation Measurement (ARM) Science Team Meeting. Daytona Beach, Florida.

Stramler, K, AD Del Genio, and DG Martinson. 2004. "Arctic surface and atmospheric states: NSA analogs to SHEBA and interannual variability." Presented at the 2004 American Geophysical Union (AGU) Fall Meeting. San Francisco, California.

Strawa, A, A Hallar, P Arnott, D Covert, R Ellerman, J Ogren, B Schmid, and A Luu. 2005. "In situ measurements of aerosol optical properties using new cavity ring-down and comparison with more traditional techniques." Presented at the Fifteenth Atmospheric Radiation Measurement (ARM) Science Team Meeting. Daytona Beach, Florida.

Sviridenkov, M, A Emilenko, A Isakov, and V Kopeikin. 2005. "Comparison of BC content, aerosol optical, and microphysical characteristics in Moscow and Moscow region." Presented at the Fifteenth Atmospheric Radiation Measurement (ARM) Science Team Meeting. Daytona Beach, Florida. 


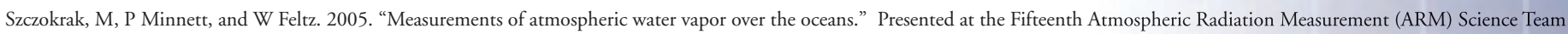
Meeting. Daytona Beach, Florida.

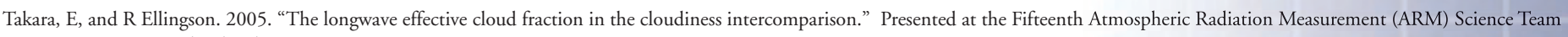
Meeting. Daytona Beach, Florida.

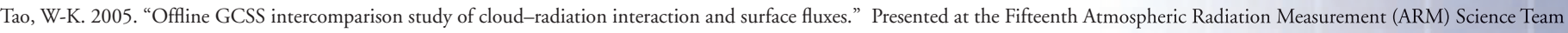
Meeting. Daytona Beach, Florida.

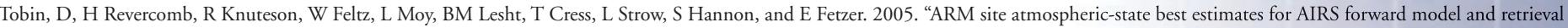
validation.” Presented at the Fifteenth Atmospheric Radiation Measurement (ARM) Science Team Meeting. Daytona Beach, Florida.

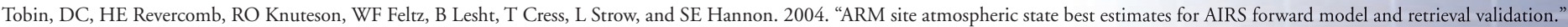
Presented at the 2004 American Geophysical Union (AGU) Fall Meeting. San Francisco, California.

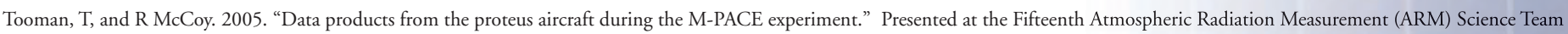
Meeting. Daytona Beach, Florida.

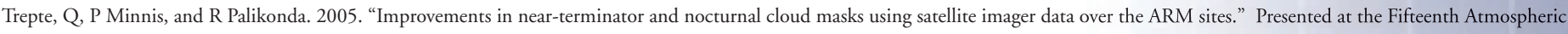
Radiation Measurement (ARM) Science Team Meeting. Daytona Beach, Florida.

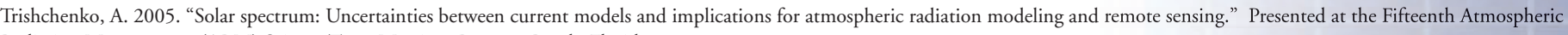
Radiation Measurement (ARM) Science Team Meeting. Daytona Beach, Florida.

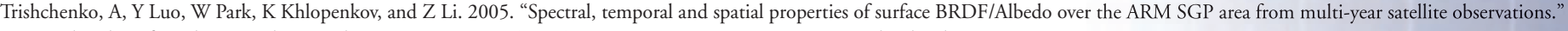
Presented at the Fifteenth Atmospheric Radiation Measurement (ARM) Science Team Meeting. Daytona Beach, Florida.

Troyan, D. 2005. "Publication trends of ARM research." Presented at the Fifteenth Atmospheric Radiation Measurement (ARM) Science Team Meeting. Daytona Beach, Florida.

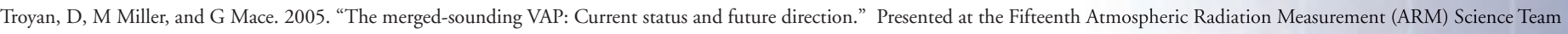
Meeting. Daytona Beach, Florida.

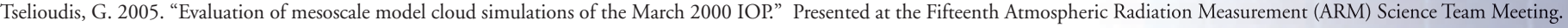
Daytona Beach, Florida.

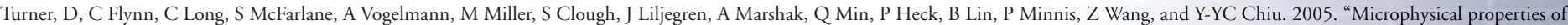
clouds with low liquid water paths: An update from CLOWD." Presented at the Fifteenth Atmospheric Radiation Measurement (ARM) Science Team Meeting. Daytona Beach, Florida.

Turner, D, and J Goldsmith. 2005. “The refurbishment and upgrade of the ARM roman lidar.” Presented at the Fifteenth Atmospheric Radiation Measurement (ARM) Science Team Meeting. Daytona Beach, Florida.

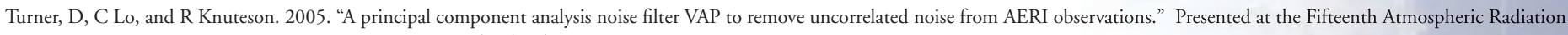
Measurement (ARM) Science Team Meeting. Daytona Beach, Florida.

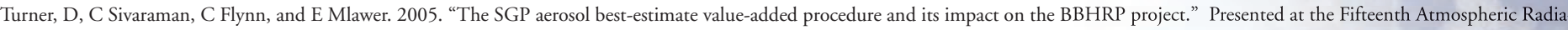
tion Measurement (ARM) Science Team Meeting. Daytona Beach, Florida.

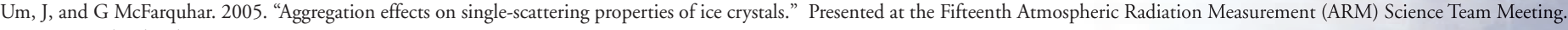
Daytona Beach, Florida.

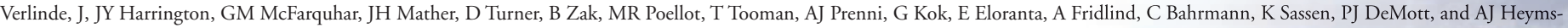
field. 2005. "Overview of the mixed-phase arctic cloud experiment (M-PACE)." Presented at the 85th American Meteorological Society (AMS) Annual Meeting. San Diego, California.

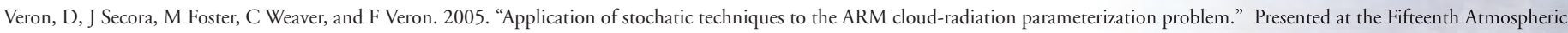
Radiation Measurement (ARM) Science Team Meeting. Daytona Beach, Florida.

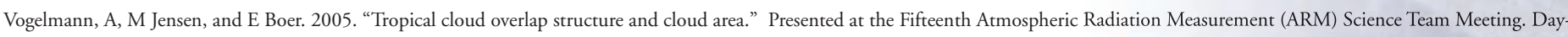
tona Beach, Florida.

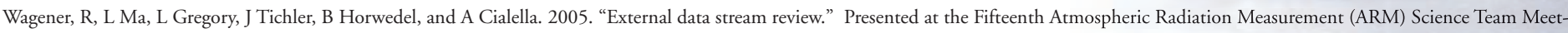
ing. Daytona Beach, Florida.

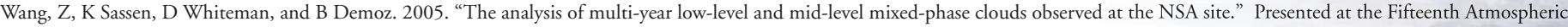
Radiation Measurement (ARM) Science Team Meeting. Daytona Beach, Florida.

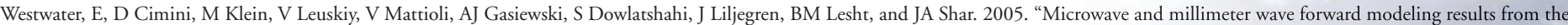
2004 North Slope of Alaska Arctic winter radiometric experiment.” Presented at the Fifteenth Atmospheric Radiation Measurement (ARM) Science Team Meeting. Daytona Beach, Florida.

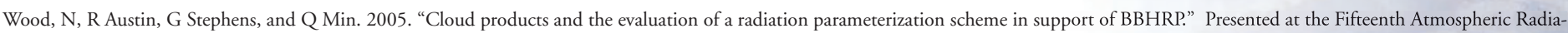
tion Measurement (ARM) Science Team Meeting. Daytona Beach, Florida.

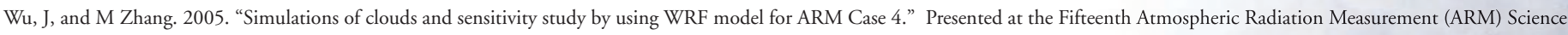
Team Meeting. Daytona Beach, Florida.

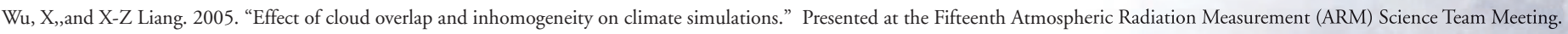
Daytona Beach, Florida.

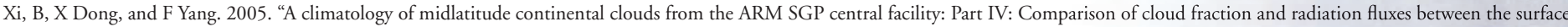
observation and the NCEP NWP forecast." Presented at the Fifteenth Atmospheric Radiation Measurement (ARM) Science Team Meeting. Daytona Beach, Florida.

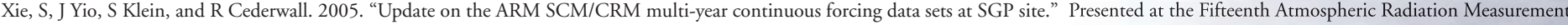
(ARM) Science Team Meeting. Daytona Beach, Florida.

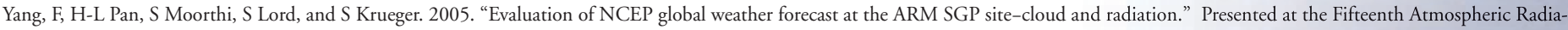
tion Measurement (ARM) Science Team Meeting. Daytona Beach, Florida. 
Yannuzzi, V. 2005. "Weather and forecasting during M-PACE.” Presented at the Fifteenth Atmospheric Radiation Measurement (ARM) Science Team Meeting. Daytona Beach, Florida.

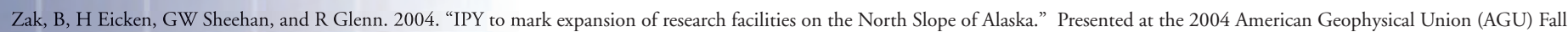
Meeting. San Francisco, California.

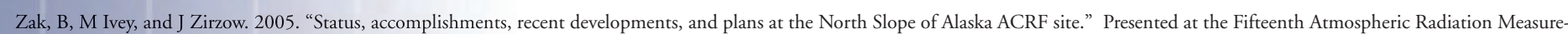
ment (ARM) Science Team Meeting. Daytona Beach, Florida.

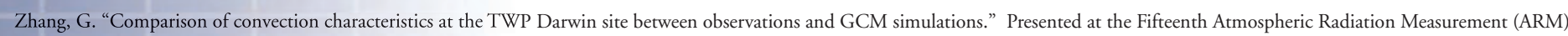
Science Team Meeting. Daytona Beach, Florida.

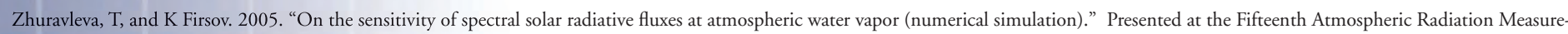
ment (ARM) Science Team Meeting. Daytona Beach, Florida.

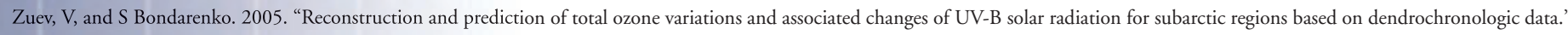
Presented at the Fifteenth Atmospheric Radiation Measurement (ARM) Science Team Meeting. Daytona Beach, Florida.

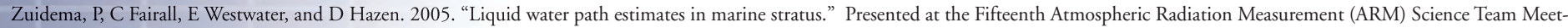
ing. Daytona Beach, Florida.

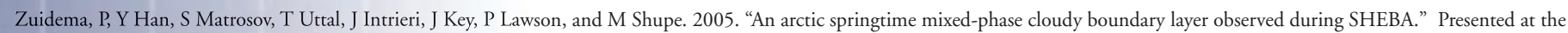
Fifteenth Atmospheric Radiation Measurement (ARM) Science Team Meeting. Daytona Beach, Florida.

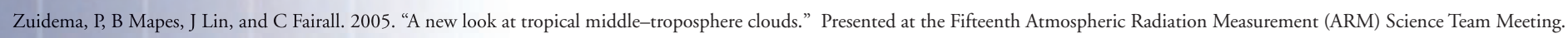
Daytona Beach, Florida.

\section{Technical Reports}

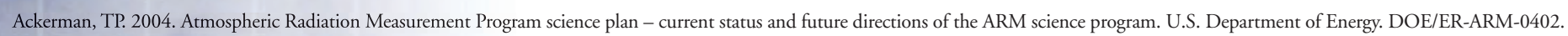

Ackerman, TP. 2005. The role of global observations for climate and other applications. U.S. Department of Energy. ARM TR-067.

Black, K. 2005. Whole sky imager (WSI) handbook. U.S. Department of Energy. ARM TR-043.

Bond, D. 2005. Soil water and temperature system (SWATS). U.S. Department of Energy. ARM TR-063.

Cook, DR, and MS Pekour. 2005. Eddy correlation flux measurement system handbook. U.S. Department of Energy. ARM TR-052.

Cook, DR. 2005. Energy balance bowen ratio (EBBR) handbook. U.S. Department of Energy. ARM TR-037.

Cook, DR. 2005. Towers instrument handbook. U.S. Department of Energy. ARM TR-050.

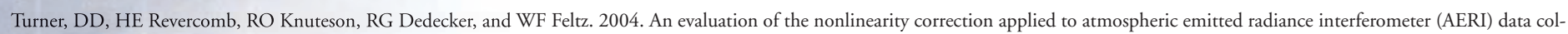
lected by the Atmospheric Radiation Measurement program. ARM TR-013.

Demirgian, J, and R. Dedecker. 2005. Atmospheric emitted radiance interferometer (AERI) handbook. U.S. Department of Energy. ARM TR-054.

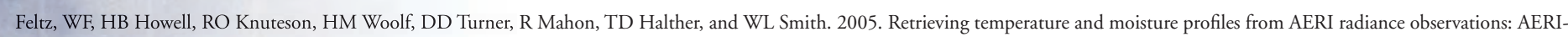
PROF value-added product technical description. U.S. Department of Energy. ARM TR-066.

Fischer, ML. 2005. Carbon dioxide flux measurement systems (CO2FLX) handbook. U.S. Department of Energy. ARM TR-048.

Flynn, C. 2005. Belfort laser ceilometer (BLC) handbook. U.S. Department of Energy. ARM TR-040.

Flynn, D, and G Hodges. 2005. Multi-filter radiometer (MFR) Handbook. U.S. Department of Energy. ARM TR-058.

Flynn, D, and G, Hodges. 2005. Multi-filter rotating shadowband radiometer (MFRSR) handbook. U.S. Department of Energy. ARM TR-059.

Jefferson, A. 2005. Aerosol observing system (AOS) handbook. U.S. Department of Energy. ARM TR-014.

Kiedron, PW, JA Schlemmer, and M Rainwater. 2005. Rotating shadowband spectroradiometer (RSS) handbook. U.S. Department of Energy. ARM TR-051.

Miller, MA, A Bucholtz, B Albrecht, and P Kollias. 2005. Marine stratus radiation, aerosol, and drizzle (MASRAD) science plan. U.S. Department of Energy. DOE/ER-ARM-0501.

Morris, VR. 2005. Infrared thermometer (IRT) handbook. U.S. Department of Energy. ARM TR-015.

Morris, VR. 2005. Microwave radiometer (MWR) handbook. U.S. Department of Energy. ARM TR-016.

Morris, VR. 2005. Total sky imager (TSI) handbook. U.S. Department of Energy. ARM TR-017.

Moudry, D. 2005. Tower camera handbook. U.S. Department of Energy. ARM TR-064.

Rainwater, M and L Gregory. 2005. Cimel sunphotometer (CSPHOT) handbook. U.S. Department of Energy. ARM TR-056.

Ritsche, MT. 2005. Chilled mirror (CM)dew point hygrometer handbook. U.S. Department of Energy. ARM TR-032.

Ritsche, MT. 2005. Surface meteorological observation system (SMOS) handbook. U.S. Department of Energy. ARM TR-031.

Ritsche, MT. 2005. Surface meteorology (SMET) handbook. U.S. Department of Energy. ARM TR-033.

Ritsche, MT. 2005. Temperature, humidity, wind, and pressure system (THWAPS) handbook. U.S. Department of Energy. ARM TR-030.

Stoffel, T. 2005. Solar infrared radiation station (SIRS) handbook. U.S. Department of Energy. ARM TR-025

Torn, M. 2005. Precision gas system (PGS) handbook. U.S. Department of Energy. ARM TR-049.

Widener, KB, and K Johnson. 2005. Millimeter wave cloud radar (MMCR) handbook. U.S. Department of Energy. ARM TR-018.

\section{Books}

Marshak, A, and A Davis (eds.). 2005. 3D Radiative Transfer in Cloudy Atmospheres. Springer-Verlag, New York. 686 p. 233 illus. 


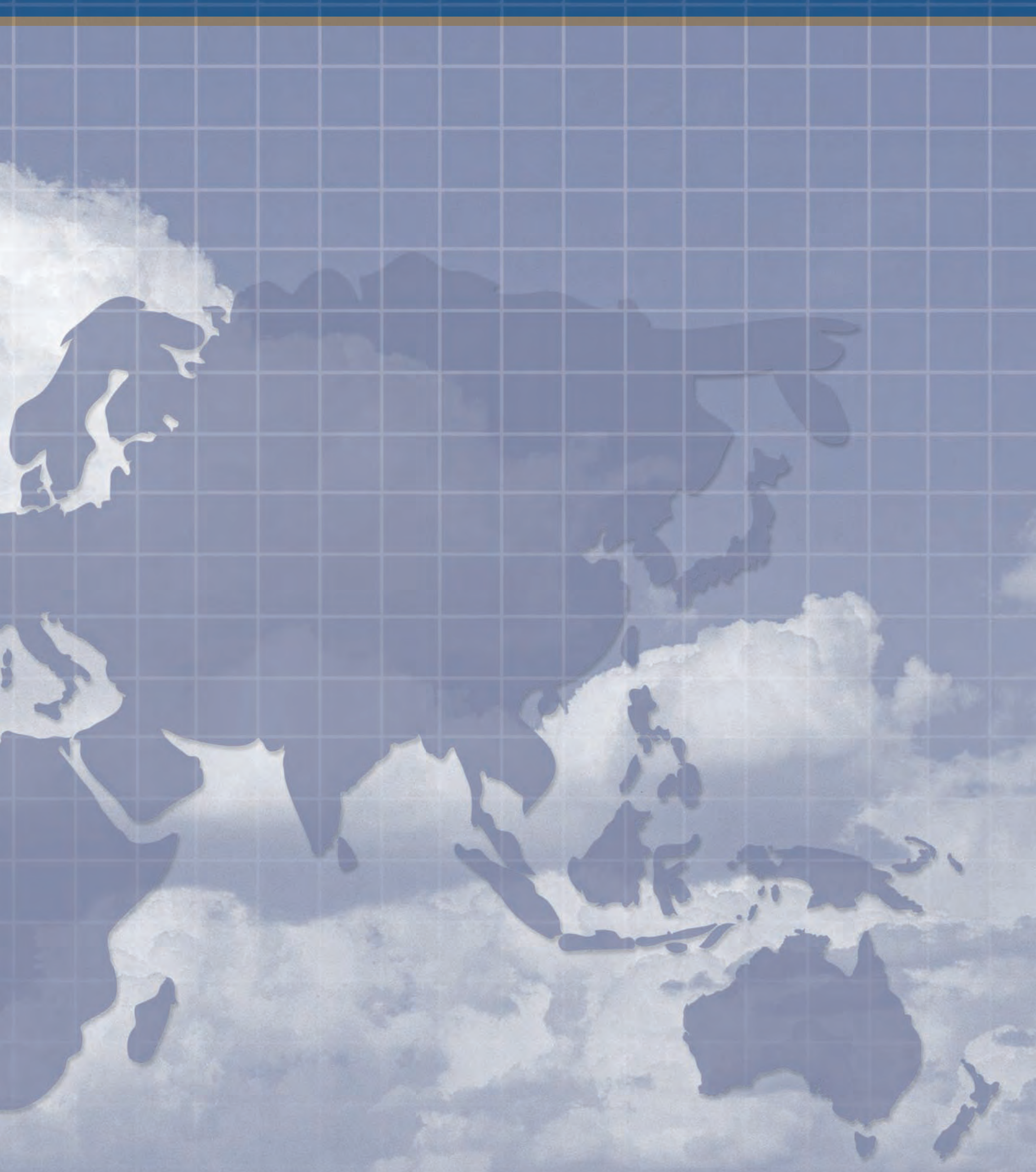




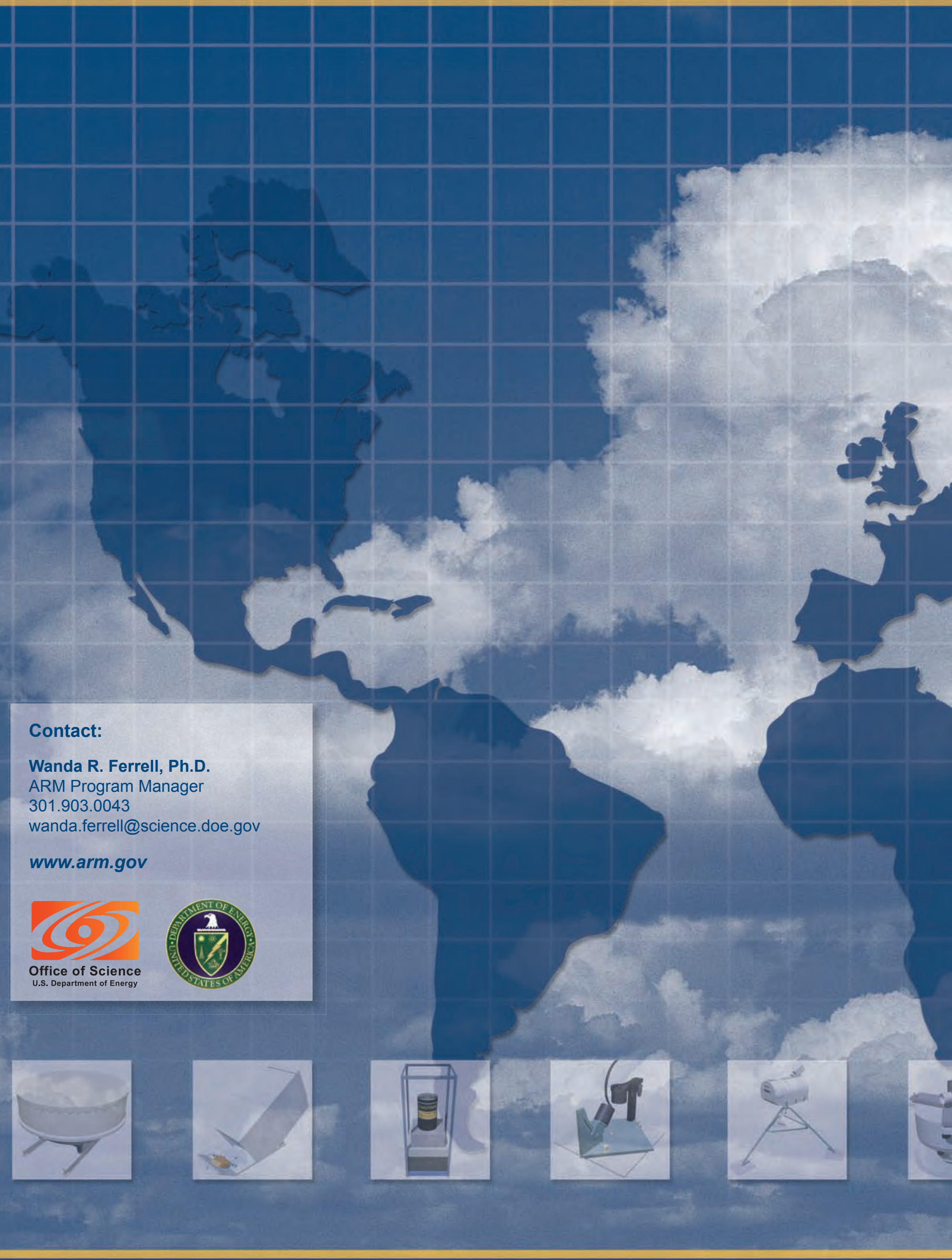

